DISSERTAÇÃO DE MESTRADO EM CIÊNCIAS MECÂNICAS

ANÁLISE DA COLHEITA DE ENERGIA DE UM GERADOR PIEZELÉTRICO SUJEITO A EXCITAÇÕES HARMÔNICA E ALEATÓRIA

Por:

TIAGO LEITE PEREIRA 
UNIVERSIDADE DE BRASÍLIA

FACULDADE DE TECNOLOGIA DEPARTAMENTO DE ENGENHARIA MECÂNICA

PROGRAMA DE PÓS GRADUAÇÃO EM CIÊNCIAS MECÃNICAS

\begin{abstract}
ANÁLISE DA COLHEITA DE ENERGIA DE UM GERADOR PIEZELÉTRICO SUJEITO A EXCITAÇÕES HARMÔNICA E ALEATÓRIA
\end{abstract}

TIAGO LEITE PEREIRA

ORIENTADORA: ALINE SOUZA DE PAULA CO-ORIENTADOR: ADRIANO TODOROVIC FABRO DISSERTAÇÃO DE MESTRADO EM CIÊNCIAS MECÂNICAS PUBLICAÇÃO: 244 BRASÍLIA/DF: AGOSTO - 2016 
UNIVERSIDADE DE BRASÍLIA

FACULDADE DE TECNOLOGIA

DEPARTAMENTO DE ENGENHARIA MECÂNICA

PROGRAMA DE PÓSGRADUAÇÃO EM CIÊNCIAS MECÃNICAS

\section{ANÁLISE DA COLHEITA DE ENERGIA DE UM GERADOR PIEZELÉTRICO SUJEITO A EXCITAÇÕES HARMÔNICA E ALEATÓRIA}

DISSERTAÇÃO SUBMETIDA AO PROGRAMA DE PÓS-GRADUAÇÃO EM CIÊNCIAS MECÂNICAS DA FACULDADE DE TECNOLOGIA DA UNIVERSIDADE DE BRASÍLIA, COMO PARTE DOS REQUISITOS NECESSÁRIOS PARA OBTENÇÃO DO GRAU DE MESTRE EM CIÊNCIAS MECÂNICAS.

APROVADA POR:

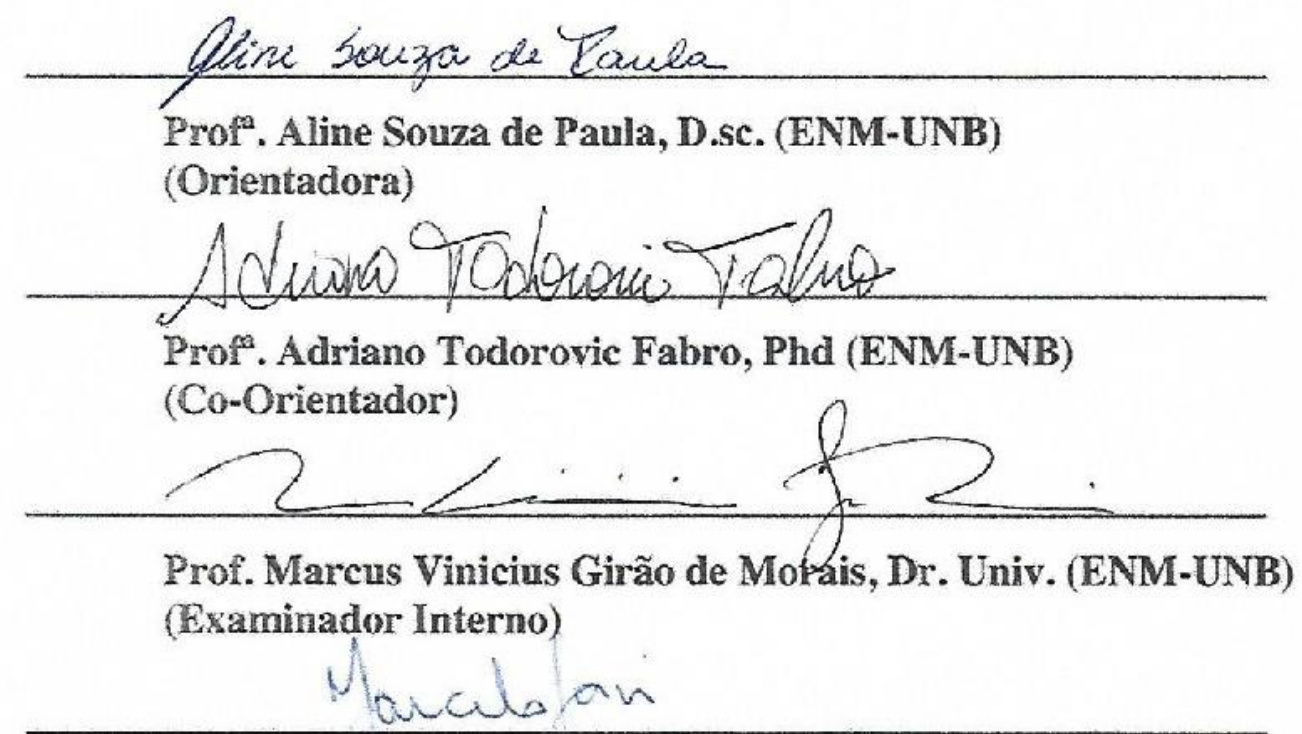

Prof. Marcelo Amorim Savi, D.sc. (COPPE-UFRJ)

(Examinador Externo)

BRASÍLIA/DF, 31 DE AGOSTO DE 2016. 


\section{FICHA CATALOGRÁFICA}

\section{PEREIRA, TIAGO LEITE}

Análise da colheita de energia de um gerador piezelétrico sujeito a excitações harmônica e aleatória [Distrito Federal] 2016.

xvi, 68p. 210x297mm (PPGCM/FT/Unb, Mestre, Ciências Mecânicas, 2016).

Dissertação de Mestrado - Universidade de Brasília. Faculdade de Tecnologia.

Programa de Pós-Graduação em Ciências Mecânicas.

1. Dinâmica não-linear 2. Gerador piezelétrico 3.Colheita de energia 4.Excitação Aleatória

\section{ENM/FT/Unb}

\section{II.Brasília}

\section{REFERÊNCIA BIBLIOGRÁFICA}

PEREIRA, T.L Análise da colheita de energia de um gerador piezelétrico sujeito a excitação harmônica e aleatória. Dissertação de Mestrado em Ciências Mecânicas. Publicação ENM.DM - 244, Programa de Pós-Graduação em Ciências Mecânicas, Universidade de Brasília - Faculdade de Tecnologia, Brasília, DF, 68p.

\section{CESSÃO DE DIREITOS}

\section{AUTOR: TIAGO LEITE PEREIRA}

TÍTULO: Análise da colheita de energia de um gerador piezelétrico sujeito a excitações harmônica e aleatória

\section{GRAU: Mestre ANO:2016}

É concedida à Universidade de Brasília permissão para reproduzir cópias desta dissertação de mestrado e para emprestar ou vender tais cópias somente para propósitos acadêmicos e científicos. $\mathrm{O}$ autor reserva outros direitos de publicação e nenhuma parte dessa dissertação de mestrado pode ser reproduzida sem autorização por escrito do autor.

TIAGO LEITE PEREIRA

SCRN 702/703 Bloco D entrada 36 apt. 108 70720-640 Brasília - DF - Brasil. 
Aos meus Pais 


\section{AGRADECIMENTOS}

Aos meus pais, Benjamim e Maria Aparecida que proporcionaram a minha existência, e que sempre cultivaram princípios que me proporcionaram ser o que sou. Obrigado por todo carinho, amor e suporte de sempre. Gratidão infinita a vocês, sem vocês não estaria onde estou. Á minha irmã que desde pequena tem sido minha melhor amiga.

A minha orientadora Aline que me acolheu tão bem quando cheguei na UnB e me proporcionou estudar o tão fascinante mundo da dinâmica de sistemas. Ao meu coorientador Adriano que auxiliou imensamente no desenvolvimento da pesquisa me proporcionando um espaço para discussões. A todos os professores que participaram da minha formação.

Aos meus amigos de Anápolis que mesmo distantes me deram suporte. Obrigado pela compreensão da ausência em momentos tão importantes. E obrigado por todos os momentos vividos juntos que me proporcionaram ser o que sou.

Aos meus amigos de Brasília que em tantas noites de estudo não me deixaram dormir ou que durante o dia me proporcionaram discussões enriquecedoras. Ao João Cósmico por nos acolher tão bem.

A CAPES pelo suporte financeiro. 
"...Acreditar em tudo ou duvidar de tudo são duas soluções convenientes; ambas dispensam a necessidade de reflexão..."

Henri Poinicaré

“...Você pode dizer o que é isso? Você ao menos sabe? Se é Liberdade, ou confiança? Talvez paz? Isso pode ser amor? Ilusões, fantasias da percepção. Construções temporárias da débil inteligência humana tentando desesperadamente justificar a existência que é sem sentindo ou propósito..." Morpheus - Matrix

“...A essência da mente é como o céu; Às vezes está encoberta pelas nuvens dos pensamentos que fluem; Então, sopra o vento de ensinamentos do mestre interior; E se movem as nuvens flutuantes. Sem apreensão, o fluir dos pensamentos é, em si mesmo, a iluminação. A experiência é tão natural quanto a luz do sol e da lua, apesar de estar além do espaço e do tempo...."

Canção da Essência da Mente 


\title{
RESUMO
}

\section{ANÁliSE DA COLHEITA DE ENERGIA DE UM GERADOR PIEZELÉTRICO SUJEITO A EXCITAÇÕES HARMÔNICA E ALEATÓRIA}

\author{
Autor: Tiago Leite Pereira \\ Orientadora: Aline Souza de Paula \\ Co-orientador: Adriano Todorovic Fabro \\ Departamento de Engenharia Mecânica \\ Brasília, 31 de Agosto de 2016.
}

Diversas fontes de energias são foco de pesquisa nas últimas décadas, a colheita de energia do ambiente é uma dessas possibilidades e tem sido explorada recentemente através do uso de materiais piezelétricos. A colheita de energia, das vibrações mecânicas a partir da utilização materiais piezelétricos, é possível pelo efeito direto, onde o material é capaz de converter energia mecânica em energia elétrica. Essa energia obtida pode ser utilizada para alimentar dispositivos eletrônicos de baixa potência. Este trabalho apresenta um estudo de uma estrutura magnética que consiste em uma viga ferromagnética engastada em uma extremidade e livre na outra. A extremidade livre da viga possui um imã e a uma distância vertical $d$ da extremidade existe outro imã que, devido a força repulsiva, cria um sistema não-linear biestável. Com o objetivo de usar essa estrutura como gerador piezelétrico, duas camadas de piezoceramica são fixadas na superfície da viga e um gerador bi laminar é obtido. A estrutura é submetida a três tipos de excitação: harmônica pura, aleatória pura e harmônica combinada com aleatória. No último caso, para identificar o forçamento define-se o parâmetro RRS que é a razão entre o forçamento aleatório pelo forçamento harmônico. O objetivo deste trabalho é avaliar e comparar o desempenho do gerador piezelétrico quando sujeito aos diferentes forçamentos. Neste contexto, propõe-se um método para avaliação do desempenho apropriada tanto para excitações harmônicas como para excitações aleatórias. Para isso, analisa-se os sinais de entrada, forçamento adimensional, e de saída, tensão elétrica adimensional, através da Densidade Espectral de Potência (PSD, do inglês Power Spectral Density) e estabelece-se um parâmetro $r$ que avalia a razão entre PSD de entrada e saída. Os resultados obtidos são classificados levando em consideração a periodicidade da resposta e observa-se que em relação a energia colhida os comportamentos que apresentam as melhores respostas estão relacionados com as maiores amplitudes. 


\title{
ABSTRACT \\ ENERGY HARVESTING ANALYSIS IN A PIEZOELETRIC GENERATOR SUBJECTED TO HARMONIC AND RANDOM EXCITATIONS
}

\author{
Author: Tiago Leite Pereira \\ Advisor: Aline Souza de Paula \\ Co-Advisor: Adriano Todorovic Fabro \\ Department: Mechanical Engineering \\ Brasília, 31 de Agosto de 2016.
}

Many alternative energy sources have been investigated in the last decades, energy harvesting from the environment is of these possibilities and have been explored recently by using piezoelectric material. This vibration-based energy harvesting using piezoelectric elements is possible by exploring the direct effect, where the piezoelectric material is able convert mechanical in to electrical energy. This application can be very useful for applications in powering small electronic devices. The energy harvesting system presented in this work is a magnetoelastic structure that consists of a ferromagnetic cantilevered beam with two permanent magnets, one located in the free end of the beam and the other at a vertical distance $d$ from the beam free end. In order to use this device as a piezelectric power generator, two piezoceramic layers are attached to the root of the cantilever and a bimorph generator is obtained. The piezomagnetoelastic structure is subjected to harmonic excitation, random excitation and harmonic combined with random excitation. The parameter $R R S$ is proposed in order to verify different combination between random excitation to the harmonic excitation. The goal of the proposed analysis in this work is to evaluate the energy harvested and the performance of the piezomagnetoelastic. The numerical analysis presents a comparison between the Power Spectral Density (PSD) of the input, dimensionless force, and output signal, dimensionless electrical voltage, setting a parameter $r$ that evaluates the ratio of PSD of the input and output signal. The results are classified according the periodicity of the response, and can be observed that the energy harvested are better in cases that the response amplitude are bigger. 


\section{SUMÁRIO}

1. INTRODUÇÃO ................................................................................................................6

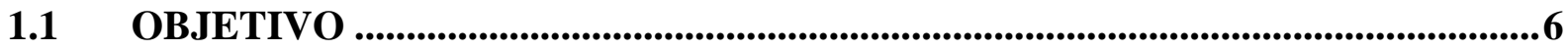

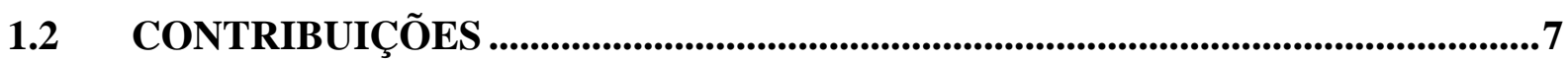

1.3 ORGANIZAÇÃO DO TRABALHO.......................................................................7

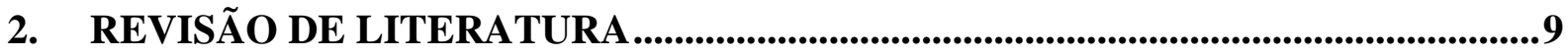

3. ANÁLISE DINÂMICA DO SISTEMA PIEZOMAGNETOELASTICO...................14

3.1 SISTEMA PIEZOMAGNETOELÁSTICO ......................................................14

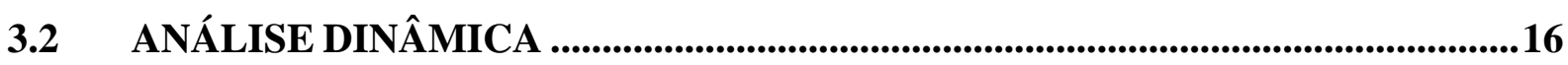

3.2.1 PONTOS DE EQUILÍBRIO E ESTABILIDADE..................................................17

3.2.2 COMPORTAMENTOS PERIÓDICOS E CAÓTICOS.................................................19

4. ANÁLISE DO DESEMPENHO E DA COLHEITA DE ENERGIA...........................23

4.1 MÉTODO DE AVALIAÇÃO DA COLHEITA DE ENERGIA .............................23

4.2 FORÇAMENTO HARMÔNICO...........................................................................24

4.3 FORÇAMENTO ALEATÓRIO........................................................................30

4.4 FORÇAMENTOS HARMÔNICO E ALEATÓRIO COMBINADOS .....................33

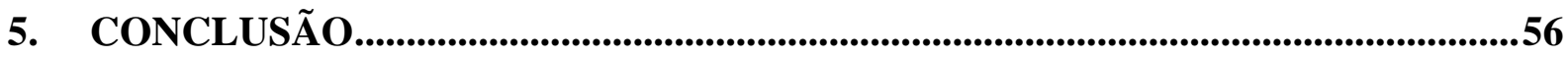

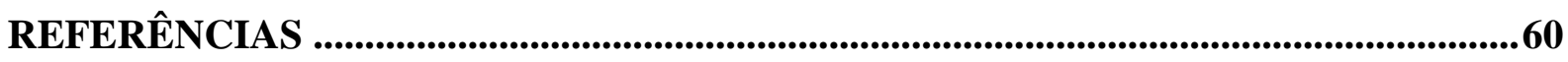

ANEXO A: DINÂMICA NÃO LINEAR.....................................................................63

Sistemas Dinâmicos ...........................................................................................................................63

Espaço de fase ....................................................................................................................63

Seção de Poincaré ................................................................................................................64

Bifurcação ..........................................................................................................................................66

Sensibilidade às condições iniciais ........................................................................................66

ANEXO B: VARIÁVEIS ALEATÓRIAS, PROCESSOS ESTOCÁSTICOS, FUNÇÃO DE DENSIDADE. .....................................................................................................................................68 


\section{LISTA DE ILUSTRAÇÕES}

Figura 2.1 Principais efeitos físicos na transformação de energia em domínios físicos 10

Figura 3.1. Sistema Piezomagnetoelástico

Figura 3.2. Resposta no domínio do tempo e espaço de fase sem forçamento para condições iniciais de (a) e (b) $(x ; x ; v)=(1,5 ; 0 ; 0)(c)$ e (d) $(x ; x ; v)=(0 ;-2 ; 0)$ e (e) e (f) $(\mathrm{x} ; \mathrm{x} ; \mathrm{v})=(0,1 ; 0 ; 0)$

Figura 3.3 Bacia de atração para os valores de parâmetros de forçamento de (a) $f_{0}=0,083$ e

$\omega=0,8,(b) f_{0}=0,1$ e $\omega=0,8$ e (c) $f_{0}=0,083$ e $\omega=0,9$ 20

Figura 3.4 Órbita para $\mathrm{f}_{0}=0,083$ e $\omega=0$,8 e condições iniciais de $(\mathrm{x}(0) ; \dot{\mathrm{x}}(0) ; \mathrm{v}(0))=$ $(1 ; 1 ; 0)$ (a) resposta no tempo e (b) espaço de fase e seção de Poincaré 20

Figura 3.5. Órbita com valores de $\mathrm{f}_{0}=0,083, \omega=0,8$ e condições iniciais de $(\mathrm{x}(0) ; \dot{\mathrm{x}}(0) ; \mathrm{v}(0))=(1 ; 0 ; 0)$ iniciais de de o iniciais

Figura 3.6 Diagrama de Bifurcação, (a) variando a amplitude $f_{0}$ e frequência $\omega=0,8$

(b) variando a frequência $\omega$ e amplitude $\mathrm{f}_{0}=0,083$. 22

Figura 4.1 Espaço de fase e seção de Poincaré para um forçamento harmônico para (a) casos 1 ao 3, (b) caso 4, (c) caso 5, (d) caso 6, (e) casos 7 e 8 e (f) caso 9.

Figura 4.2 Curvas de PSD em função da frequência com forçamento harmônico para o (a) caso 2 , (b) caso 4, (c) caso 7 e (d) caso 9.

Figura 4.3 Amplitude de deslocamento no domínio do tempo para os casos 2 e 4 .

Figura 4.4 Espaço de fases para um forçamento aleatório Gaussiano com (a) $\sigma=0.2$,

(b) $\sigma=0.4$, (c) $\sigma=0.6 \mathrm{e}$ (d) $\sigma=2$..

Figura 4.5 Curva de PSD em função da frequência com forçamento aleatório para os valores de (a) $\sigma=0,2$, (b) $\sigma=0.4$, (c) $\sigma=0.6$ e (d) $\sigma=2$ 32

Figura 4.6 Digrama de Bifurcação com forçamento aleatório para (a) RRS $=1 \%$, (b) RRS = $5 \%,(\mathrm{c}) \mathrm{RRS}=30 \%,(\mathrm{~d}) \mathrm{RRS}=100 \%$, (e) RRS $=200 \%$, (f) RRS $=500 \% \ldots \ldots .36$

Figura 4.7 Digrama de Bifurcação para (a) RRS $=1 \%$, (b) RRS $=5 \%$, (c) RRS $=30 \%$, (d) $\mathrm{RRS}=50 \%,(\mathrm{e}) \mathrm{RRS}=100 \%$ e (f) RRS $=500 \%$ 38

Figura 4.8 Espaço de fase (azul) e seção de Poincaré (vermelho) para forçamento harmônico com níveis de ruído (a) RRS $=1 \%$ (b) RRS $=100 \%$ (c) RRS $=150 \%$ e (d) RRS $=500 \%$ 40

Figura 4.9 Curvas de PSD em função da frequência para forçamento harmônico contaminado com ruíd com os níveis (a) RRS $=1 \%$ (b) RRS $=100 \%$ (c) RRS $=150 \%$ e (d) RRS $=500 \%$. 
Figura 4.10 Espaço de fase (azul) e seção de Poincaré (vermelho) para forçamento harmônico com ruído de (a) RRS $=1 \%$ (b) RRS $=10 \%$ (c) RRS $=30 \%$ d) RRS $=70 \%$ e (e) RRS $=500 \%$.

Figura 4.11 Curvas de PSD em função da frequência para forçamento harmônico contaminado com ruído com os níveis (a) RRS $=1 \%$ (b) RRS $=10 \%$ (c) RRS $=$ $30 \%$ (d) RRS $=70 \%$ (e) RRS $=500 \%$

Figura 4.12 Resposta no domínio do tempo para o $2^{\circ}$ caso de forçamento harmônico contaminado com ruído com RRS $=70 \%$

Figura 4.13 Espaço de fase (azul) e seção de Poincaré (vermelho) para forçamento harmônico com ruído de (a) RRS $=1 \%$, (b) RRS $=50 \%$, (c) RRS $=200 \%$ e (d) RRS $=$ $500 \%$. 46

Figura 4.14 Curvas de PSD em função da frequência para forçamento harmônico contaminado com ruído com os níveis (a) RRS $=1 \%$, (b) RRS $=50 \%$, (c) RRS $=200 \%$ e $(d)$ RRS $=500 \%$.

Figura 4.15 Espaço de fase (azul) e seção de Poincaré (vermelho) para forçamento harmônico com ruído de (a) RRS $=1 \%$, (b) RRS $=5 \%$, (c) RRS $=50 \%$, (d) RRS $=70 \%$, (e) $\mathrm{RRS}=150 \%$ e (f) RRS $=500 \%$

Figura 4.16 Curvas de Ppara os valores de ruído de a) $R R S=1 \%$, b) $R R S=5 \%$, c) $R R S=$ $50 \%$, d) RRS $=70 \%$, e) RRS $=150 \%$ e f) RRS $=500 \%$

Figura 4.17 Espaço de fase (azul) e seção de Poincaré (vermelho) para forçamento harmônico com ruído de (a) RRS $=1 \%$, (b) RRS $=30 \%$, (c) RRS $=50 \%$, (d) RRS $=100 \%$ e (e) RRS $=500 \%$.

Figura 4.18 Curvas de PSDpara os valores de ruído de a) RRS $=1 \%$, b) RRS $=30 \%$, c)

$$
\mathrm{RRS}=50 \%, \mathrm{~d}) \mathrm{RRS}=100 \%, \mathrm{e}) \mathrm{RRS}=500 \%
$$

Figura 0.1 Órbita periódica (a) parametrizada e (b) reparametrizada .64

Figura 0.2 Órbita periódica (a) parametrizada e (b) reparametrizada 65

Figura 0.3 Ilustração da Seção de Poincaré. 66

Figura 0.4 Resposta no domínio do tempo para condições inicias próximas. 67 


\section{LISTA DE TABELAS}

Tabela 2.1 Domínios Físicos e Variáveis de Estados relacionadas .......................................

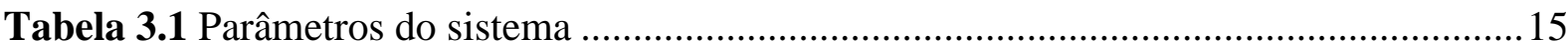

Tabela 4.1 Parâmetros de forçamento, condições iniciais e comportamento dinâmico para os casos 1 a 9 analisados com forçamento harmônico.

Tabela 4.2 Valores da área sob a curva de PSD da tensão e forçamento para casos sob condição de forçamento harmônico.

Tabela 4.3 Valores da área sob a curva de PSD do forçamento e tensão elétrica para forçamento aleatório.

Tabela 4.4 Parâmetros de forçamento harmônico no caso de excitação combinada 38

Tabela 4.5 Valores da área sob a curva de PSD do forçamento e tensão elétrica para forçamento harmônico contaminado com ruído para o $1^{\circ}$ caso de excitação combinada.

Tabela 4.6 Valores da área sob a curva de PSD do forçamento e tensão elétrica para forçamento harmônico contaminado com ruído para o $2^{\circ}$ caso de excitação combinada.

Tabela 4.7 Valores da área sob a curva de PSD do forçamento e tensão elétrica para forçamento harmônico contaminado com ruído para o $3^{\circ}$ caso de excitação combinada.

Tabela 4.8 Valores da área sob a curva de PSD do forçamento e tensão elétrica para forçamento harmônico contaminado com ruído para o $4^{\circ}$ caso de excitação combinada.

Tabela 4.9 Valores da área sob a curva de PSD do forçamento e tensão elétrica para forçamento harmônico contaminado com ruído para o $1^{\circ}$ caso de excitação combinada. 


\section{INTRODUÇÃO}

Energias renováveis tem sido tópico de diversas pesquisas nas últimas décadas, e estão relacionadas com a intensa procura por meios alternativos e mais sustentáveis de gerar energia. Diversas pesquisas apresentam sistemas que podem obter energia renovável, através da conversão da energia presente, por exemplo, nos ventos, no movimento das ondas do mar ou nas vibrações mecânicas em energia elétrica.

Nessa busca por fontes de energias renováveis, a exploração de materiais que são capazes de transformar energia mecânica em energia elétrica, devido a uma propriedade química, está sendo amplamente pesquisada. Esses materiais são conhecidos como piezelétricos. De um modo mais específico os materiais piezelétricos são capazes de colher a energia mecânica presente em ambientes, convertendo-a em energia elétrica. Há um grande interesse na utilização desses materiais em sistemas que contém tecnologias wireless e/ou contém dispositivos eletrônicos de baixa potência.

Diversos sistemas com materiais piezelétricos voltados para a colheita de energia já estão presentes na literatura. Alguns desses sistemas são lineares, porém diversos estudos apresentam sistemas não-lineares. Os sistemas lineares apresentam um bom desempenho para frequências fixas de trabalho, as frequências de ressonância. Pequenas mudanças em relação a essas frequências, no entanto, fazem com que a energia colheitada caia bruscamente. $\mathrm{O}$ uso de sistemas não-lineares, por sua vez, busca o aumento da faixa de trabalho. Estudos mostram que, apesar de o sistema apresentar diferentes tipos respostas, mudanças na frequência não causam grandes decaimentos na energia colheitada, ou seja, aumentam sua faixa de trabalho.

Neste trabalho apresenta-se um sistema biestável não-linear para colheita de energia com material piezelétrico sujeito a diferentes tipos de excitação.

\subsection{OBJETIVO}

Tem-se como objetivo principal apresentar um método de avaliação do desempenho do sistema que pode ser aplicado tanto para excitações harmônicas como para aleatórias. Com esse método, objetiva-se avaliar o desempenho do gerador piezelétrico sujeito a três condições de forçamento diferentes: harmônico puro; aleatório puro; e forçamentos harmônico e aleatório combinados 


\subsection{CONTRIBUIÇÕES}

Os trabalhos presentes na literatura analisam o sistema piezomagnetoelástico mostrando que as não-linearidades podem melhorar o desempenho do gerador piezelétrico quando comparado ao sistema linear equivalente. Fazendo um estudo do sistema sujeito a um forçamento harmônico puro ou a um forçamento aleatório puro. Neste trabalho, o mesmo sistema é revisitado. Agora, no entanto, além de analisar excitações harmônicas e aleatórias puras, estuda-se também o desempenho do gerador para essas excitações combinadas. Apresentando-se também um método para avaliação da colheita de energia baseado na Densidade Espectral de Potência (PSD).

\subsection{ORGANIZAÇÃO DO TRABALHO}

Esse trabalho está organizando em 5 capítulos e 2 anexos. No capítulo 1, apresenta-se uma breve introdução aos tópicos estudados nesse trabalho, incluindo os objetivos e motivações, assim como uma apresentação da organização do trabalho.

No capítulo 2 é apresentada uma revisão de literatura acerca da colheita de energia e os diversos tópicos de estudos dentro dessa área. Apresentam-se estudos relacionados com o presente trabalho, deixando evidente a relevância dos estudos realizados.

No capítulo 3 apresenta-se, inicialmente, o sistema peizomagnetoelástico e suas equações de movimento, que é seguida de uma análise dos pontos de equilíbrio e suas estabilidades. Em seguida, é realizado um estudo da dinâmica do sistema quando submetido a uma condição de forçamento harmônica, onde diferentes tipos de comportamentos são apresentados.

No capítulo 4 estão contidos os resultados do trabalho. Organizados por tipo de forçamento: harmônico puro; aleatório puro; e excitação combinada. Para o forçamento puramente harmônico apresentam-se nove casos de estudos, que são classificados qualitativamente de acordo com seus tipos de respostas. Com um forçamento aleatório puro nenhuma classificação em relação ao tipo de comportamento é apresentada, contudo escolhese diversos níveis ruído. E por fim um forçamento combinado é levado em consideração, verificando-se a dinâmica para diversos níveis de ruído assim como o desempenho para cada nível.

No capítulo 5 apresentam-se as conclusões desse trabalho. 
Nos anexos estão contidos alguns conceitos utilizados no trabalho. No Anexo A a teoria referente ao estudo da dinâmica não linear é apresentada. No Anexo B estão contidos os conceitos da analise aleatória. 


\section{REVISÃO DE LITERATURA}

Os materiais inteligentes estão sendo estudados mais intensamente nos últimos anos. Suas propriedades são interessantes e envolvem características que não são típicas em materiais comumente utilizados. Tais capacidades envolvem: alterar seu volume; encolher ou expandir; ou se mover quando esquentados ou esfriados; produzir cargas elétricas, entre outras capacidades peculiares.

Uma definição mais formal de materiais inteligentes está relacionada com a capacidade de converter energia entre domínios multi-físicos. Usando os conceitos apresentados por Leo (2007) pode-se dizer que um domínio físico é um conjunto de duas variáveis de estado que podem descrever tal domínio, por exemplo: o domínio mecânico está relacionado com as variáveis de estado de tensão e deformação, enquanto o domínio elétrico está relacionado com as variáveis de estado de campo elétrico e deslocamento elétrico. A Tabela 2.1 apresenta as variáveis de estado dos principais domínios físicos.

Tabela 2.1 Domínios Físicos e Variáveis de Estados relacionadas

\begin{tabular}{|c|c|c|c|c|c|}
\hline Domínio & Mecânico & Elétrico & Térmico & Magnético & Químico \\
\hline $\begin{array}{c}\text { Variáveis } \\
\text { de }\end{array}$ & Tensão & Campo Elétrico & Temperatura & $\begin{array}{c}\text { Campo } \\
\text { Magnético }\end{array}$ & Concentração \\
\hline Estado & Deformação & $\begin{array}{c}\text { Deslocamento } \\
\text { Elétrico }\end{array}$ & Entropia & $\begin{array}{c}\text { Fluxo } \\
\text { Magnético }\end{array}$ & $\begin{array}{c}\text { Fluxo } \\
\text { Volumétrico }\end{array}$ \\
\hline
\end{tabular}

Define-se então que um material inteligente possui um acoplamento entre dois domínios físicos. Os acoplamentos estão relacionados com a ideia de que variações de uma variável de estado em um domínio físico causa mudanças em uma variável de estado em outro domínio.

A partir da Figura 2.1 observa-se que existem materiais inteligentes que são capazes de levar energia mecânica para o domínio elétrico e vice e versa, os materiais piezelétricos. Por haver dois sentidos de conversão define-se que quando energia mecânica é levada ao domínio elétrico tem-se o efeito piezelétrico direto, ou seja, uma deformação mecânica acarreta um deslocamento elétrico. Por outro lado, quando a energia elétrica é levada ao domínio mecânico tem-se o efeito piezelétrico inverso, ou seja, deslocamentos elétricos causam deslocamentos mecânicos. 


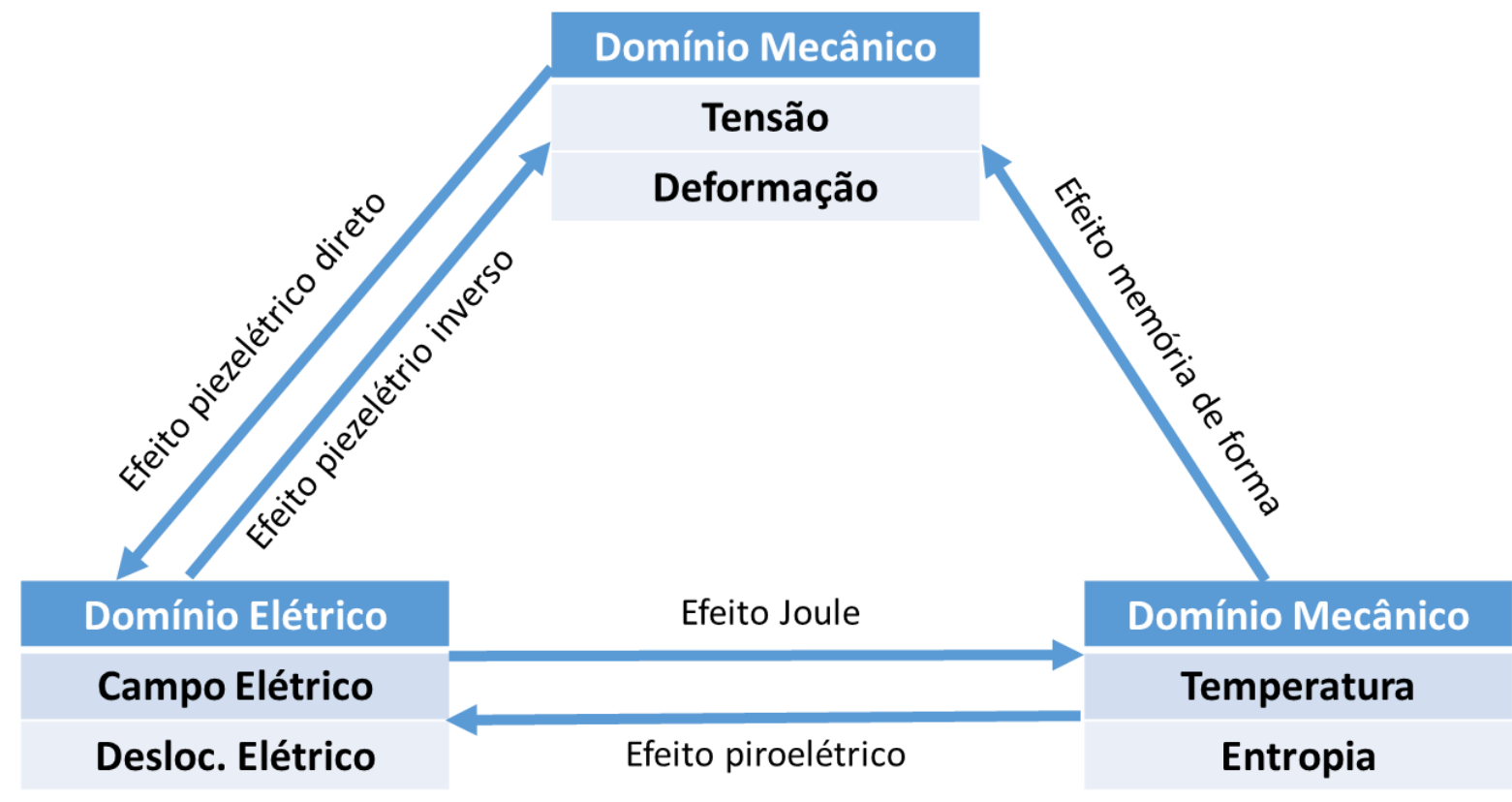

Figura 2.1 Principais efeitos na transformação de energia entre domínios físicos, Leo (2007)

Por apresentarem essa capacidade de converter energia entre dois domínios físicos distintos os materiais piezelétricos tem sido tópico de diversas pesquisas, envolvendo sua utilização como sensores, atuadores e, mais recentemente, para colheita de energia.

As aplicações de materiais piezelétricos podem acontecer em diversos ambientes que apresentam energia mecânica em forma de vibração. Feenstra et al. (2008) e Rome et al. (2005) apresentam um sistema que colhe a energia presente no movimento de caminhada. Para isso apresenta-se um equipamento que pode ser utilizado dentro de uma mochila.

Devido a diversidade de estudos de sistema de colheita de energia, alguns trabalhos tentam classificar as diferentes estudos. Tang et al. (2010), por exemplo, apresenta uma classificação desses estudos. Existem três linhas principais de pesquisa: ajustes de frequência de ressonância, método multimodal de colheita de energia e técnicas não-lineares.

A técnica de ajuste de frequência é apresentada para sistemas lineares, onde é possível ajustar a frequência de ressonância do sistema realizando adaptações nos parâmetros geométricos e dimensões do sistema. Quando o sistema oscila fora da frequência de ressonância, no entanto, há quedas bruscas na energia obtida. Segundo Roundy e Zhang (2005) técnicas de ajuste de frequência podem acontecer de modo ativo ou passivo.

Adhikari et al. (2009) apresentam um trabalho que analisa a resposta elétrica de um sistema de um grau de liberdade quando ligado a dois tipos de circuito diferentes, um puramente resistivo e um indutivo. Tendo em vista uma excitação aleatória, as equações de 
potência elétrica são derivadas para os dois circuitos e em seguida simulações numéricas são apresentadas. Na conclusão apresentam-se os parâmetros ótimos do sistema.

Os trabalhos que utilizam o método multimodal exploram sistemas com dois ou mais graus de liberdade, deste modo existem mais picos de frequência que podem ser explorados. Neste contexto, o trabalho de Yang et al. (2015), tem como objetivo apresentar uma estrutura que seja capaz de colher a energia presente em ambientes através de vibrações em duas direções diferentes. Para isso, camadas de materiais piezelétricos são fixadas em uma estrutura que apresentava modos de vibrações na vertical e na horizontal.

Erturk et al. (2008) também apresentam um trabalho que se enquadra nas técnicas multimodais e realiza um estudo de um sistema linear que consiste de uma viga engastada com uma abordagem analítica e experimental. O sistema é acoplado a um circuito puramente elétrico e a resposta em frequência é avaliada quando a resistência é alterada. O trabalho apresenta uma frequência e resistência ótima para o sistema.

Tol (2015) também apresenta um sistema que consiste de uma viga e realiza um estudo de dois sistemas elétrico: resistivo e resistivo-indutivo. O sistema resistivo-indutivo tem um desempenho melhor quando comparado com o sistema resistivo. Uma massa na extremidade da viga é inserida no sistema apresentando a uma eficiência de $95 \%$ quando conectado a um sistema resistivo-indutivo. Uma análise de condições de contorno é apresentada e estabelece-se uma faixa para o posicionamento da massa na extremidade que maximiza os valores de potência.

Dentre as diversas aplicações das estruturas que usam os materiais piezelétricos para colher energia presente em vibrações algumas utilizam sistemas não-lineares. Os sistemas não-lineares são abordados por 2 motivos: busca por aumento da faixa de operação do gerador uma vez que não existem frequências características que maximizam a resposta do sistema; e busca por órbitas que aumentam a amplitude de oscilação do sistema em relação ao sistema linear.

Triplett e Quinn (2009) estudam analiticamente um sistema de colheita de energia nãolinear com um acoplamento piezelétrico não-linear. Utilizando uma abordagem de potência média, esse trabalho verifica que pequenas não-linearidades podem fazer com que a energia colhida aumente em relação a um sistema linear. O aumento da não-linearidades, no entanto, pode causar uma diminuição do desempenho.

Beeby et al. (2007) apresentam um pequeno gerador eletromagnético utilizando componentes discretos e otimizado para vibrações do ambiente de pequena amplitude. $\mathrm{O}$ sistema é aplicado a uma unidade compressora de ar. Utilizando uma abordagem de 
distribuição de potência normalizada, avaliam-se as melhores frequências de trabalho do sistema. Observa-se que o comportamento não-linear que produz uma histerese na saída do sistema.

Mann e Owens (2010) estudam um sistema não-linear biestável que usa interação magnétia para criar um gerador inercial.. O modelo analítico é desenvolvido mostrando que o sistema apresenta coexistência de soluções. Os resultados mostram que o sistema biestável aumenta a largura de banda em relação ao sistema linear.

Tehrani e Elliott (2014) apresentam uma análise de um sistema com amortecimento não-linear. Utilizando uma solução analítica para o valor de potência média, verifica-se que o sistema não-linear pode collher significativamente mais energia na região de ressonânica do que o sistema linear, quando excitado harmonicamente.

Litak (2015) apresenta uma análise do sistema de viga invertida com uma massa na ponta. O sistema é tratado como um sistema de um grau de liberdade não-linear biestável. Um estudo é apresentado sobre a estabilidade do sistema para diferentes valores de massa na extremidade da viga. Algumas respostas caóticas e periódicas são apresentadas, mostrando que o comportamento caótico reduz signifcativamente a energia colheitada. Stanton et al. (2010) realiza um estudo parecido que confirma que órbitas caóticas não apresentam os melhores valores de colheita de energia quando comparado com órbitas periódicas.

Alguns artigos estudam formas de adaptar a estrutura mecânica apresentada primeiramente por Moon e Holmes (1979) como um gerador piezelétrico não-linear. O modelo mecânico apresentado por Moon e Holmes (1979) consiste em um sistema de um grau de liberdade e leva em conta as forças magnéticas, forças dissipativas e forças de restauração. Baseado nesse trabalho, Erturk e Inman (2008) adicionam na modelagem a parte do domínio elétrico e obtêm a equação de governo do gerador piezelétrico. Esse gerador consiste em um sistema piezomagnetoelástico não-linear. Os trabalhos a seguir utilizam esse mesmo modelo.

Considerando excitação harmônica, Erturk e Inman (2011) e Erturk et al. (2009) mostram que algumas órbitas de grandes amplitudes apresentam um desempenho superior, em termos de energia obtida quando comparado ao sistema linear. Essas órbitas aparecem em uma faixa de frequência, aumentando a faixa de trabalho do gerador em comparação ao equivalente linear.

Ferrari et al. (2011) mostram que para uma excitação harmônica e baixas frequências ocorrem saltos dinâmicos, enquanto para altas frequências um efeito de histerese é observado. Para uma excitação aleatória do tipo de ruído branco gaussiano mostra-se que para um 
sistema biestável a voltagem RMS de saída é $400 \%$ maior do que para quando o sistema é montável.

Zhao e Erturk (2013) também trabalharam com um sistema piezomagnetoelastico apresentando uma configuração monoestável e biestável. O estudo mostra que quando submetido a excitações aleatórias o sistema biestável só é melhor para intensidades de excitação específicas, quando o sistema oscila entre os dois pontos de equilíbrio estável.

Litak et al. (2010) também considera o forçamento como um ruído branco gaussiano. O comportamento do sistema apresenta uma ressonância estocástica. De Paula et al. (2015) apresenta um estudo experimental e numérico da estrutura piezomagnetoelástica. Os autores comparam uma estrutura linear, não-linear biestável e não-linear mono estável. Os resultados experimentais e numéricos mostram que a colheita de energia é melhor no sistema biestável quando ele oscila em torno dos dois pontos de equilíbrios. Uma investigação é apresentada a fim de descobrir para quais valores de $\sigma^{2}$ o sistema visita ambos os pontos de equilíbrio e produz mais energia.

Barbosa et al. (2015) apresenta um estudo da mesma estrutura piezomagnetoelástica não-linear sujeita a uma excitação puramente harmônica com objetivo de controlar o sistema simultaneamente com a colheita de energia. Nesse caso, a energia obtida é utilizada para alimentar o controlador, que visa mitigar as vibrações mecânicas. 


\section{ANÁLISE DINÂMICA DO SISTEMA PIEZOMAGNETOELASTICO}

Neste capítulo, inicialmente apresenta-se uma descrição do sistema piezomagnetoelástico. Em seguida, apresenta-se uma análise dinâmica do sistema, incluindo avaliação dos pontos de equilíbrio e tipo de estabilidade e comportamentos que surgem como resposta a um forçamento harmônico. Neste contexto, ferramentas de dinâmica não-linear, como seção de Poincaré, diagrama de Bifurcação e bacia de atração são utilizadas.

\subsection{SISTEMA PIEZOMAGNETOELÁSTICO}

O sistema estudado nesse trabalho é apresentado na Figura 3.1. O sistema é composto por uma estrutura magnetoelástica que possui uma viga ferromagnética engastada em uma extremidade e livre na outra. Na extremidade livre encontra-se um imã e a uma distância $d$ deste imã encontra-se outro imã. A interação entre os imãs produz um campo magnético não uniforme que caracterizam as não linearidades do sistema. Esse sistema foi inicialmente proposto por Moon e Holmes (1979).

Com o intuito de colheita de energia, Erturk et al. (2009) propôs a inserção de uma camada de material piezelétrico nas faces da viga. Obtêm-se assim uma estrutura piezomagnetoelástica com capacidade de colher a energia presente na vibração. Para avaliação da energia elétrica obtida, o sistema é acoplado a um circuito puramente resistivo

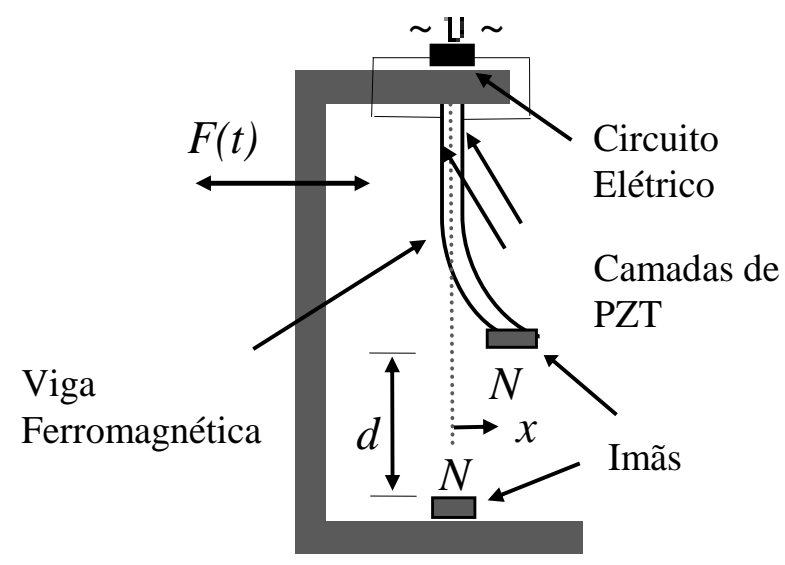

Figura 3.1. Sistema Piezomagnetoelástico 
O sistema pertence a dois domínios físicos distintos, um domínico mecânico e um domínio elétrico. Existe, portanto, uma equação de movimento para cada domínio. O acoplamento entre as equações mecânicas e elétricas foi proposto por Erturk e Inman (2008).

As equações de movimento utilizadas nesse trabalho são as mesma que as apresentadas no trabalho de Erturk e Inman (2011) e dadas pela equação a seguir:

$$
\begin{aligned}
& \ddot{u}+2 \zeta \dot{u}-\frac{1}{2} u\left(1-u^{2}\right)-\chi v=F(t), \\
& \dot{v}+\lambda v+\kappa \dot{u}=0 .
\end{aligned}
$$

onde o parâmetro $u$ é o deslocamento admensional da extremidade livre da viga na direção transversal, $v$ é a tensão elétrica admensional através da carga de resistência, $\zeta$ a constante diz respeito ao valor admensional da razão de amortecimento mecânico, $\chi$ é o termo admensional do acoplamento piezelétrico na equação mecânica, e $\kappa$ é termo admensional do acoplamento piezelétrico na equação elétrica. Os valores de parâmetros físicos do sistema são os mesmo que apresentados por Erturk et al. (2009) e podem ser verificados na Tabela 3.1.

Tabela 3.1 Parâmetros do sistema

\begin{tabular}{|c|c|}
\hline$\zeta=0,01$ & $\chi=0,05$ \\
\hline$\lambda=0,05$ & $\kappa=0,5$ \\
\hline
\end{tabular}

É importante destacar que as equações de movimento apresentadas nesse trabalho estão em sua forma adimensional. A integração das equações do movimento é obtida a partir do método de integração numérica de Runge Kutta de quarta ordem, utilizando rotinas escritas em Linguagem $\mathrm{C}$.

O termo independente $F(t)$ da Eq. (1) é o termo de forçamento externo da equação. Estuda-se, neste trabalho, o comportamento do sistema sujeito a três excitações diferentes: puramente harmônico, puramente aleatório e harmônico e aleatório combinados.

Quando a excitação é puramente harmônica considera-se que:

$$
F(t)=f_{0} \cos (\omega t)
$$

onde $f_{0}$ é a amplitude de excitação adimensional e $\omega$ é a frequência de excitação adimensional. 
No caso de excitação puramente aleatória o termo independente é dado por:

$$
F(t)=N(\sigma, \bar{\mu}),
$$

onde $N(\sigma, \bar{\mu})$ é um ruído Gaussiano Branco, $\bar{\mu}$ é a média relacionada com a geração dos valores aleatórios e $\sigma$ é o desvio padrão. A média permanece inalterada para todas as simulações apresentadas, porém o desvio padrão recebe diversos valores. Entende-se que a variação dos valores de desvio padrão está relacionada com as amplitudes do forçamento.

Para os forçamentos harmônico e aleatório combinados, as duas parcelas apresentadas nas Eqs. (4) e (5) são somadas no termo independente:

$$
F(t)=f_{0} \cos (\omega t)+N(\sigma, \bar{\mu})
$$

Para mensurar os níveis de ruído é estabelecido uma quantidade denominada Razão Ruído-Sinal $(R R S)$ que é uma razão entre o valor de $\sigma$ e o valor de $f_{0}$ como apresentado na Eq. (6). As variações nos valores de $R R S$ acontecem para $f_{0}$ fixo, e $\sigma$ variando. Deste modo se $\sigma=0$ o comportamento do sistema é conhecido.

$$
R R S(\%)=\frac{\sigma}{f_{0}} 100
$$

\subsection{ANÁLISE DINÂMICA}

Para a análise dinâmica do sistema, incluindo sua integração numérica, as equações de movimento (Eqs. 1 e 2) são reescritas como um sistema de equações diferenciais ordinárias de primeira ordem do tipo $\dot{\boldsymbol{x}}=f(\boldsymbol{x})$, conforme apresentado nas Eqs. (7-9). Dessa forma, o sistema é descrito pelas variáveis de estados, $\boldsymbol{x}$, sendo $x_{1}$ o deslocamento da extremidade livre da viga, $x_{2}$ a velocidade da extremidade livre da viga e $x_{3}$ a tensão elétrica.

$$
\begin{aligned}
& \dot{x}_{1}=x_{2}, \\
& \dot{x}_{2}=-2 \zeta x_{2}+\frac{1}{2} x_{1}\left(1-x_{1}{ }^{2}\right)+\chi x_{3}+F(t), \\
& \dot{x}_{3}=-\lambda x_{3}-\kappa x_{2}
\end{aligned}
$$




\subsubsection{PONTOS DE EQUILÍBRIO E ESTABILIDADE}

Para uma análise dos pontos de equilíbrio e seu tipo de estabilidade avalia-se o sistema sem forçamento, $F(t)=0$. A condição estacionária é alcançada quando $\dot{\boldsymbol{x}}=\mathbf{0}$. Com isso:

$$
\begin{aligned}
& \dot{x}_{1}=x_{2}=0, \\
& \dot{x}_{2}=-2 \zeta x_{2}+\frac{1}{2} x_{1}\left(1-x_{1}{ }^{2}\right)+\chi x_{3}=0, \\
& \dot{x}_{3}=-\lambda x_{3}-\kappa x_{2}=0 .
\end{aligned}
$$

Portanto os valores dos pontos de equilíbrio são dados por $(x ; \dot{x} ; v)=( \pm 1 ; 0 ; 0) \mathrm{e}$ $(x ; \dot{x} ; v)=(0 ; 0 ; 0)$. A estabilidade dos pontos de equilíbrio é avaliada pela linearização em torno dos pontos de equilíbrio, de onde obtém-se que $(x ; \dot{x} ; v)=(0 ; 0 ; 0)$ é um ponto de equilíbrio instável do tipo sela e $(x ; \dot{x} ; v)=( \pm 1 ; 0 ; 0)$ são pontos de equilíbrio estável do tipo espiral. Dessa forma, tem-se um sistema biestável.

A Figura 3.2 apresenta algumas respostas no tempo e espaço de fase do sistema sem forçamento externo e diferentes condições iniciais. Observa-se na Figura 3.2 (a) e (b) que apesar da consideração de condições iniciais mais próximas do ponto de equilíbrio estável $(+1 ; 0 ; 0)$ o sistema oscila em torno do outro ponto de equilíbrio estável $(-1,0,0)$. Isso ocorre pois as condições iniciais impostas $(1,5 ; 0 ; 0)$ ao sistema fornecem energia suficiente para transitar entre os pontos de equilíbrio. A Figura 3.2 (c) e (d) mostra que com condições iniciais de $(x ; \dot{x} ; v)=(0 ;-2 ; 0)$ as oscilações inicialmente ocorrem em torno dos dois pontos de equilíbrio estável, porém, após um período de tempo as oscilações são realizadas em torno do ponto de equilíbrio $(x ; \dot{x} ; v)=(1 ; 0 ; 0)$. Esse comportamento mostra que o sistema precisa de energia mecânica (cinética e potencial) maior do que a energia potencial magnética para oscilar em torno de ambos os pontos de equilíbrio estável. Por outro lado, se condições iniciais próximas ao ponto de equilíbrio instável forem dadas ao sistema $(0 ; 0,1 ; 0)$, como mostrado na Figura 3.2 (e) e (f), a trajetória é repelida do ponto de equilíbrio.

Percebe-se que sem forçamento externo, o comportamento do sistema é dado pelo tipo de estabilidade dos pontos de equilíbrio. Quando o sistema está submetido a um forçamento harmônico, diferentes tipos de comportamento surgem na resposta do sistema, como explorado a seguir. 
a)

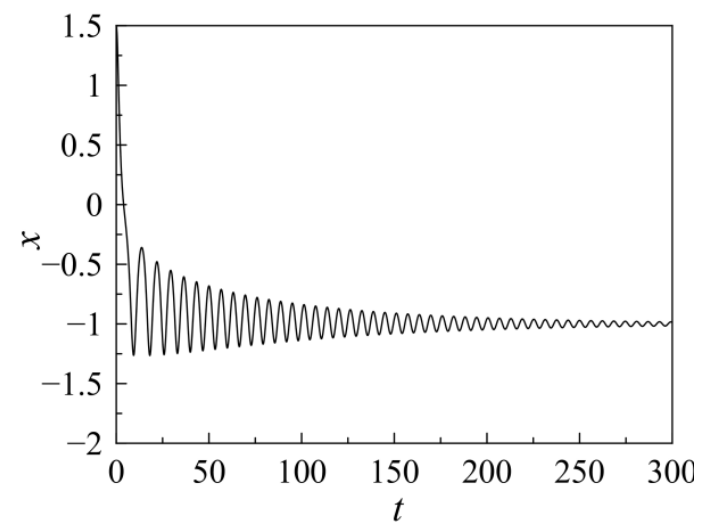

c)

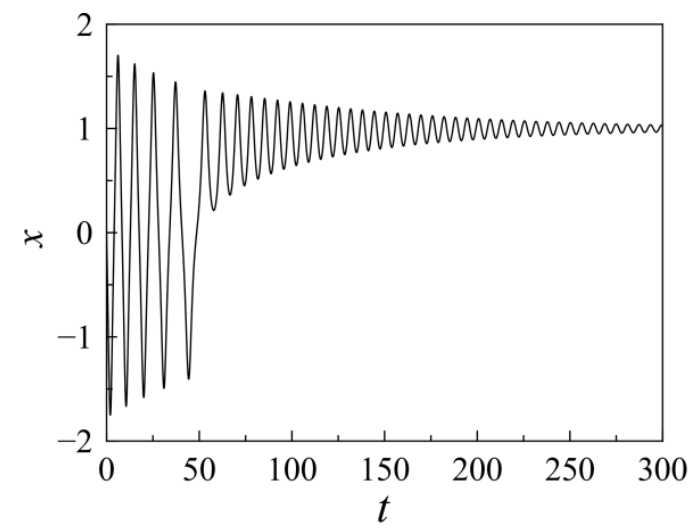

e)

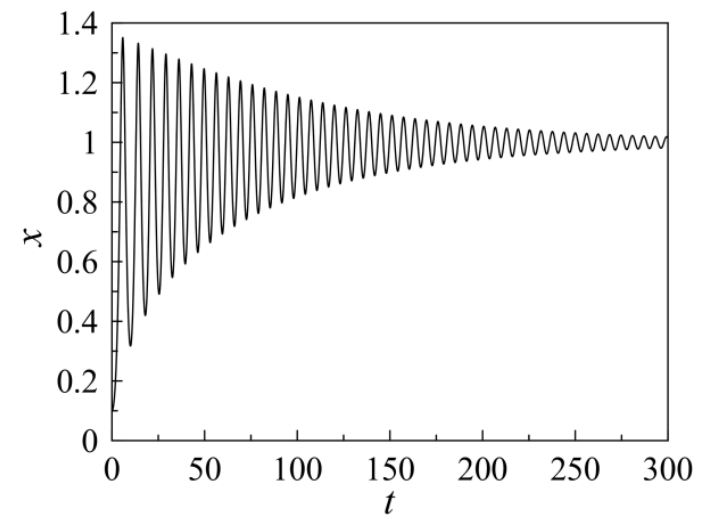

b)

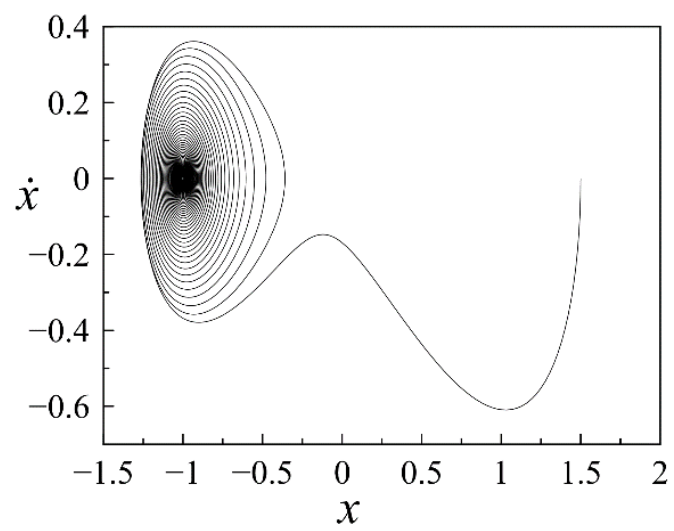

d)

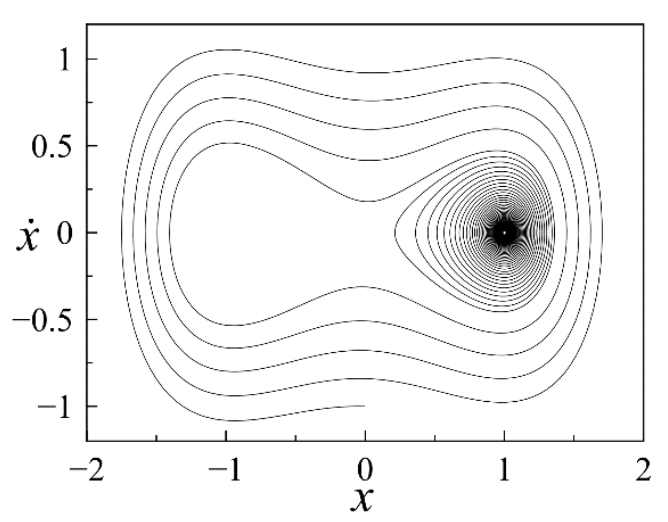

f)

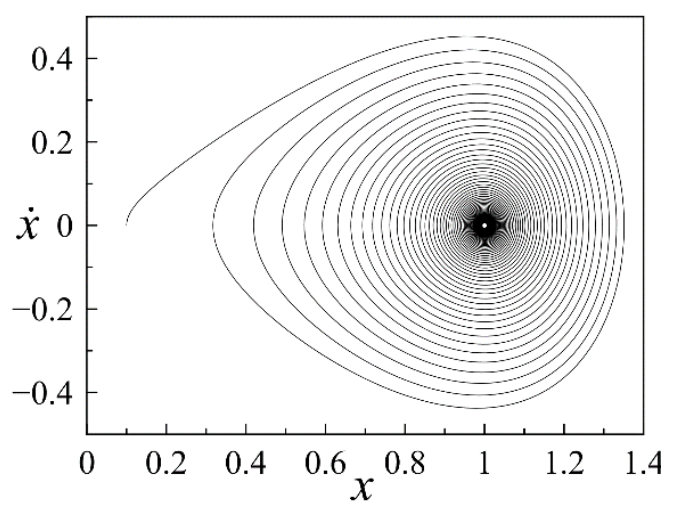

Figura 3.2. Resposta no domínio do tempo e espaço de fase sem forçamento para condições iniciais de (a) e $(\mathrm{b})(x ; \dot{x} ; v)=(1,5 ; 0 ; 0)$ (c) e (d) $(x ; \dot{x} ; v)=$ $(0 ;-2 ; 0)$ e (e) e (f) $(x ; \dot{x} ; v)=(0,1 ; 0 ; 0)$ 


\subsubsection{COMPORTAMENTOS PERIÓDICOS E CAÓTICOS}

Parte-se agora para o estudo da dinâmica do sistema quando submetido a condições de forçamento puramente harmônico. Sob essas condições o sistema pode apresentar diferentes tipos de resposta. A investigação dos diferentes tipos de comportamento é realizada através do espaço de fase e da seção de Poincaré. Os aspectos teóricos da seção de Poincaré são apresentados no Anexo A.

Quando determinadas condições de forçamento são impostas ao sistema, percebe-se que o sistema pode responder de diferentes formas. Para entender melhor a existência de comportamentos coexistentes para as mesmas condições de forçamento, porém com diferentes condições inicias apresenta-se aqui a bacia de atração. A bacia de atração identifica, através de cores, diferentes respostas do sistema em regime permanente considerando-se os mesmos parâmetros do sistema e a mesma condição de forçamento, no entanto, diferentes condições iniciais.

A Figura 3.3 (a) apresenta a bacia de atração para $f_{0}=0,083$ e $\omega=0,8$. Observam-se duas regiões distintas, a região de cor branca está relacionada com condições inicias associadas a um atrator caótico, enquanto a região de cor preta está relacionada com condições iniciais que levam a um atrator periódico. Identifica-se então a existência de dois atratores distintos e coexistentes. As Figura 3.3 (b) apresenta a bacia de atração para $f_{0}=0,1$ e $\omega=0,8$ e a Figura 3.3 (c) apresenta a bacia de atração para $f_{0}=0,083$ e $\omega=0,9$. A estrutura apresentada na bacia de atração da Figura 3.3 (a) e (b) apresenta um limite bem definido entre um atrator caótico e periódico. Contudo na Figura 3.3 (c) essa estrutura não é mais apresentada, apesar de existir uma região bem delimitada de cor preta, atrator periódico, existe uma região com uma nuvem de pontos brancos que estão relacionados com o atrator caótico. As três bacias de atração mostram a coexistência de comportamento para as três condições de de forçamento distintas.

Devido a coexistência de comportamento apresentando na bacia de atração escolhe-se dois conjuntos de condições iniciais distintas, porém com as mesmas condições de forçamento. O primeiro conjunto apresenta os parâmetros de forçamento de $f_{0}=0,083$ e $\omega=0,8$ e condições iniciais de $(x(0) ; \dot{x}(0) ; v(0))=(1 ; 1 ; 0)$ o sistema apresenta o espaço de fase apresentado na Figura 3.4. O espaço de fase para essas condições de forçamento consiste em uma curva fechada, com isso espera-se que essa órbita possua uma periodicidade. A seção de Poincaré é apresentada junto com o espaço de fase na Figura 3.4 e apresenta apenas um ponto, indicando que essa órbita é periódica e possui periodicidade igual a 1. 
Pode-se observar também que o sistema oscila em torno de ambos os pontos de equilíbrio estáveis, possuindo aproximadamente uma amplitude pico a pico de três unidades de deslocamento.

a)

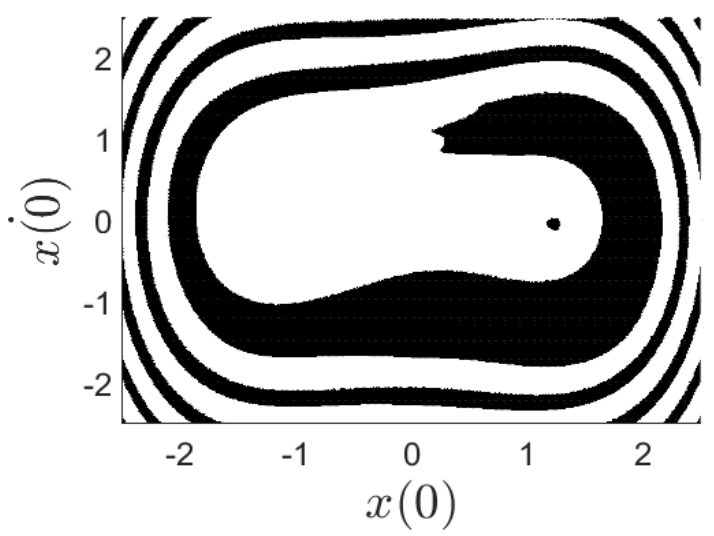

b)

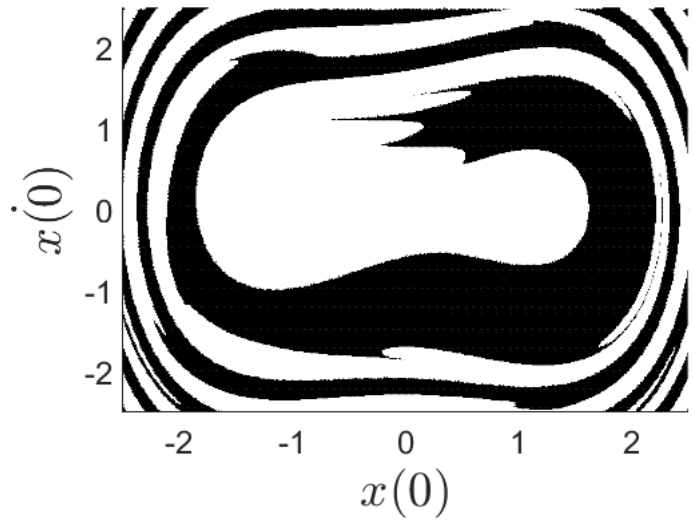

c)

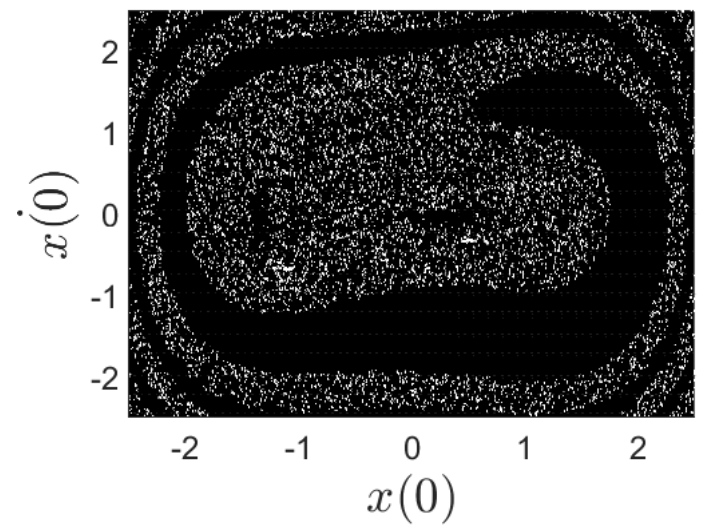

Figura 3.3 Bacia de atração para os parâmetros de forçamento de (a) $\boldsymbol{f}_{\mathbf{0}}=\mathbf{0 , 0 8 3}$ e $\omega=0,8$, (b) $f_{0}=0,1$ e $\omega=0,8$ e (c) $f_{0}=0,083$ e $\omega=0,9$

a)

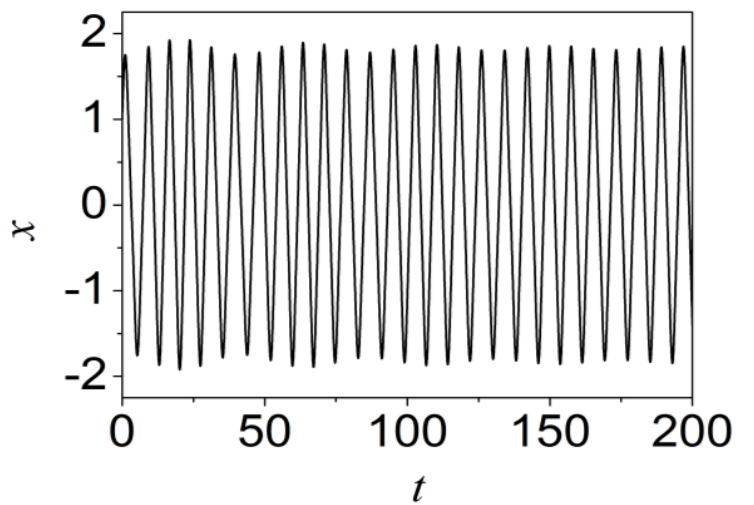

b)

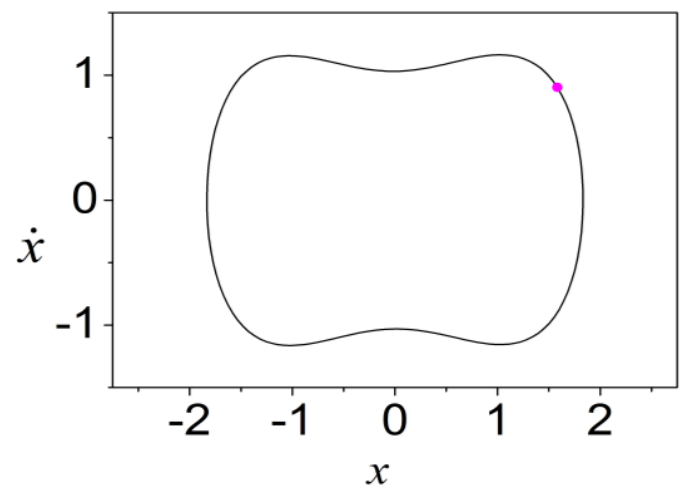

Figura 3.4 Órbita para $\boldsymbol{f}_{\mathbf{0}}=\mathbf{0 , 0 8 3}$ e $\boldsymbol{\omega}=\mathbf{0 , 8}$ e condições iniciais de $(\boldsymbol{x}(\mathbf{0}) ; \dot{\boldsymbol{x}}(\mathbf{0}) ; \boldsymbol{v}(\mathbf{0}))=(\mathbf{1} ; \mathbf{1} ; \mathbf{0})$ (a) resposta no tempo e (b) espaço de fase e seção de Poincaré 
O outro conjunto de condições iniciais é igual à $(x(0) ; \dot{x}(0) ; v(0))=(1 ; 0 ; 0)$ e está submetido sob as mesmas condições de forçamento apresentadas anteriormente, $f_{0}=0,083 \mathrm{e}$ $\omega=0,8$. O sistema apresenta uma resposta no domínio do tempo apresentada na Figura 3.4 na qual pode-se perceber nenhum padrão de oscilação. Observa-se então que apenas uma alteração nas condições iniciais levou o sistema a duas órbitas distintas. A Figura 3.4 também apresenta o espaço de fase e seção de Poincaré para essa órbita, a seção de Poincaré apresenta características que levam ao indicativo que essa resposta é caótica.

Os primeiros resultados mostram que variações de condições levam o sistema a comportamentos distintos. A seguir, a partir dos dois comportamentos identificados, avaliamse como as variações dos parâmetros de forçamento alteram a resposta do sistema. Essa análise é apresentada através do diagrama de bifurcação.

Para cada ponto de parâmetro de forçamento apresenta-se uma projeção dos pontos da seção de Poincaré. Assim, se a seção de Poincaré apresenta uma nuvem de pontos quando projetada no diagrama de bifurcação observa-se uma linha na vertical. Com isso as regiões mais cheias nos diagramas de bifurcação estão relacionadas com parâmetros que levam às respostas não periódicas.

a)

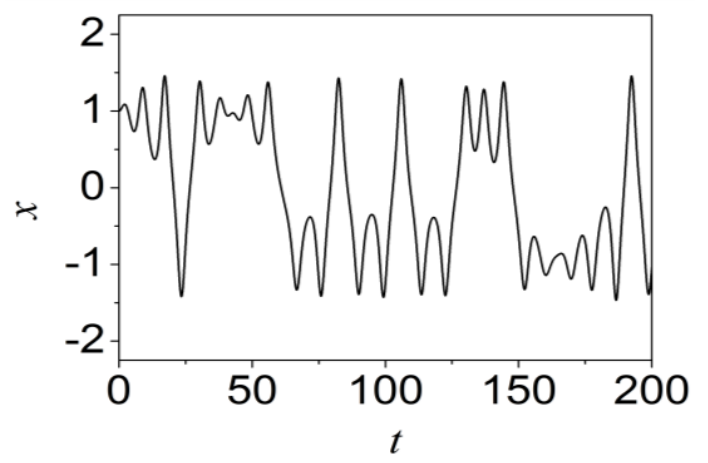

b)

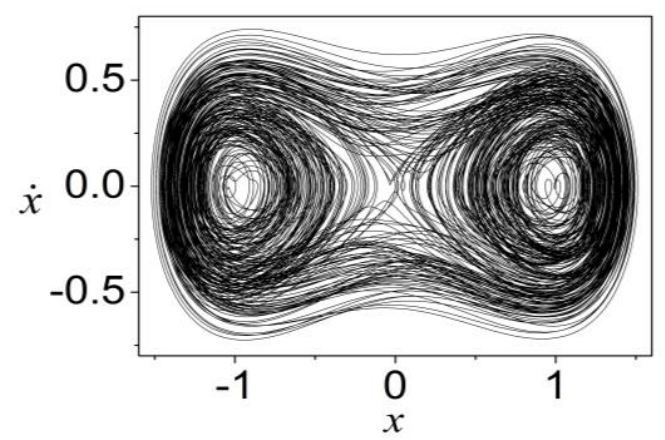

c)

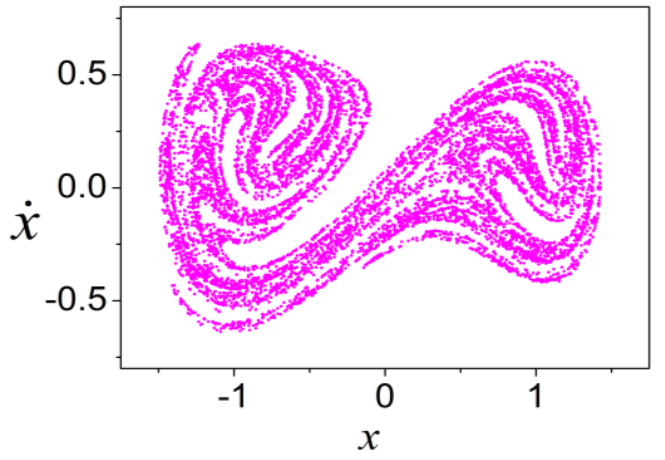

Figura 3.5. Órbita com valores de $f_{0}=0,083, \omega=0,8$ e condições iniciais de 


$$
(x(0) ; \dot{x}(0) ; v(0))=(1 ; 0 ; 0) \text {, iniciais de de o iniciais }
$$

Os diagramas de bifurcação mostrado na Figura 3.6 foram construídos partindo-se das duas órbitas apresentadas anteriormente e que estão sujeitas aos mesmos valores de forçamento, porém as condições iniciais para cada órbita são distintas. Os pontos pretos partem da uma órbita caótica que tem as condições iniciais de $(x(0) ; \dot{x}(0) ; v(0))=(1 ; 0 ; 0)$. $\mathrm{E}$ os pontos rosa partem da órbita periódica que tem condições iniciais de $(x(0) ; \dot{x}(0) ; v(0))=(1 ; 1 ; 0)$. Ambas as órbitas apresentam parâmetros de forçamento iguais à $f_{0}=0,083$ e $\omega=0,8$. A partir dessas condições iniciais e frequência de forçament $\omega=0,8$ o valor da amplitude de forçamento $f_{0}$ são aumentados e diminuídos e plotados no mesmo gráfico como pode ser observado na Figura 3.6 (a). O mesmo procedimento de aumento e diminuição é replicado, porém agora na frequência de forçamento $\omega$ e valor fixo de $f_{0}=0,083$,que pode ser observado na Figura 3.6 (b). Para os pontos rosa percebe-se que eles formam uma linha contínua, isso está relacionado com um comportamento periódico de período 1 para todos os valores analisados de $f_{0}$. Os pontos pretos, por outro lado, apresentam um padrão de comportamento diferente. Neste caso, as duas regiões que aparecem nuvens de pontos estão relacionadas com respostas caóticas. Nas regiões em que aparecem linhas pretas as órbitas são periódicas, sendo identificadas órbitas de período 1 e de período 4 . A partir dos resultados em preto e em rosa é possível perceber a coexistência de dois comportamentos distintos para $f_{0}<0.11$, acima desse valor as linhas preta e rosa são coincidentes mostrando que há apenas uma órbita estável.

a)

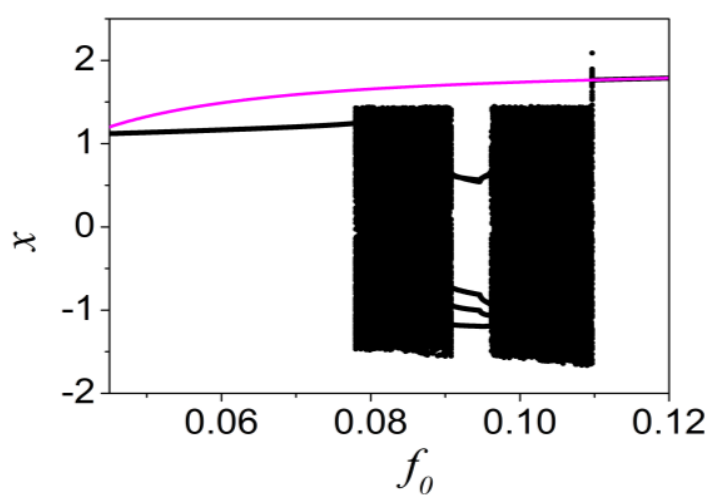

b)

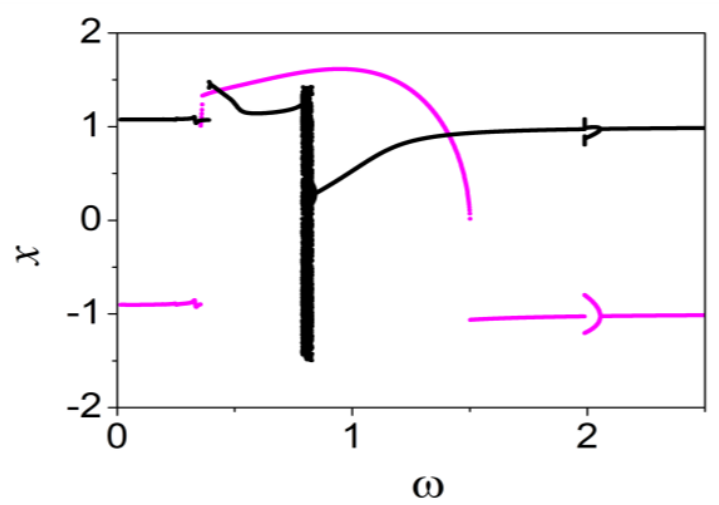

Figura 3.6 Diagrama de Bifurcação, (a) variando a amplitude $f_{0}$ e frequência $\omega=0,8$ (b) variando a frequência $\omega$ e amplitude $f_{0}=0,083$. 


\section{ANÁLISE DO DESEMPENHO E DA COLHEITA DE ENERGIA}

A análise dinâmica apresentada no capítulo anterior realizada sob um forçamento puramente harmônico mostra que o sistema pode responder de diferentes maneiras quando submetido a condições de forçamento semelhantes, apresentando coexistência de comportamento.

Este capítulo apresenta os resultados obtidos através de um método de análise, comparando as melhores respostas elétricas do sistema e seus respectivos desempenhos entre entrada e saída. Os resultados são apresentados em três sessões: a primeira é referente ao forçamento puramente harmônico; a segunda com o forçamento puramente aleatório; e a terceira apresenta-se como uma combinação de forçamento harmônico e aleatório.

\subsection{MÉTODO DE AVALIAÇÃO DA COLHEITA DE ENERGIA}

Inicialmente, simulações form realizadas para as potências elétricas e mecânicas do sistema porém os resultados não foram conclusivos, assim sendo propõem se um método para analisar a colheita de energia e o desempenho do sistema piezomagnetoelástico, que pode ser extendido para outros sistemas de colheita de energia, assim como outros sistemas dinâmicos aos quais se deseja verificar o desempenho do sistema.

O método porposto neste trabalho se baseia no cálculo da Densidade Espectral de Potência (PSD, do inglês power spectal density). A verificação da PSD avalia a transformada de Fourier de um sinal, como apresentada na eq. (13). que leva um sinal que está no domínio do tempo para o domínio da frequência, apresentando-se assim, as principais frequências envolvidas no sinal analisado.

$$
X(\omega)=\int_{-\infty}^{\infty} x(t) e^{-i 2 \pi \omega t} d t
$$

onde $X(\omega)$ é a transformada de Fourier, $x(t)$ é um sinal no domínio do tempo, $i$ é o número imaginário. Define-se a PSD de um sinal como sendo o quadrado do módulo da transformada de Fourier:

$$
\operatorname{PSD}=\lim _{T \rightarrow \infty} \frac{|X(\omega)|^{2}}{T}
$$


percebe-se que a PSD é uma distribuição de energia do sinal ao longo das frequências. A estimativa da PSD utiliza os resultados das simulações e é feita via Periodograma (método de Welch, Newland (1993)), e janelamento hanning com a respectiva compensação de potência do sinal.

Com isso pode se definir o potência envolvida em um sinal como a área debaixo da curva da PSD em uma largura de banda $B$. Com isso estabelece-se o valor de Potência do Sinal (PS) como:

$$
P S=\frac{1}{t} \int_{B} P S D(\omega) d \omega
$$

Para avaliar a colheita de eneriga e desempenho do sistema avalia-se os valores de PS do sinal de entrada, forçamento admensional, definido como $P S_{f}$, e avalia-se também o valor de PS do sinal de saída, tensão admensional, definido como $P S_{v}$. Portando pode-se definir um valor de razão entre entrada e saída $r$, onde:

$$
r=\frac{P S_{v}}{P S_{f}}
$$

\subsection{FORÇAMENTO HARMÔNICO}

Nesta seção, o desempenho do sistema é avaliado usando a abordagem por PSD quando o sistema está submetido a condições de forçamento puramente harmônico. Foram escolhidos alguns casos que norteiam a análise pelo tipo de comportamento da resposta do sistema. Os casos escolhidos estão relacionados a determinados parâmetros de forçamento e condições iniciais apresentados na Tabela 4.1 e estão agrupados de modo a comparar a colheita de energia para comportamentos semelhantes. Os casos foram encontrados através de uma verificação da dinâmica do sistema por meio do diagrama de bifurcação, Figura 3.6.

Explora-se nessa abordagem casos que apresentam as mesmas condições de forçamento e diferentes condições iniciais levando o sistema para duas órbitas distintas, como pode-se verificar no caso 2 e 4, Tabela 4.1. Além do mais, compara-se a colheita de energia para casos de mesmo tipo de comportamento, por isso apresentamos mais de um caso periódico e mais de um caso caótico. 
Tabela 4.1 Parâmetros de forçamento, condições iniciais e comportamento dinâmico para os casos 1 a 9 analisados com forçamento harmônico.

\begin{tabular}{|c|c|c|c|c|}
\hline & $\boldsymbol{\omega}$ & $\boldsymbol{f}_{\mathbf{0}}$ & Condições Iniciais & Comportamento \\
\hline Caso 1 & 0,500 & 0,100 & $(1,4263 ; 0,4801 ;-0,7263)$ & Periódico \\
\hline Caso 2 & 0,800 & 0,083 & $(1,0000 ; 1,0000 ; 0,0000)$ & Periódico \\
\hline Caso 3 & 1,400 & 0,100 & $(0,9609 ; 2,966 ;-0,5192)$ & Periódico \\
\hline Caso 4 & 0,800 & 0,083 & $(1,0000 ; 0,0000 ; 0,0000)$ & Caótico \\
\hline Caso 5 & 0,800 & 0,100 & $(-1,2316 ;-0,0048 ; 0,3478)$ & Caótico \\
\hline Caso 6 & 0,850 & 0,100 & $(-0,6814 ; 0,3135 ;-0,0503)$ & Caótico \\
\hline Caso 7 & 0,800 & 0,093 & $(1,0000 ; 0,0000 ; 0,0000)$ & Periódico \\
\hline Caso 8 & 0,815 & 0,100 & $(0,2983 ; 0,4198 ;-0,5181)$ & Periódico \\
\hline Caso 9 & 0,800 & 0,063 & $(1,1736 ;-0,0027 ;-0,0993)$ & Periódico \\
\hline
\end{tabular}

O comportamento dinâmico de cada caso é indicado pela seção de Poincaré apresentado na Figura 4.1. Junto com a seção de Poincaré, apresenta-se o espaço de fase do sistema. Através do espaço de fase, podem ser observadas as amplitudes de deslocamento de base $x$ e velocidade $\dot{x}$. Pelas equações de movimento Eqs. (1) e (2), verifica-se que o acoplamento entre o sistema mecânico e o sistema elétrico é linear, logo a relação entre amplitude de deslocamento de base $x$ e de tensão elétrica são linearmente relacionados. 
a) Casos 1 a 3

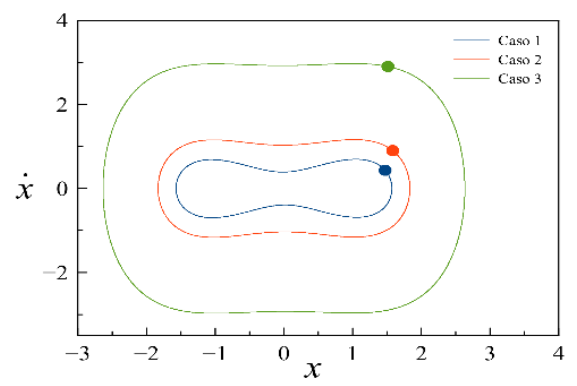

c) Caso 5

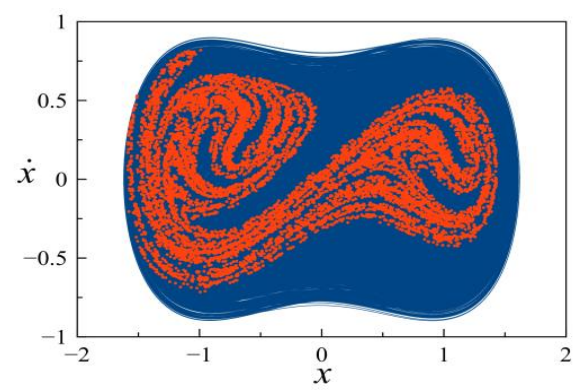

e) Casos 7 e 8

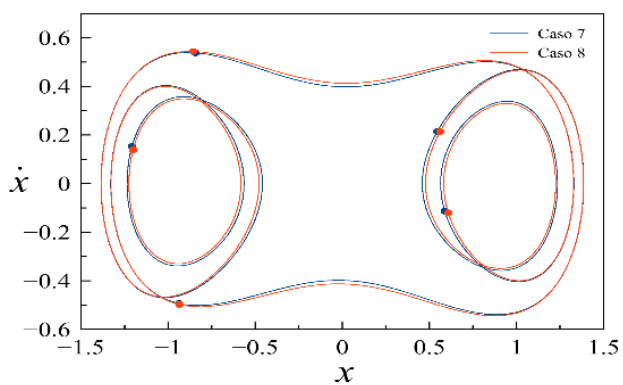

b) Caso 4

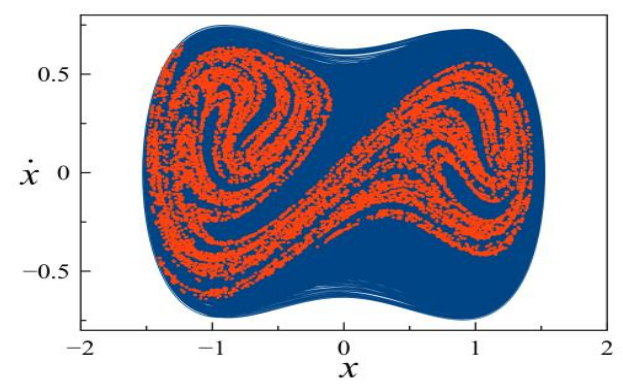

d) Caso 6

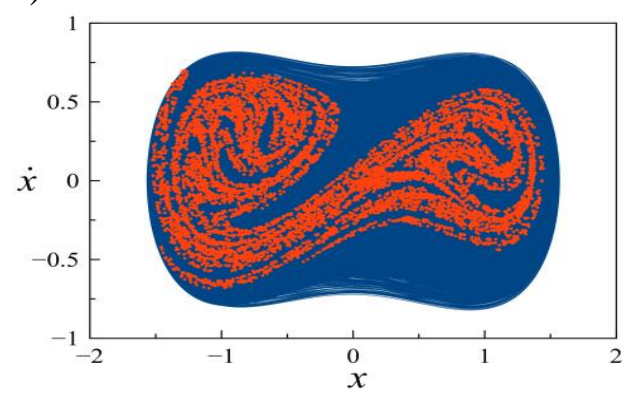

f) Caso 9

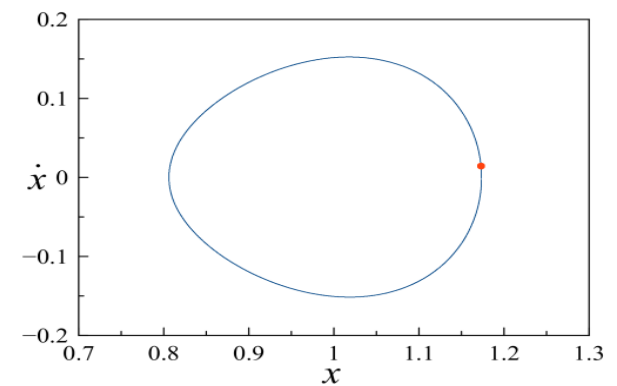

Figura 4.1 Espaço de fase e seção de Poincaré para um forçamento harmônico para (a) casos 1 ao 3, (b) caso 4, (c) caso 5, (d) caso 6, (e) casos 7 e 8 e (f) caso 9.

Junto com as seções de Poincaré e espaços de fase, as curvas de PSD auxiliam na análise do sinal. Todos os gráficos de curvas de PSD apresentados nesse trabalho estão em escala logarítmica tanto no eixo vertical quanto no eixo horizontal. A Figura 4.2 apresenta a distribuição do valor de potência do sinal de entrada $\left(P S D_{f}\right)$ assim como a distribuição de potência de resposta mecânica $\left(P S D_{x}\right)$ e elétrica $\left(P S D_{v}\right)$ em função da frequência. Tais distribuições auxiliam na caracterização do sinal através da identificação das frequências com maior potência. Para simplificar a análise, a Figura 4.2 apresenta as respectivas curvas de PSD para cada comportamento apresentado, de acordo com a Tabela 4.1. Com isso, Figura 4.2 (a) apresenta a curva de PSD para um sinal de periodicidade igual a 1, tal periodicidade pode ser observada na Figura 4.1 (a), esse sinal apresenta uma concentração de potência em certos valores de frequência apresentando assim alguns picos, um dos picos de $P S D_{v}$ e $P S D_{f}$ é coincidente com a frequência de excitação $P S D_{f}$. Os outros picos apresentados após a 
frequência fundamental aparecem devido aos harmônicos da resposta periódica

a) Caso 2

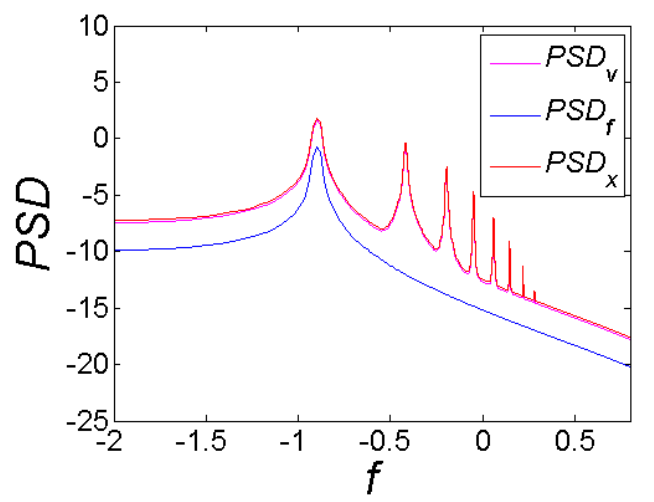

c) Caso 7

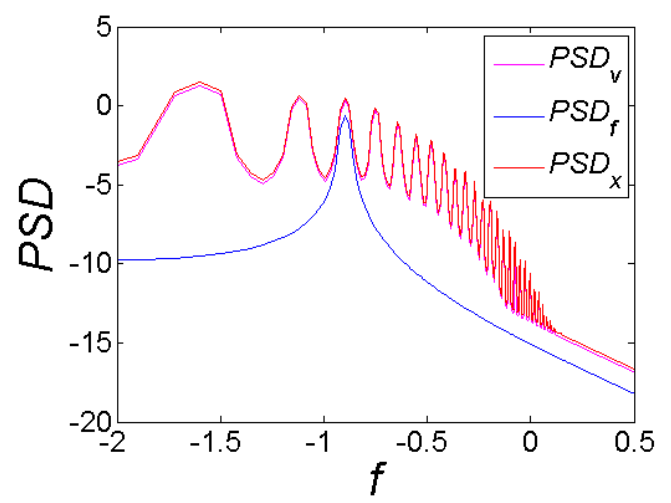

b) Caso 4

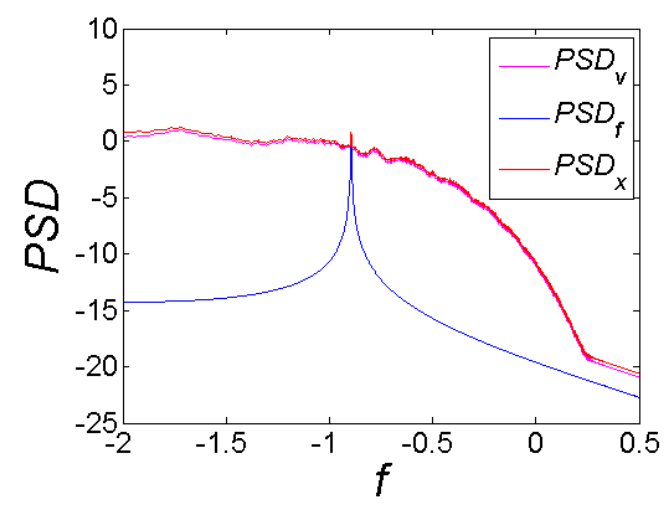

d) Caso 9

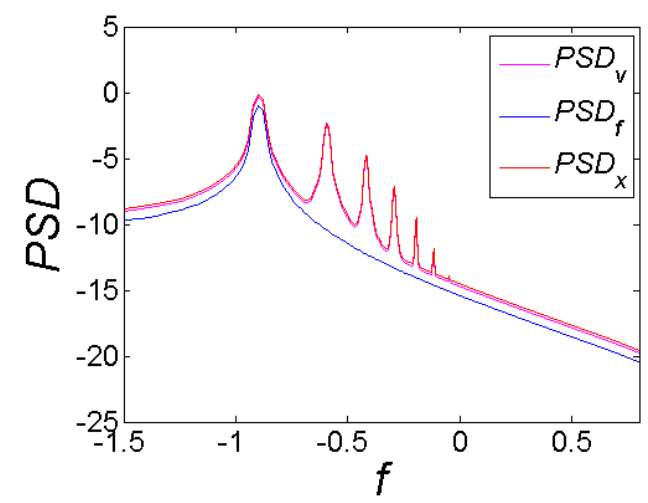

Figura 4.2 Curvas de $P S D$ em função da frequência com forçamento harmônico para o (a) caso 2, (b) caso 4, (c) caso 7 e (d) caso 9.

Para a Figura 4.2 (b) a resposta do sistema apresenta uma distribuição suave de potência para as frequências mais baixas, com decréscimo dos valores de amplitude com o aumento da frequência. Essa distribuição de potência é esperada e acontece devido à imersão de diversas órbitas periódicas no atrator estranho nessa resposta caótica.

A Figura 4.2 (c) apresenta uma curva de PSD para um caso de periodicidade igual a 5. Percebe-se que no início da curva de resposta há alguns picos com maiores valores de PSD, que estão relacionados com as frequências fundamentais desse sinal, além de um pico nos sinais de resposta do sistema, coincidente com o pico de maior potência do sinal do forçamento $P S D_{f}$.

A Figura 4.2 (d) apresenta uma semelhança com a Figura 4.2 (a), ambos os casos têm periodicidade igual a 1, porém no caso 9 os picos apresentam valores menores, tanto para o sinal de entrada quanto para o sinal de saída. Isso é esperado, dados os espaços de fase da Figura 4.1 
A abordagem do sistema em relação a colheita de energia e de desempenho é apresentada na Tabela 4.2 mostrando os valores obtidos do cálculo da $P S_{v}, P S_{f}$ e $r$. O parâmetro $P S_{x}$, respectivo ao deslocamento da extremidade da viga, foi analisado inicialmente. Porém o acoplamento piezelétrico é linear, logo existe uma linearidade entre $P S_{v}$ e $P S_{x}$, por esse motivo não se considerou os valores de $P S_{x}$. Relembrando que os valores de $P S_{v}$ representam a potência do sinal de saída elétrica do sistema, o valor de $P S_{f}$ representa a energia do sinal de entrada mecânica do sistema, e $r$ é a razão entre saída e entrada em função da frequência, calculado a partir dos valores de $P S_{v}$ e $P S_{f}$. Os valores apresentados na Tabela 4.2 são referentes a área debaixo da curva de PSD como definido na seção anterior.

Os casos de 1 até 3 apresentam comportamento periódico, porém as amplitudes de oscilação no espaço de fase são diferentes. O caso 3 apresenta maior amplitude e o caso 1 a menor amplitude. Com menores amplitudes de deslocamento, a energia colhida pelo material piezelétrico será menor, como pode-se verificar pelos valores de $P S_{v}$ da Tabela 4.2. Verificamos também que o valor de $r$ aumenta junto com as amplitudes de reposta, visto que o caso 1 apresenta a menor amplitude e o caso 3 a maior amplitude dos caos analisados. Portanto, para os casos periódicos as melhores respostas elétricas e performances estão relacionadas com os maiores valores de amplitude de resposta.

Os casos de 4 até 6 são casos de comportamentos caótico. Pela Tabela 4.2, verifica-se que os casos caóticos apresentam menores valores de $P S_{v}$ quando comparados com os casos periódicos, em uma mesma faixa de valores, contudo o caso 5 apresenta uma resposta elétrica melhor do que os demais casos caóticos. Além do mais, o caso 4 apresenta o melhor valor de $r$, indicando que esse caso tem o melhor desempenho, de acordo com o critério abordado nesse trabalho.

Nota-se que os casos 2 e 4 apresentam as mesmas condições de forçamento com condições iniciais diferentes, contudo os valores de $P S_{v}$ são bem distintos. O que é esperado tendo em vista a diferença dos tipos de respostas. $\mathrm{O}$ caso 2 apresenta um valor de $P S_{v}$ maior do que para o caso 4 mostrando que o caso periódico apresenta uma colheita de energia melhor. A mesma conclusão pode ser verificada observando-se os valores de $r$.

A diferença entre os valores de $P S_{v}$ dos casos periódicos para os caóticos está relacionada com a ideia de que o caos é composto por diversas órbitas periódicas instáveis. Portanto, o deslocamento da extremidade livre da viga $x$, quando caótico, realiza oscilações não periódicas com diferentes amplitudes, hora oscilando em torno de um ponto de equilíbrio estável, hora oscilando em ambos os pontos de equilíbrio estáveis. Dessa maneira, o 
comportamento caótico oscila menos em torno de dois pontos de equilíbrio estáveis, apresentando assim uma variação da amplitude de resposta. Dessa forma, se comparado com o comportamento periódico, não consegue manter sempre as maiores amplitudes de vibrações possíveis, o que pode ser verificado na Figura 4.3 que mostra a reposta no domínio do tempo para o caso 2, que é periódico, e para o caso 4, que é caótico. Dessa forma, em um determinado intervalo de tempo, os casos periódicos 1, 2 e 3 visitam mais vezes os dois pontos de equilíbrio do que o caso caótico. Com isso, as deformações experimentadas pelo material piezelétrico são menores nos casos caóticos e apresentam menor colheita de energia que os comportamentos periódicos citados.

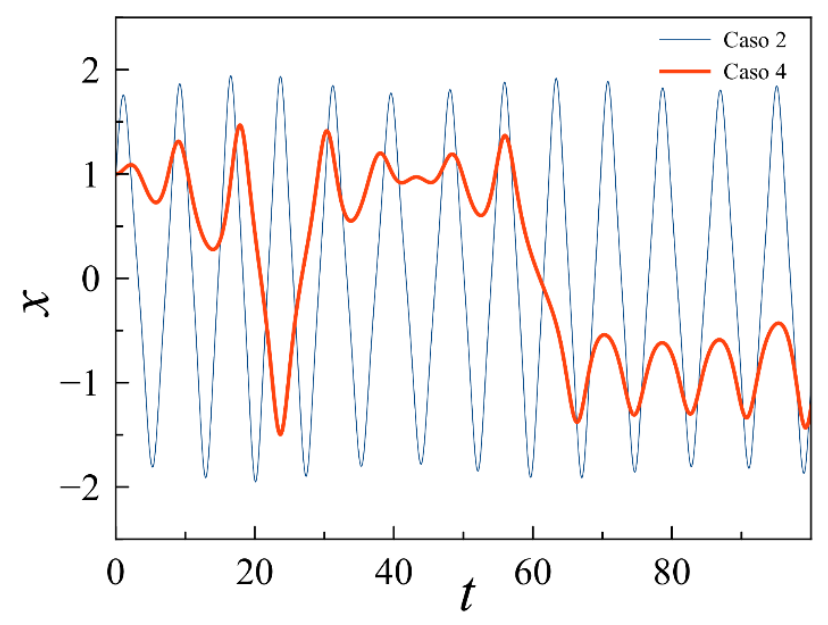

Figura 4.3 Amplitude de deslocamento no domínio do tempo para os casos 2 e 4.

Os casos 7 e 8 foram escolhidos pela observação do diagrama de bifurcação da Figura 3.6 (a), que apresenta uma pequena região com linhas contínuas, indicando uma janela periódica. Esses casos apresentam uma órbita de periodicidade igual a 5, que podem ser observadas através da seção de Poincaré da Figura 4.1. De acordo com a Tabela 4.2 de valores de PS, esses casos apresentam valores de $P S_{v}$ menores do que os casos 1 a 3 , que são periódicos de período 1 , porém um pouco maiores que os casos 4 a 6 , que são caóticos. Tais casos apresentam colheita de energia e desempenho intermediário entre o caos e a periodicidade 1 que visita os dois pontos de equilíbrio estável. Apesar dos casos 7 e 8 apresentarem valores próximos de $P S_{v}$, os valores de $r$ mostram que o caso 7 apresenta a melhor razão de colheita de energia.

O caso 9 apresenta um comportamento periódico de periodicidade igual a 1, porém suas oscilações acontecem em torno de apenas um ponto de equilíbrio, o que resulta em menores amplitudes de oscilação, como observado na Figura 4.1. Verificando-se os valores de 
$P S_{v}$ para esse caso, Tabela 4.2, percebe-se que esse caso é o que apresenta a colheita de energia com menor valor de $P S_{v}$ e de $r$.

Tabela 4.2 Valores da área sob a curva de PSD da tensão e forçamento para casos sob condição de forçamento harmônico.

\begin{tabular}{|c|c|c|c|}
\hline & $\boldsymbol{P S}_{\boldsymbol{f}}$ & $\boldsymbol{P S}_{\boldsymbol{v}}$ & $\boldsymbol{r}$ \\
\hline Caso 1 & $0,10.10^{-3}$ & $11,09 \cdot 10^{-3}$ & 110,96 \\
\hline Caso 2 & $0.68 \cdot 10^{-3}$ & $17,81 \cdot 10^{-3}$ & 258,53 \\
\hline Caso 3 & $0,10.10^{-3}$ & $39,31 \cdot 10^{-3}$ & 393,13 \\
\hline Caso 4 & $0,68 \cdot 10^{-3}$ & $7,36.10^{-3}$ & 106,87 \\
\hline Caso 5 & $1,00.10^{-3}$ & $7,96.10^{-3}$ & 79,60 \\
\hline Caso 6 & $1,00.10^{-3}$ & $7,60.10^{-3}$ & 76,01 \\
\hline Caso 7 & $0,86.10^{-3}$ & $9,30.10^{-3}$ & 107,59 \\
\hline Caso 8 & $1,00.10^{-3}$ & $9,43.10^{-3}$ & 94,33 \\
\hline Caso 9 & $0,39.10^{-3}$ & $0,19.10^{-3}$ & 4,83 \\
\hline
\end{tabular}

De uma maneira mais ampla, quando o sistema está submetido a condições de forçamento harmônico, entende-se que os valores de $P S_{v}$ são melhores para casos de oscilações periódicas em torno dos dois pontos de equilíbrio estável e com periodicidade igual a 1. O pior caso ocorre quando o comportamento é periódico com oscilações em torno de apenas um ponto de equilíbrio com periodicidade igual a 1. Os comportamentos periódicos são coexistentes com os comportamentos caóticos, portanto é importante uma escolha adequada de condições iniciais que levem o sistema ao melhor comportamento para colheita de energia. O mesmo acontece com os casos de período 5.

Verificamos também que o sistema apresenta grande sensibilidade a condições iniciais e de forçamento. $\mathrm{O}$ que leva a concluir que comportamentos distintos podem ser alcançados apenas com pequenas diferenças nesses parâmetros, como o valor de $r$ está relacionado com os valores de forçamento e de tipo de comportamento, ele apresenta grande sensibilidade ao tipo de resposta. Além disso, pode-se concluir que o fator determinante para o desempenho do gerador são as amplitudes de oscilação da ponta da viga. As respostas que apresentam maiores amplitudes de resposta por mais tempo são as que possuem o melhor desempenho.

\subsection{FORÇAMENTO ALEATÓRIO}

Nessa seção, uma análise da performance do sistema sob condições de forçamento não determinístico é realizada. O forçamento aleatório é modelado como um processo estocástico do tipo ruído Gaussiano branco, com média zero e desvio padrão $\sigma, N(\sigma ; 0)$ Papoulis e Pillai (2002). As análises dinâmicas realizadas na seção anterior devem ser colocadas em 
perspectiva, uma vez que assumem forçamento do tipo harmônico. Essa condição não é atendida para o caso do forçamento do tipo aleatório.

Espera-se que a colheita de energia seja influenciada pelos valores de $\sigma$, que indica o nível de dispersão do ruído sobre a média, ou seja, quanto maior $\sigma$, maior o nível de potência do forçamento. A Tabela 4.3 apresenta diversos valores para esse parâmetro de modo a se analisar a colheita de energia através dos valores de PS.

A Figura 4.4 apresenta os espaços de fase para os casos de $\sigma=0,2 ; 0,4 ; 0,6 \mathrm{e}$ 2,0. Para o caso em que $\sigma=0,2$, percebe-se pelo espaço de fase que o sistema oscila apenas em torno de um ponto de equilíbrio, devido à baixa probabilidade de existir uma força grande o suficiente tal que leve o sistema para o outro ponto de equilíbrio estável. Para o caso de $\sigma=0,4$, o sistema troca de ponto de equilíbrio estável duas vezes. No caso em que $\sigma=0,6, \mathrm{o}$ sistema visita o ponto de equilíbrio estável diversas vezes. O mesmo pode ser observado para $\sigma=2,0$, porém a densidade de trajetórias na região de transição onde as trajetórias trocam de ponto de equilíbrio estável é maior do que para $\sigma=0,6$. Os espaços de fase para os valores de $\sigma$ entre 0,6 e 2,0 foram simulados e valores crescentes nas amplitudes foram verificados, contudo sua dinâmica é muito parecida com o caso $\sigma=2,0$, e para uma melhor apresentação dos resultados decidiu-se omitir tais gráficos.

A Figura 4.5 apresenta as curvas de PSD que também indicam a evolução da dinâmica do sistema pelos picos de potência para diversos valores de $\sigma$. Para o valor de $\sigma=0,2$, a curva de PSD apresenta um pico de potência, mostrando que existe uma frequência fundamental, essa é a mesma frequência de oscilação em torno de apenas um ponto de equilíbrio. Para os casos de $\sigma=0,4 ; 0,6$ e 2,0 o pico que era apresentado para $\sigma=0,2$ se espalha em uma banda mais larga em baixas frequências, ficando evidente que o sistema é um tipo de filtro, que leva uma distribuição uniforme de potência ao longo de todas as frequências para baixas frequências

A abordagem de avaliação de colheita de energia no caso de excitação aleatório é semelhante à abordagem dada para as respostas do sistema quando submetido a condições de forçamento puramente harmônico. As curvas de PSD são calculadas para todas as respostas e a área sob a curva é expressa na Tabela 4.3. Verifica-se que os valores de $P S_{f}$ aumentam para valores maiores de $\sigma$, isso é esperado já que os valores de $\sigma$ estão relacionados com dispersão dos valores gerados no ruído Gaussiano, quanto maior $\sigma$ maior a dispersão. Da mesma maneira, os valores de $P S_{v}$, apresentam um crescimento. 
a)

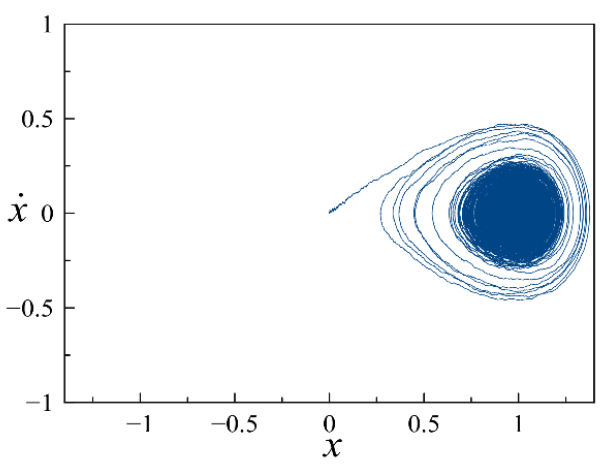

c)

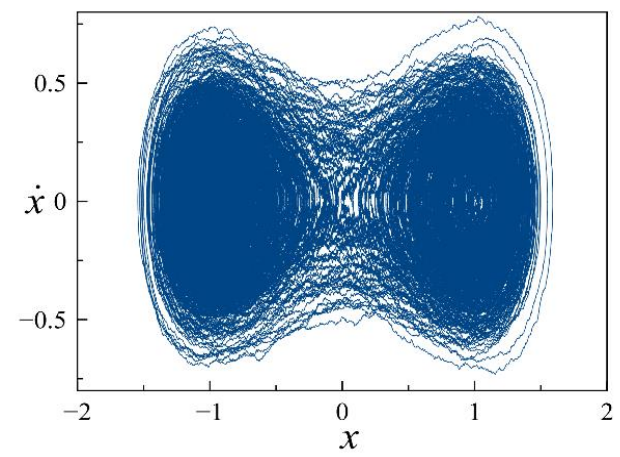

b)

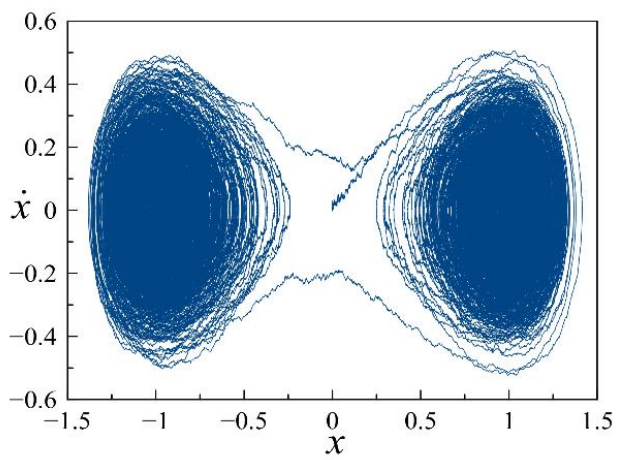

d)

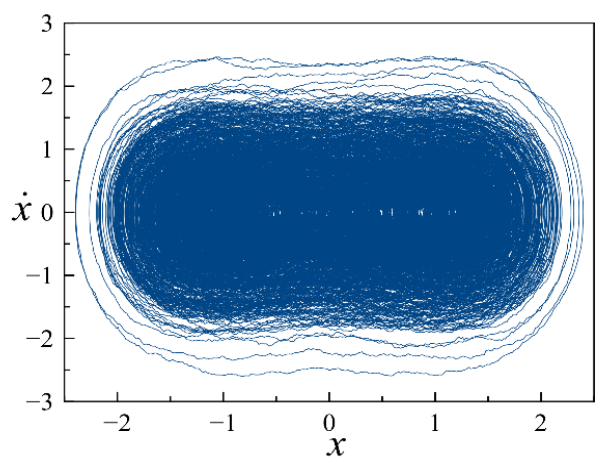

Figura 4.4 Espaço de fases para um forçamento aleatório Gaussiano com (a) $\sigma=0.2$, (b) $\sigma=0.4$, (c) $\sigma=0.6$ e (d) $\sigma=2$.

a)

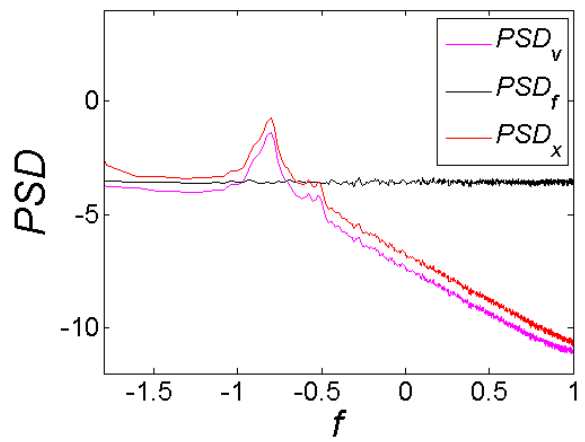

c)

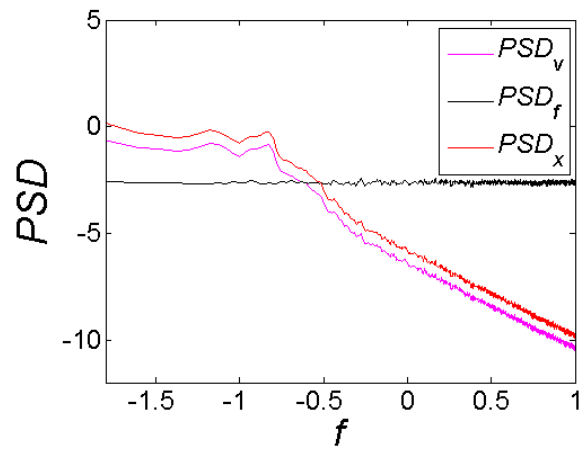

b)

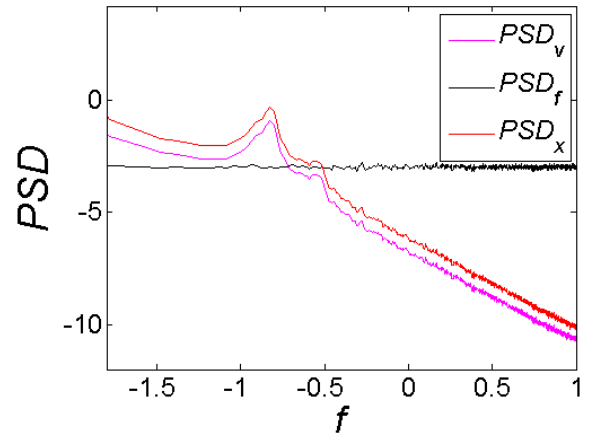

d)

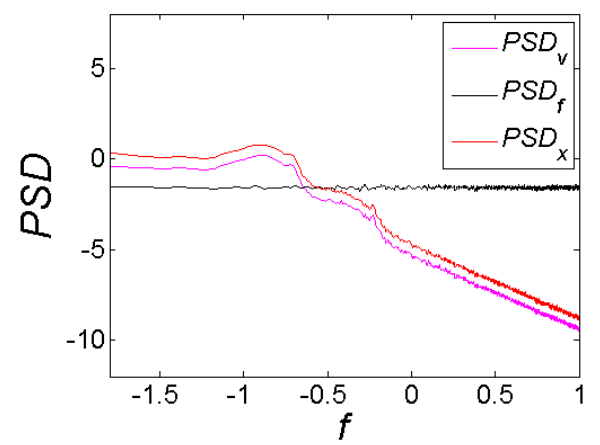

Figura 4.5 Curva de PSD em função da frequência com forçamento aleatório para os valores de (a) $\sigma=0,2$, (b) $\sigma=0.4$, (c) $\sigma=0.6$ e (d) $\sigma=2$. 
Tabela 4.3 Valores da área sob a curva de PSD do forçamento e tensão elétrica para forçamento aleatório.

\begin{tabular}{|c|c|c|c|}
\hline$\sigma$ & $P S_{f}$ & $P S_{v}$ & $r$ \\
\hline 0,2 & $8,06 \cdot 10^{-4}$ & $0,03 \cdot 10^{-3}$ & 0,04 \\
\hline 0,4 & $32,26 \cdot 10^{-4}$ & $0,19 \cdot 10^{-3}$ & 0,06 \\
\hline 0,6 & $72,59 \cdot 10^{-4}$ & $0,86 \cdot 10^{-3}$ & 0,11 \\
\hline 0,8 & $129,05 \cdot 10^{-4}$ & $1,52 \cdot 10^{-3}$ & 0,11 \\
\hline 1,0 & $201,64 \cdot 10^{-4}$ & $1,90 \cdot 10^{-3}$ & 0,09 \\
\hline 1,2 & $290,36 \cdot 10^{-4}$ & $3,28 \cdot 10^{-3}$ & 0,11 \\
\hline 1,4 & $395,21 \cdot 10^{-4}$ & $3,69 \cdot 10^{-3}$ & 0,09 \\
\hline 1,6 & $516,20 \cdot 10^{-4}$ & $4,13 \cdot 10^{-3}$ & 0,08 \\
\hline 1,8 & $653,31 \cdot 10^{-4}$ & $4,17 \cdot 10^{-3}$ & 0,06 \\
\hline 2,0 & $806,64 \cdot 10^{-4}$ & $5,67 \cdot 10^{-3}$ & 0,07 \\
\hline
\end{tabular}

Apesar da Tabela 4.3 mostrar que o melhor caso de resposta elétrica é para o valor de $\sigma=2,0$. Os valores de $r$ permitem analisar os casos que possuem melhor desempenho, e são apresentados para os valores de $\sigma=0,6, \sigma=0,8$ e $\sigma=1,2$. Os valores de $r$ apresentam grande sensibilidade aos valores de $P S_{f}$ e $P S_{v}$. As variações para as $P S_{f}$ e $P S_{v}$ são sempre crescentes, contudo essa taxa de crescimento não é linear, pois se fossem linear os valores de $r$ seriam sempre constantes. Portanto conclui-se que os valores de $P S_{f}$ e $P S_{v}$ não apresentam relação direta entre seu crescimento.

\subsection{FORÇAMENTOS HARMÔNICO E ALEATÓRIO COMBINADOS}

No capítulo anterior apresentou-se a abordagem dinâmica do sistema e nas seções anteriores os resultados da avaliação da colheita de energia para o sistema sob os forçamentos harmônico e aleatório atuando separadamente no sistema.

Nessa seção, propõem-se uma abordagem de maneira a incluir um forçamento harmônico com uma parcela de aleatório. Inicia-se a análise com parâmetros de forçamento e condições iniciais que levam a um comportamento conhecido, em seguida, parcelas de forçamento aleatório são adicionadas até que a amplitude dos forçamentos harmônicos e aleatório seja parecida. Tenta-se entender o comportamento desses diferentes níveis de ruído na dinâmica do sistema, posteriormente analisando-se os valores de PS do forçamento e da tensão elétrica de saída e estabelecendo-se os melhores comportamentos para a colheita de energia e de melhor desempenho.

Os diferentes níveis de combinação entre forçamento harmônico e aleatório são estabelecidos pelo parâmetro $R R S$. Com o aumento dos valores de $R R S$, a dinâmica do 
sistema é avaliada através do diagrama de bifurcação. Esses diagramas fornecem a evolução do comportamento do sistema com um aumento no valor de $R R S$. Nesse sentido, apresentamse os diagramas de bifurcação para esses diferentes níveis de ruído, de modo a indicar uma mudança qualitativa da resposta do sistema.

O mesmo método utilizado no capítulo anterior para os diagramas de bifurcação é utilizado nessa seção. Nas Figura 4.6 e Figura 4.7, observa-se os diagramas de bifurcação obtidos com diferentes valores de níveis de ruído $R R S$.

Na Figura 4.6 são apresentados os diagramas de bifurcação variando-se os valores de $f_{0}$ e aumentando o valor de $R R S$. Verifica-se que diagrama de bifurcação para $R R S=1 \%$, apresenta uma pequena alteração quando comparado com o diagrama da Figura 3.6, que não está sob influência de ruído. A região que apresenta a janela periódica, relacionada com órbitas de periodicidade igual a 5, começa a apresentar uma maior espessura em suas linhas, o que leva a entender que a seção de Poincaré deve apresentar não mais cinco pontos, mas cinco regiões que apresentam um aglomerado de pontos. No diagrama de bifurcação da Figura 4.6 inicia-se as variações nos parâmetros de forçamento com duas condições inicias distintas, pretende-se investigar até qual nível de ruído $R R S$ é significativo avaliar diferentes condições iniciais para o sistema. A linha rosa parte de condições iniciais iguais a $(x, \dot{x}, v)=(1,1,0) \mathrm{e}$ os pontos pretos de $(x, \dot{x}, v)=(1,0,0)$.

Com um valor de $R R S=5 \%$, o diagrama de bifurcação apresentado na Figura 4.6 (b) mostra que a região de órbitas com periodicidade igual a 5 desaparece. E nessa região é apresentada uma nuvem de pontos. Destaca-se também outra característica nesse diagrama, que é uma maior espessura na linha rosa e preta, relacionada com órbitas de período 1. Essas órbitas apresentam uma seção de Poincaré onde os pontos estão aglomerados em uma certa região.

Na Figura 4.6 (c), com $R R S=30 \%$, nota-se que mesmo com esse nível de ruído, a sensibilidade à condições iniciais ainda é apresentada, pois existe uma coexistência de dois comportamentos distintos, mesmo que não seja possível afirmar que a nuvem de pontos preta está relacionada a um comportamento caótico.

Os diagramas de bifurcação, Figura 4.6 (d), de $R R S=50 \%$ até $R R S=100 \%$ apresentam também essa sensibilidade a condições iniciais, porém a nuvem de pontos rosa, que inicialmente estava relacionada a comportamentos periódicos torna-se mais espessa. Para os valores de $R R S>100 \%$ existe grande probabilidade de existir uma força maior do que a amplitude do forçamento harmônico 
Nos diagramas de bifurcação para valores acima de $R R S=200 \%$, conforme apresentado na Figura 4.6(e), as condições iniciais não interferem no tipo de resposta do sistema, pois não há mais coexistência de comportamentos. O desaparecimento da coexistência de comportamento está relacionado com a erosão de bacia de atração, a evolução dessa erosão inicia-se ao se inserir diferentes níveis de ruído e se tem uma erosão total quando a coexistência de comportamento é extinta.

Para valores menores de $f_{0}$, os comportamentos estão relacionados a oscilações em torno de apenas um ponto de equilíbrio. Para valores maiores de $f_{0}$ observa-se que os comportamentos apresentam as mesmas características mudando apenas a amplitude máxima de oscilação. 
a)

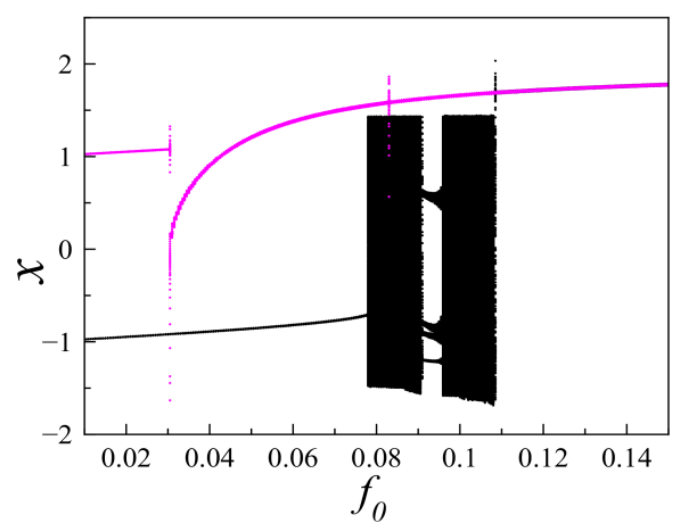

c)

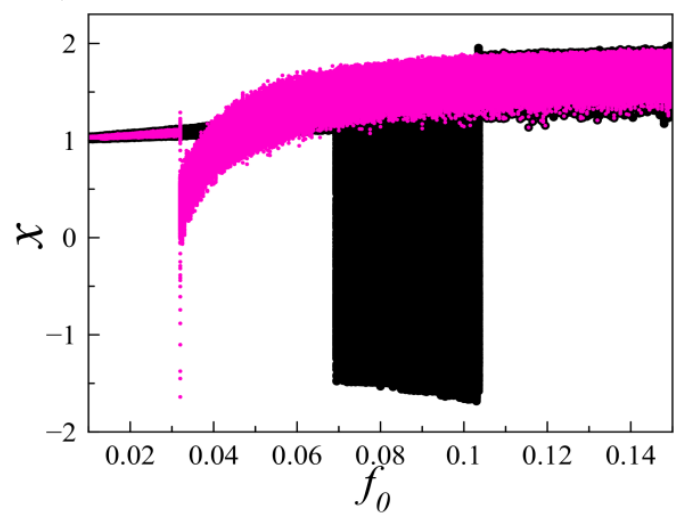

e)

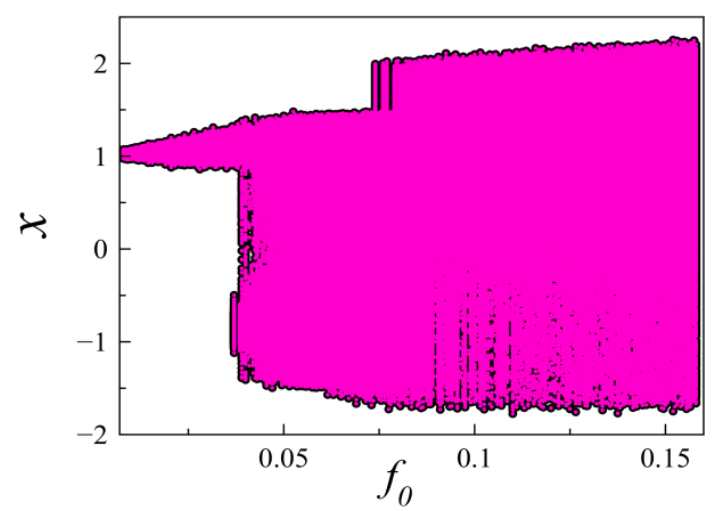

b)

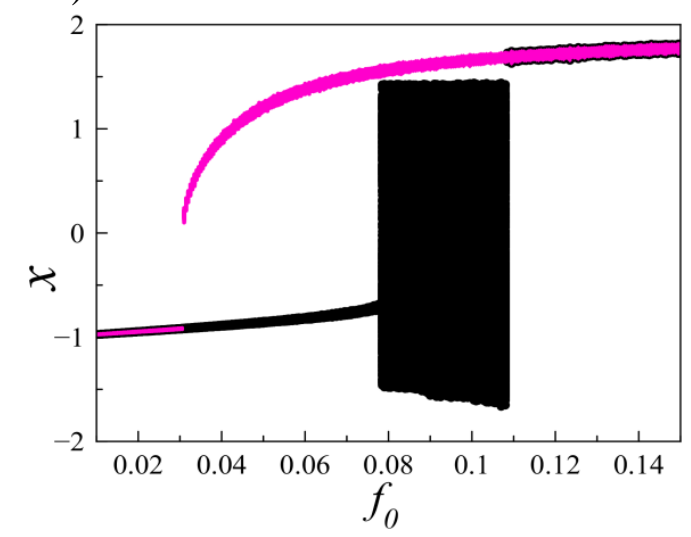

d)

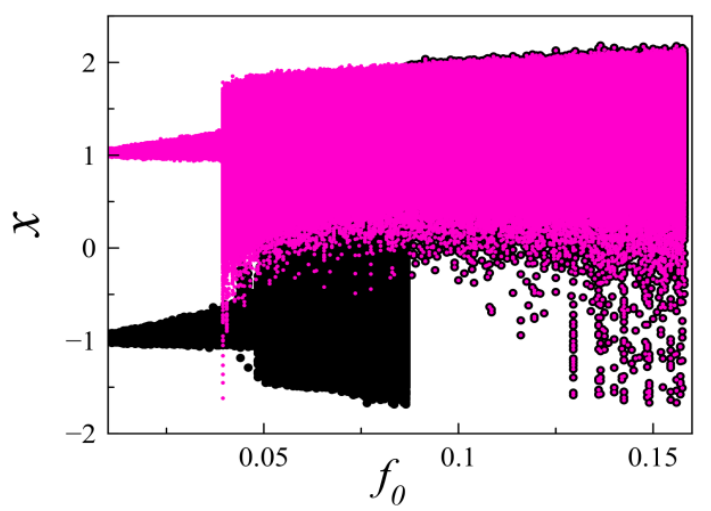

f)

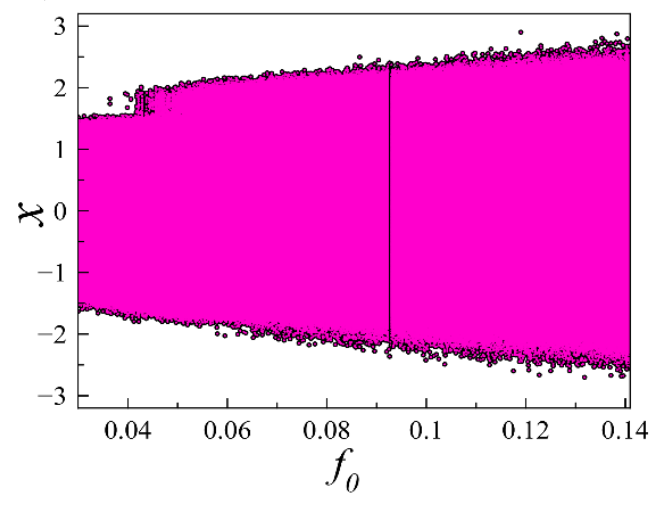

Figura 4.6 Digrama de Bifurcação com duas condições iniciais distintas e com forçamento combinado com (a) $R R S=1 \%$, (b) $R R S=5 \%$, (c) $R R S=30 \%$, (d) $R R S=100 \%$, (e) $R R S=200 \%$, (f) $R R S=500 \%$.

A Figura 4.7 apresenta os diagramas de bifurcação para variações na frequência $\omega$ de forçamento. Os diversos diagramas desta figura apresentam a evolução do sistema para os valores de $R R S$. Para os valores de $R R S$ de $1 \%$ até $10 \%$ nenhuma grande modificação nas respostas do sistema é observada. Porém, apresenta-se um aumento da espessura da linha, o que está relacionado com a dispersão dos pontos da seção de Poincaré. Para um valor de $R R S=30 \%$, o diagrama de bifurcação é alterado, mostrando ainda sensibilidade a condições iniciais. 
A Figura 4.7 (c) apresenta o diagrama de bifurcação para o valor de $R R S=30 \%$. Algumas alterações são observadas com relação ao diagrama anterior, obtido com $R R S=$ $10 \%$. Na região com valores de $\omega<0.5$, as nuvens de ponto apresentadas estão relacionadas com oscilações em torno de apenas um ponto de equilíbrio estável. Como o sistema apresenta uma simetria para os pontos de equilíbrio estável, as nuvens de pontos em torno de -1 e 1 representam apenas que o sistema oscila em torno de um ou outro ponto de equilíbrio. Para a região que começa em $\omega>0.5$, os pontos pretos apresentam uma nuvem de pontos maior e os pontos rosas apresentam uma região mais espessa. Ainda pode se observar que o sistema ainda apresenta coexistência de comportamentos, já que os pontos rosas partem das condições iniciais de $(x ; \dot{x} ; v)=(1 ; 1 ; 0)$ e os pontos pretos de $(x ; \dot{x} ; v)=(1 ; 0 ; 0)$. Para os pontos pretos uma terceira região é apresentada, que é a região $0.75<\omega<1$ que apresenta as mesmas características de oscilação de um comportamento caótico, mesmo não sendo possível classificar esse comportamento como caótico.

A Figura 4.7 (d) apresenta o diagrama de bifurcação para os valores de $R R S=50 \%$. Observa-se três regiões principais, uma para os valores $\omega<0$. uma para $\omega \approx 0.5$, e outra para $\omega>0.5$. Para a região de $\omega<0.5$ observa-se que o espaço de fase está todos preenchido. Na região em torno de $\omega \approx 0.5$, a partir do espaço de fase, verificam-se somente oscilações em torno de um ponto de equilíbrio. Para os valores de $\omega>0.5$ os pontos rosas apresentam um comportamento oscilatório em torno de ambos os pontos de equilíbrio estável, exceto a região de pontos pretos um pouco acima do valor de $\omega=0.75$, onde uma nuvem de pontos é apresentada, que apresenta características de oscilação caótica apesar de não poder se confirmar tal comportamento.

Pode-se observar através dos diagramas de bifurcação da Figura 4.7 (d), para os valores de $R R S=70 \%$ até $100 \%$, que duas regiões distintas são formadas. Na região inicial do diagrama, que vai até valores de $\omega<0.6$, o comportamento é verificado pelo espaço de fase e percebe-se que o comportamento apresenta características de oscilação não periódicas. Porém para os valores de $\omega>0.6$ o comportamento apresenta comportamento oscilatório próximo de periódico em torno dos dois pontos de equilíbrio estável. Essas duas regiões ocorrem até valores de $R R S=150 \%$. Para os valores de $R R S>200 \%$ o sistema apresenta um diagrama de bifurcação semelhante com o apresentado pela Figura 4.7 (e), onde uma única região é verificada, essa região apresenta oscilações aparentemente aleatórias. 
a)

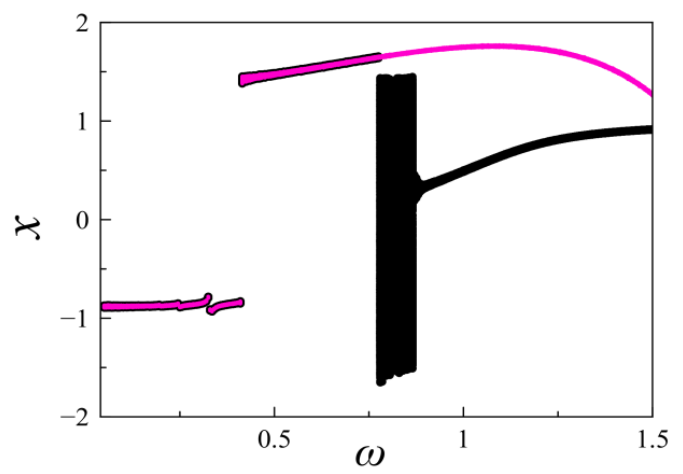

c)

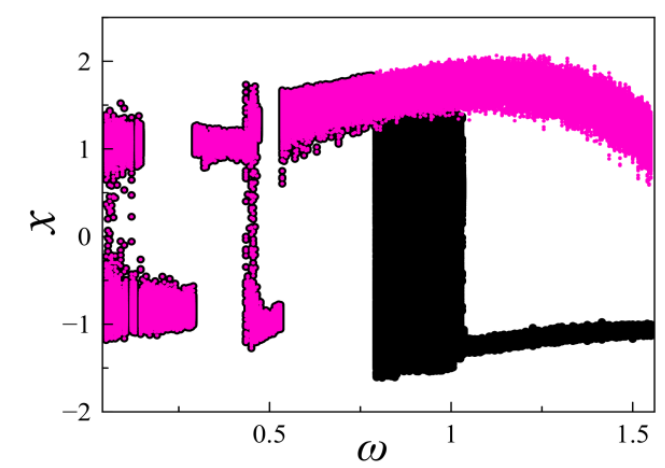

e)

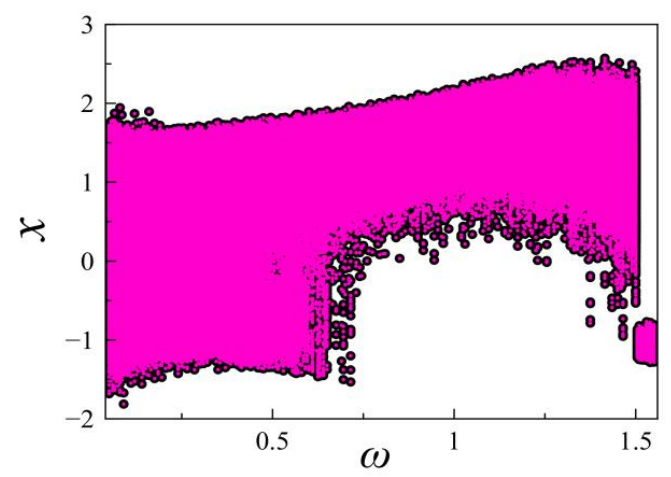

b)

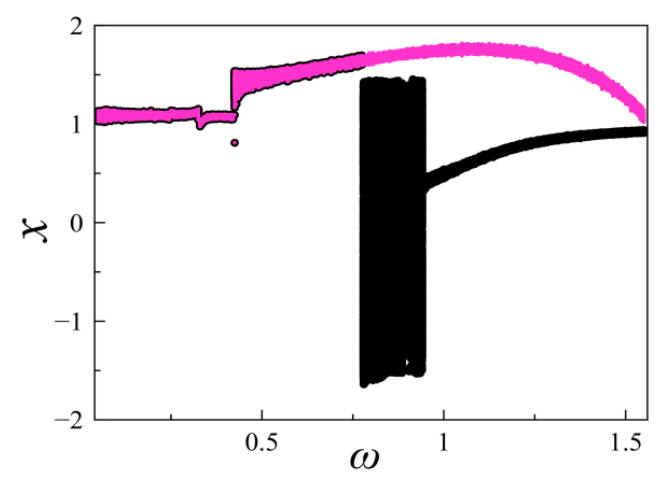

d)

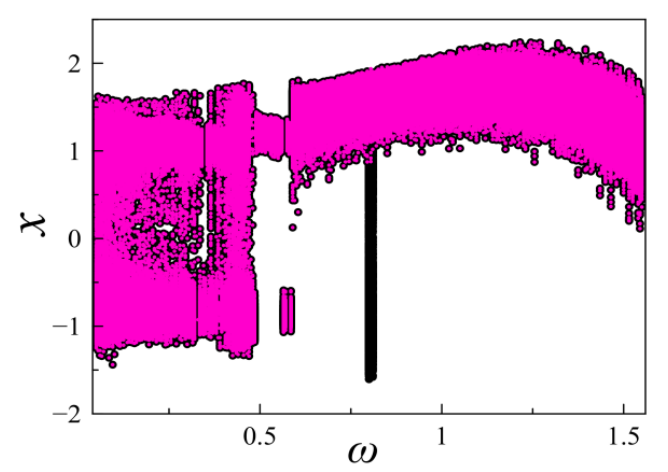

f)

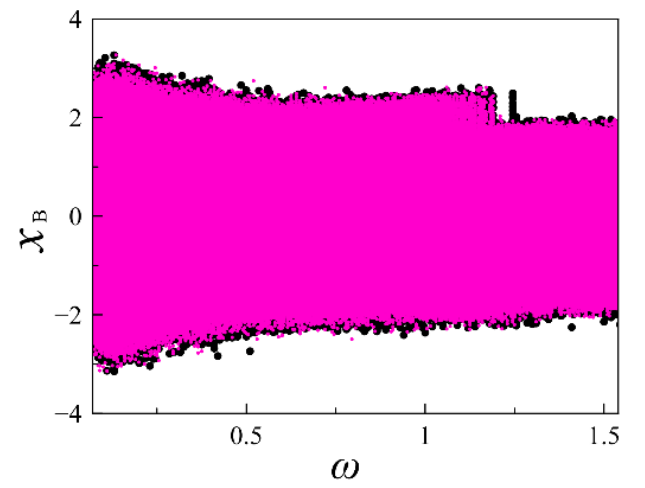

Figura 4.7 Digrama de Bifurcação com duas condições iniciais distintas e forçamento combinado para (a) $R R S=1 \%$, (b) $R R S=5 \%$, (c) $R R S=30 \%$, (d) $R R S=50 \%$, (e) $R R S=100 \%$ e (f) $R R S=500 \%$

Propõem-se agora realizar um estudo sobre a colheita de energia e desempenho do sistema quando submetido a condições de forçamento combinado, harmônico e aleatório. Para essa análise escolhem-se 5 parâmetros diferentes de forçamento harmônio. A Tabela 4.4 apresenta os parâmetros de forçamento, assim como sua periodicidade, quando $R R S=0 \%$. Um acréscimo de ruído no forçamento é realizado através do aumento dos valores de $R R S$, tais valores são aumentados até um nível de $R R S=500 \%$ pois nesse nível de ruído as possibilidades de forças aleatórias maiores do que as do forçamento harmônico são tão grandes que fazem com que o forçamento harmônico não influencie a resposta do sistema. 
Tabela 4.4 Parâmetros de forçamento harmônico no caso de excitação combinada

\begin{tabular}{|l|c|c|c|}
\hline & $\boldsymbol{f}_{\mathbf{0}}$ & $\boldsymbol{\omega}$ & $\begin{array}{c}\text { Comportamento Sem } \\
\text { Ruído }\end{array}$ \\
\hline $1^{\mathbf{0}}$ Caso & 0,100 & 1,400 & Periodicidade 1 \\
\hline $2^{\circ}$ Caso & 0,100 & 0,500 & Periodicidade 1 \\
\hline $3^{\circ}$ Caso & 0,100 & 0,800 & Caótico \\
\hline $4^{\circ}$ Caso & 0,093 & 0,800 & Periodicidade 5 \\
\hline $5^{\circ}$ Caso & 0,063 & 0,800 & Periodicidade 1 \\
\hline
\end{tabular}

\section{$1^{\circ}$ CASO}

Quando submetido a condições de forçamento puramente harmônicas com os valores de amplitude $f_{0}=1,4$ e $\omega=0,1$ o sistema apresenta resposta periódica de período 1 . Com a inserção de ruído a esses parâmetros de forçamento, o comportamento do sistema pode ser modificado.

A Figura 4.8 apresenta a evolução da dinâmica do sistema no espaço de fase, para determinados valores de ruído. Percebe-se que para os casos onde o ruído tem valores menores do que $R R S=100 \%$, o sistema apresenta sempre oscilações entre os dois pontos de equilíbrio, variando suavemente as amplitudes de deslocamento e velocidade. Para um valor de $R R S=150 \%$, um salto na amplitude é observado, com diminuição significativa das amplitudes de resposta. Além disso, o espaço de fase se torna mais denso, mostrando que essa órbita apresenta oscilações não periódicas. Na seção de Poincaré, duas nuvens de pontos são observadas no espaço de fase, ambas localizadas próximas aos pontos de equilíbrio estável. Com isso, entende-se que embora as oscilações transitem entre os pontos de equilíbrio estáveis, as regiões de preferência são as oscilações em torno de cada ponto de equilíbrio A partir desse valor de ruído, as amplitudes de respostas são crescentes e o comportamento apresenta oscilações que visitam ambos os pontos de equilíbrio estável. 
a)

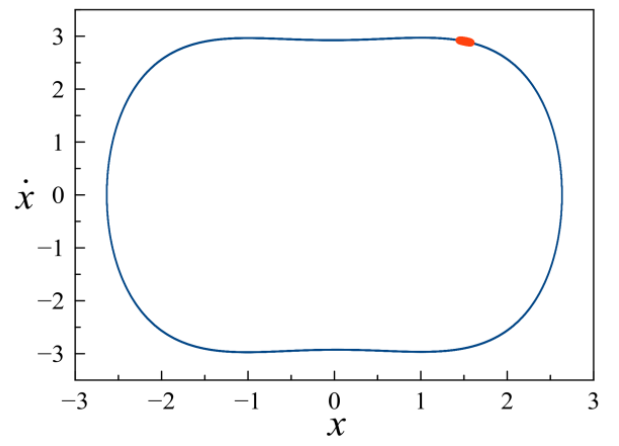

c)

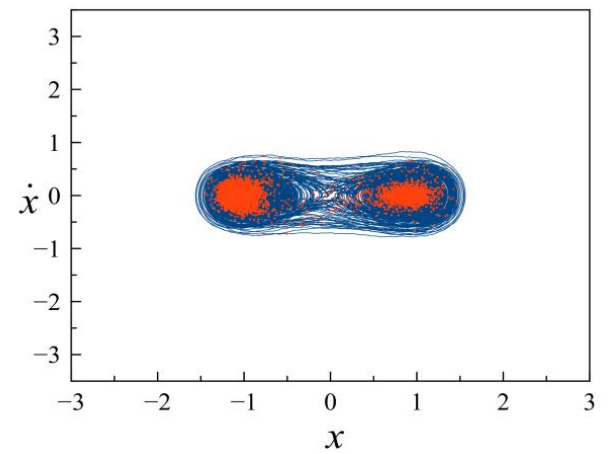

b)

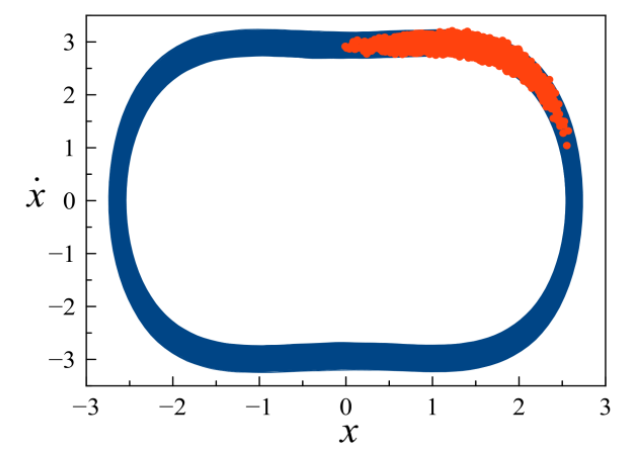

d)

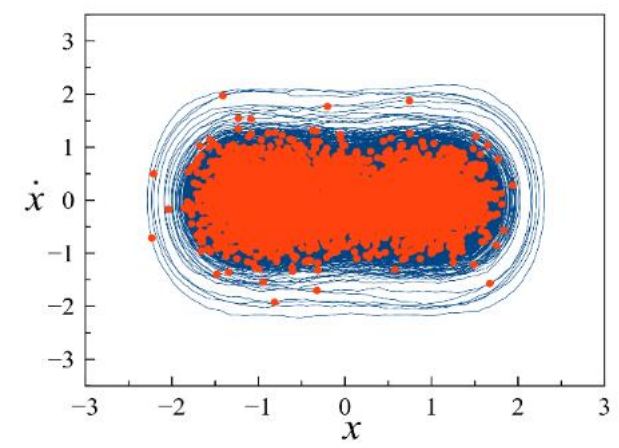

Figura 4.8 Espaço de fase (azul) e seção de Poincaré (vermelho) para forçamento harmônico com níveis de ruído (a) $R R S=1 \%$ (b) $R R S=100 \%$ (c) $R R S=150 \%$ e (d) $R R S=500 \%$.

a)

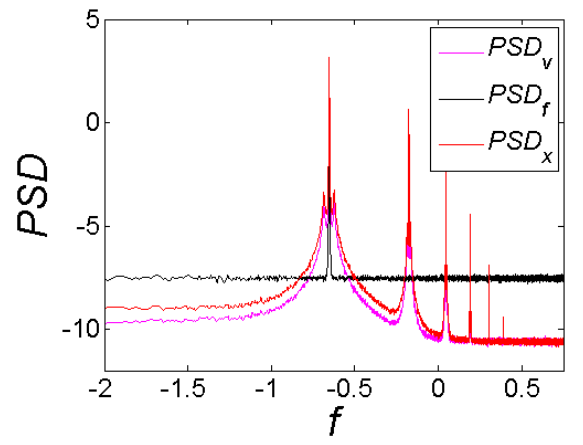

c)

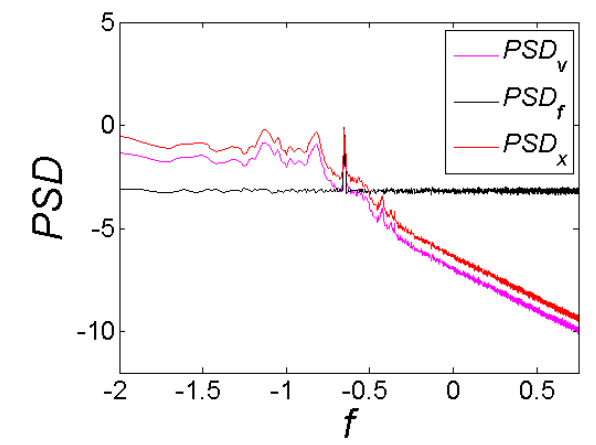

b)

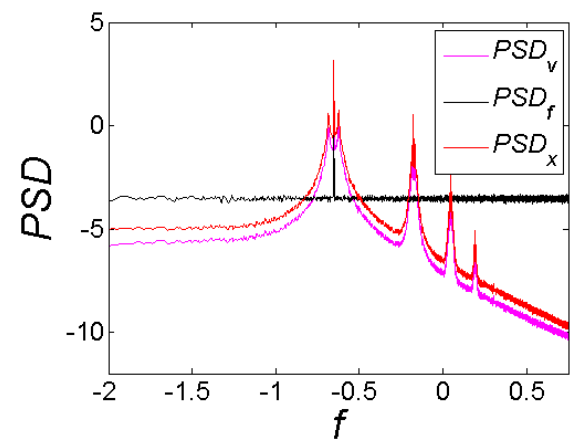

d)

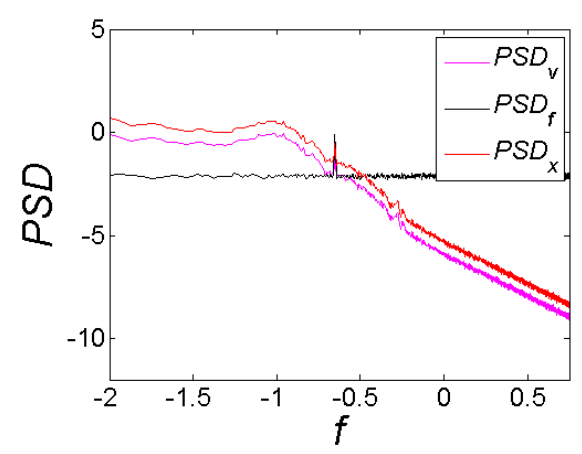

Figura 4.9 Curvas de PSD em função da frequência para forçamento harmônico contaminado com ruído com os níveis (a) $R R S=1 \%$ (b) $R R S=100 \%$ (c) $R R S=150 \%$ e (d) $R R S=500 \%$. 
As curvas de PSD, Figura 4.9, confirmam a análise dos espaços de fase, mostrando que para os comportamentos de $R R S=1 \%$ até $100 \%$ existem frequências fundamentais envolvidas no sinal, o que é típico de respostas periódicas. Porém, a curva de PSD com valor de $R R S=150 \%$ apresenta uma banda larga em baixas frequências, além de dois pequenos picos relacionados com as oscilações em torno de apenas um ponto de equilíbrio. Da mesma maneira, a curva de PSD para os valores de $R R S=500 \%$ apresenta uma banda larga para baixas frequências, com um pico relacionado às oscilações em torno do ponto de equilíbrio.

A Tabela 4.5 apresenta os valores de $P S v$ e $P S_{f}$, assim como o parâmetro de desempenho $r$. Verifica-se que os valores de $P S_{v}$ permanecem praticamente constantes, para os níveis de $R R S=1 \%$ até $R S S=100 \%$, onde o comportamento é relacionado às oscilações em ambos os pontos de equilíbrio. Para esse intervalo de nível de ruído, os valores de $P S_{f}$ aumentam com o aumento de $R S S$, porém os valores de $P S_{v}$ permanecem constantes, de modo que há uma diminuição do desempenho do sistema, que pode ser observado nos valores de $r$. Para o valor de $R R S=150 \%$, o valor de $P S_{v}$ cai drasticamente. Essa diferença é justificada observando-se os espaços de fase da Figura 4.8 e verificando-se que para esse valor de ruído que o sistema apresenta mudança no seu tipo de comportamento, como pode ser observado pela Figura 4.8. Conclui-se, então, que o tipo de comportamento influencia diretamente na colheita de energia.

Tabela 4.5 Valores da área sob a curva de PSD do forçamento e tensão elétrica para forçamento harmônico contaminado com ruído para o $1^{\circ}$ caso de excitação combinada.

\begin{tabular}{|c|c|c|c|}
\hline$R R S$ & $P S_{f}$ & $P S_{v}$ & $r$ \\
\hline $1 \%$ & $1,00 \cdot 10^{-4}$ & $15,48 \cdot 10^{-3}$ & 154,44 \\
\hline $5 \%$ & $1,00 \cdot 10^{-4}$ & $15,48 \cdot 10^{-3}$ & 153,72 \\
\hline $10 \%$ & $1,02 \cdot 10^{-4}$ & $15,48 \cdot 10^{-3}$ & 151,48 \\
\hline $30 \%$ & $1,18 \cdot 10^{-4}$ & $15,48 \cdot 10^{-3}$ & 131,00 \\
\hline $50 \%$ & $1,50 \cdot 10^{-4}$ & $15,48 \cdot 10^{-3}$ & 103,10 \\
\hline $70 \%$ & $1,98 \cdot 10^{-4}$ & $15,48 \cdot 10^{-3}$ & 78,08 \\
\hline $90 \%$ & $2,62 \cdot 10^{-4}$ & $15,48 \cdot 10^{-3}$ & 59,00 \\
\hline $100 \%$ & $3,00 \cdot 10^{-4}$ & $15,48 \cdot 10^{-3}$ & 51,52 \\
\hline $150 \%$ & $5,50 \cdot 10^{-4}$ & $0,30 \cdot 10^{-3}$ & 0,54 \\
\hline $200 \%$ & $9,01 \cdot 10^{-4}$ & $1,07 \cdot 10^{-3}$ & 1,19 \\
\hline $300 \%$ & $19,03 \cdot 10^{-4}$ & $1,81 \cdot 10^{-3}$ & 0,95 \\
\hline $500 \%$ & $51,08 \cdot 10^{-4}$ & $2,89 \cdot 10^{-3}$ & 0,56 \\
\hline
\end{tabular}




\section{$2^{\circ}$ CASO}

Nesse segundo caso, apresentam-se os resultados obtidos partindo-se da órbita periódica que está relacionada com os valores de $f_{0}=0,1, \omega=0,5$ e RRS=0. A Figura 4.10 apresenta a evolução da resposta do sistema de acordo com o aumento do valor de $R R S$. Apesar de os valores de forçamento harmônico não se alterarem com a inserção de ruído no forçamento, não se garante que a órbita da qual se parte o sistema sem ruído é a mesma para um forçamento ruidoso. Verifica-se que o sistema apresenta um comportamento oscilatório em torno de ambos os pontos de equilíbrio nos intervalos de $R R S=1 \%$ até $10 \%$. Para os valores de $R R S=30 \%$ e $R S S=50 \%$, o sistema oscila em torno apenas de um ponto de equilíbrio, não tento energia o suficiente pare trocar o ponto de equilíbrio. Para os valores de RSS maiores que 70\%, o sistema oscila em ambos os pontos de equilíbrio, aumentando-se as amplitudes de oscilação de acordo com o aumento do nível de ruído.

A Figura 4.11 apresenta as curvas de PSD para o caso analisado nesta seção. Para o valor de $R R S=1 \%$, percebe-se uma concentração de energia nas frequências fundamentais e harmônicos. É importante destacar que o pico de maior energia apresentado na resposta do sistema é coincidente com a frequência do forçamento. Para o valor de $R R S=10 \%$, há uma mudança apenas na energia do ruído, que é distribuída uniformemente ao longo de todas as frequências de forçamento. Na Figura 4.11 para o valor de $R R S=30 \%$, os picos apresentam diminuição de amplitude em relação aos picos apresentados para $R R S=10 \%$, indicando uma mudança de comportamento, como observado pelo espaço de fase Da Figura 4.10. Para os valores de $R R S=70 \%$, há uma distribuição de potência ao longo de baixas frequências, indicando uma mudança de comportamento. Contudo, o pico apresentado para a curva de PSD de forçamento também é apresentado na resposta do sistema. Na Figura 4.11, $R R S=$ $500 \%$, a distribuição de frequência apresenta valores de potência maiores para baixas frequências. 
a)

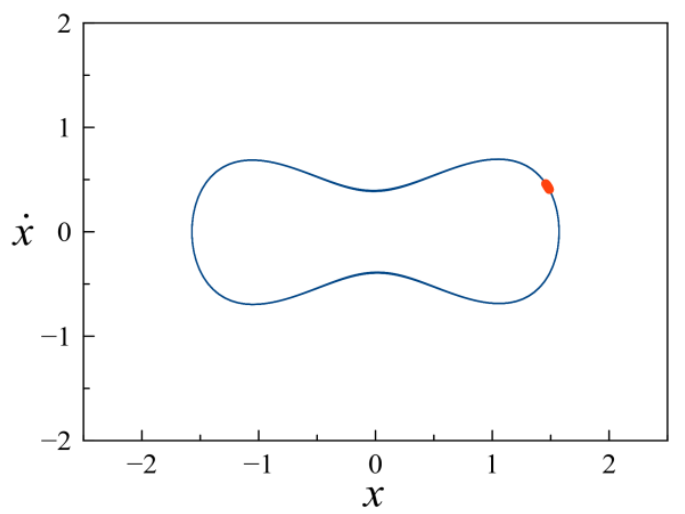

c)

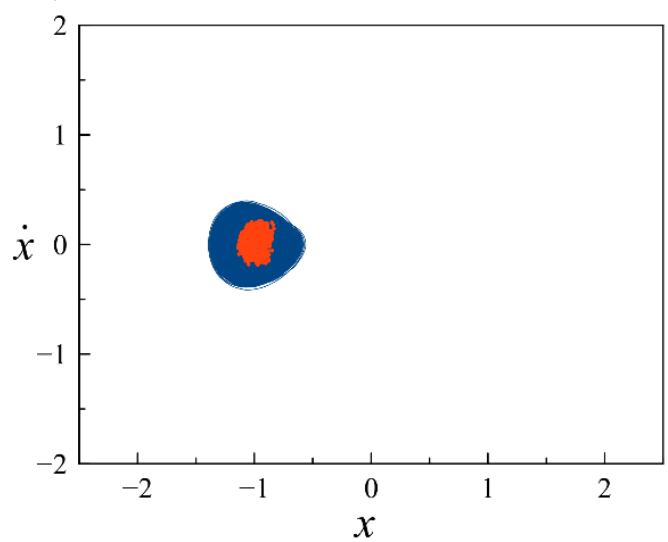

b)

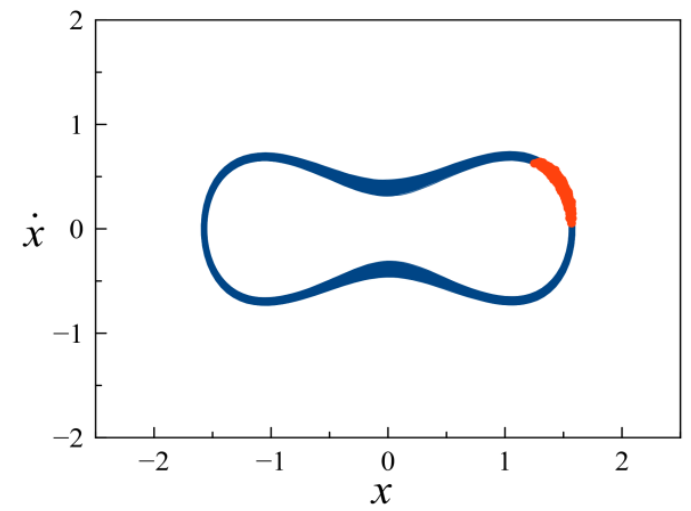

d)

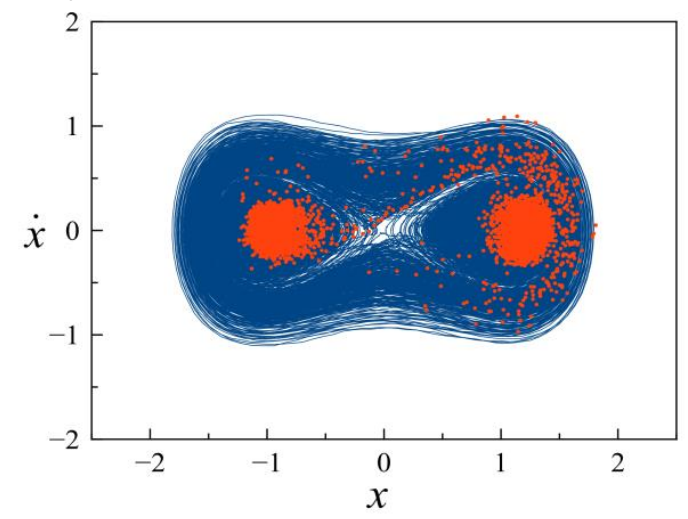

e)

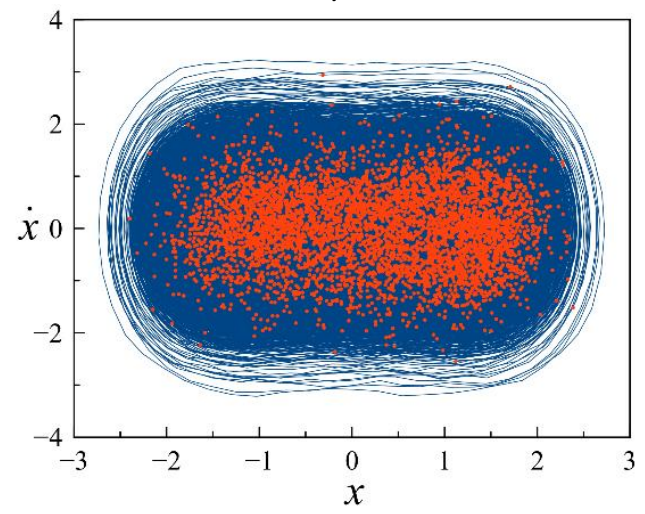

Figura 4.10 Espaço de fase (azul) e seção de Poincaré (vermelho) para forçamento harmônico com ruído de (a) $R R S=1 \%$ (b) $R R S=10 \%$ (c) $R R S=30 \%$ d) $R R S=70 \%$ e (e) $R R S=500 \%$. 
a)

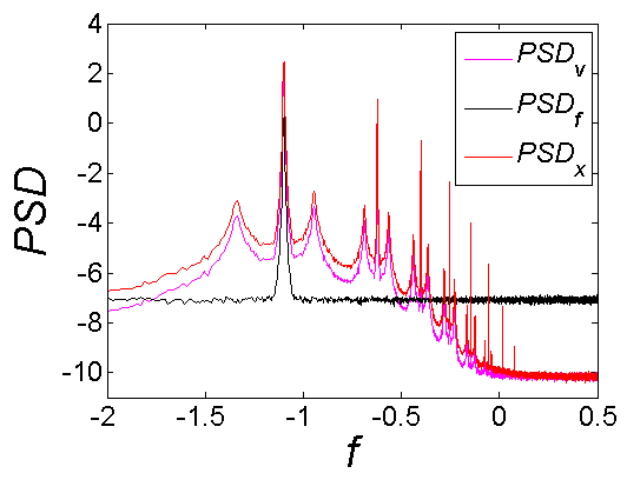

c)

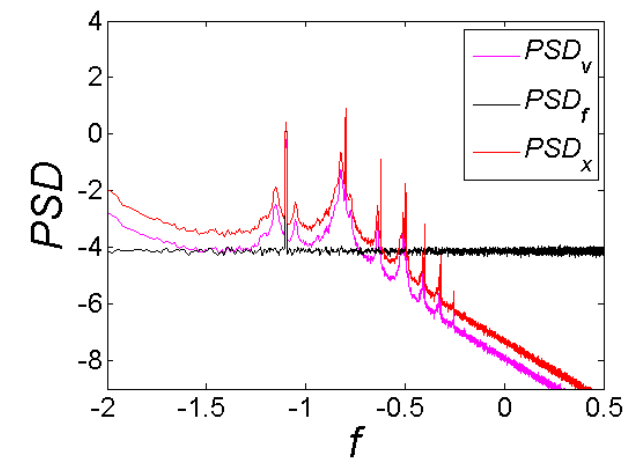

b)

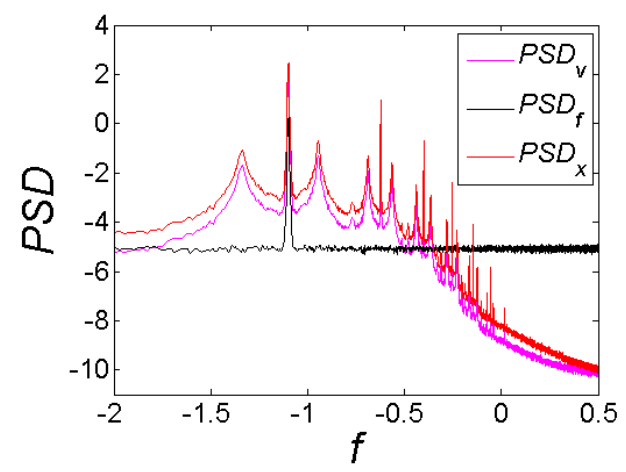

d)

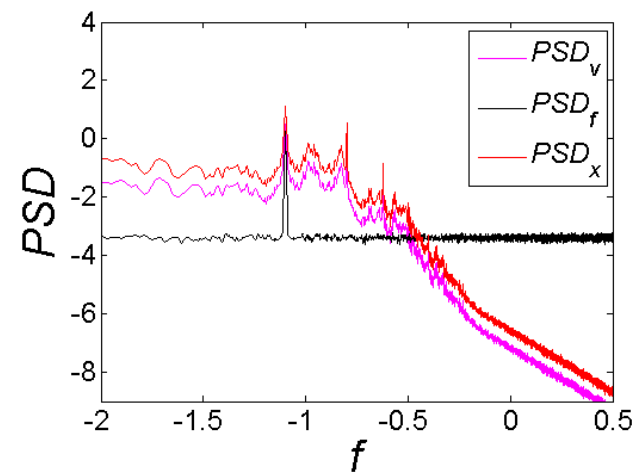

e)

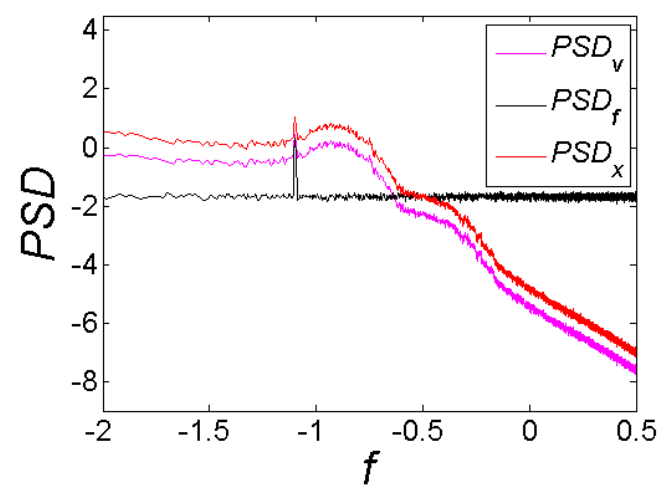

Figura 4.11 Curvas de PSD em função da frequência para forçamento harmônico contaminado com ruído com os níveis (a) $R R S=1 \%$ (b) $R R S=10 \%$ (c) $R R S=30 \%$ (d) $R R S=70 \%(\mathrm{e}) R R S=500 \%$.

A resposta no domínio do tempo, apresentada na Figura 4.12, mostra que para os valores de $R R S=70 \%$ duas regiões distintas podem ser obervadas: regiões de oscilação em torno de um ponto de equilíbrio estável e regiões de oscilação em torno de ambos os pontos de equilíbrio estável. De acordo com o aumento dos valores de $R R S$ as regiões de oscilação em torno de um ponto de equilíbrio estável se tornam menos frequentes. Por outro lado, as regiões de oscilação em torno de ambos os pontos de equilíbrio estáveis são mais recorrentes. Essas regiões estão relacionadas com as maiores amplitudes de resposta. 


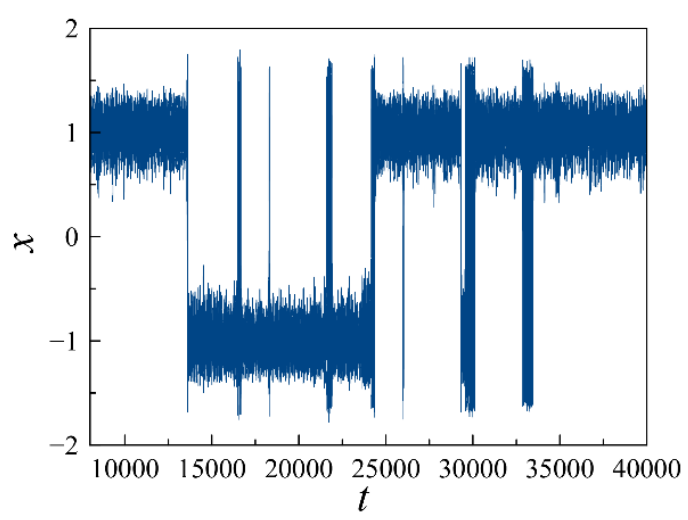

Figura 4.12 Resposta no domínio do tempo para o $2^{\circ}$ caso de forçamento harmônico contaminado com ruído com $R R S=70 \%$.

Tabela 4.6 Valores da área sob a curva de PSD do forçamento e tensão elétrica para forçamento harmônico contaminado com ruído para o $2^{\circ}$ caso de excitação combinada.

\begin{tabular}{|c|c|c|c|}
\hline$R R S$ & $P S_{f}$ & $P S_{v}$ & $r$ \\
\hline $1 \%$ & $1,00 \cdot 10^{-4}$ & $4,39 \cdot 10^{-3}$ & 43,97 \\
\hline $5 \%$ & $1,00 \cdot 10^{-4}$ & $4,39 \cdot 10^{-3}$ & 43,77 \\
\hline $10 \%$ & $1,01 \cdot 10^{-4}$ & $4,39 \cdot 10^{-3}$ & 43,13 \\
\hline $30 \%$ & $1,17 \cdot 10^{-4}$ & $0,12 \cdot 10^{-3}$ & 1,02 \\
\hline $50 \%$ & $1,50 \cdot 10^{-4}$ & $0,12 \cdot 10^{-3}$ & 0,86 \\
\hline $70 \%$ & $1,97 \cdot 10^{-4}$ & $0,50 \cdot 10^{-3}$ & 2,57 \\
\hline $90 \%$ & $2,61 \cdot 10^{-4}$ & $1,03 \cdot 10^{-3}$ & 3,96 \\
\hline $100 \%$ & $2,99 \cdot 10^{-4}$ & $1,30 \cdot 10^{-3}$ & 4,35 \\
\hline $150 \%$ & $5,51 \cdot 10^{-4}$ & $2,28 \cdot 10^{-3}$ & 4,13 \\
\hline $200 \%$ & $9,02 \cdot 10^{-4}$ & $3,26 \cdot 10^{-3}$ & 3,62 \\
\hline $300 \%$ & $19,04 \cdot 10^{-4}$ & $3,89 \cdot 10^{-3}$ & 2,04 \\
\hline $500 \%$ & $51,13 \cdot 10^{-4}$ & $5,05 \cdot 10^{-3}$ & 0,98 \\
\hline
\end{tabular}

A Tabela 4.6 apresenta os valores de $P S_{v}, P S_{f}$ e $r$. Assim como no caso anterior, os valores de $P S_{f}$ apresentam crescimento com o aumento do $R S S$, o que é esperado, porém os valores de $P S_{v}$ não acompanham esse crescimento. Nos intervalos de $R R S=1 \%$ até $R S S=10 \%$, os valores de $P S_{v}$ apresentam um leve decrescimento, e com isso os valores de $r$ diminuem. Na transição de $R R S=10 \%$ até $R R S=30 \%$, um decaimento é apresentado, decorrente da mudança de comportamento devido ao nível de ruído. No intervalo de $R R S=30 \%$ até $R S S=50 \%$, os valores de $P S_{v}$ apresentam um leve crescimento, porém o valore de $r$ diminui. Para $R R S=70 \%$, existe uma mudança no comportamento, observada no espaço de fase, e com isso há um pequeno salto no valor de $P S_{v}$. Até $500 \%$ o mesmo comportamento é observado, o que aumenta os valores $P S_{v}$. Do intervalo de $R R S=70 \%$ até 
$R R S=500 \%$, a razão $r$ aumenta até $R R S=100 \%$, logo após a esse valor os valores de $r$ apresentam um decaimento. Isso evidencia que, para esse tipo de comportamento, o nível de ruído que apresenta o melhor desempenho é $R R S=100 \%$, e para os valores de $P S_{v}$ o melhor nível de ruído é $R R S=500 \%$.

O melhor caso, quando se analisa todos os valores de $r$, ocorre quando $R R S=1 \%$. De modo geral, pode-se concluir que o intervalo de $R R S=1 \%$ até $R S S=10 \%$ é a melhor faixa de nível de ruído em que o sistema pode operar, apresentando grandes valores de desempenho, conforme indicado por $r$, assim como grandes valores de $P S_{v}$.

\section{$3^{\circ}$ CASO}

O caso aqui analisado parte de uma órbita que inicialmente apresenta comportamento caótico com condições de forçamento de $f_{0}=0,1$ e $\omega=0,8$. A Figura 4.13 apresenta a evolução do sistema mostrando o espaço de fase e seção de Poincaré com o aumento do valor de $R R S$.

a)

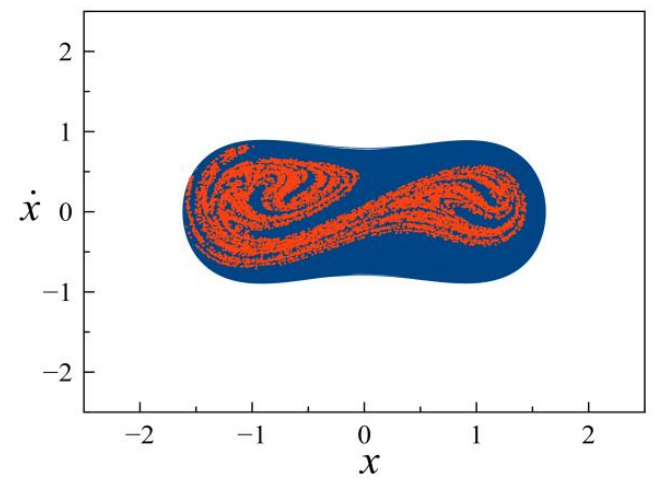

c)

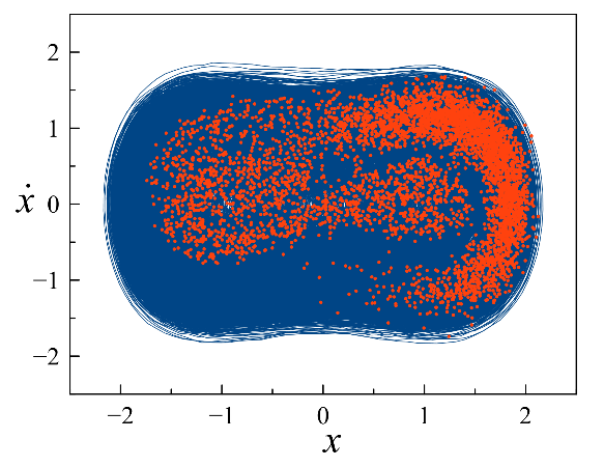

b)

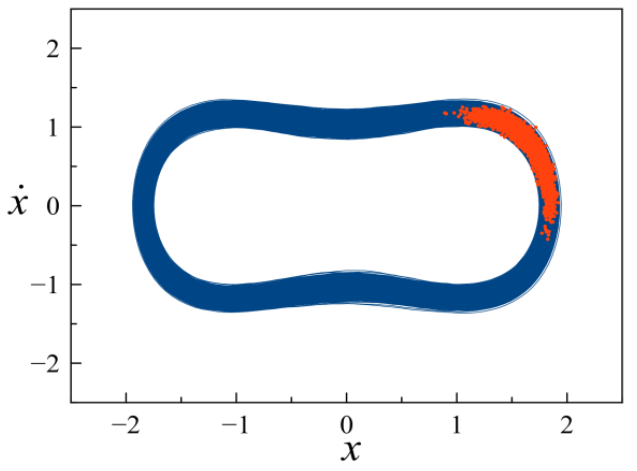

d)

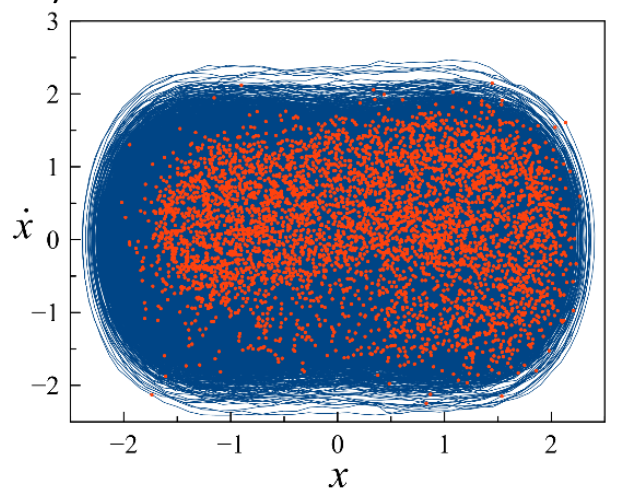

Figura 4.13 Espaço de fase (azul) e seção de Poincaré (vermelho) para forçamento harmônico com ruído de (a) $R R S=1 \%$, (b) $R R S=50 \%$, (c) $R R S=200 \%$ e (d) $R R S=$ $500 \%$. 
Para níveis baixos de ruído como $R R S=1 \%$ a seção de Poincaré é pouco influenciada, as simulações apresentam resultados parecidos até um nível de ruído de $R R S=30 \%$, onde a seção de Poincaré apresenta apenas maior dispersão em seus pontos. Para os níveis de $R R S=1 \%$ até $R S S=30 \%$ o comportamento ainda apresenta características aparentemente relacionadas com o caos. Para $R R S=50 \%$, o comportamento do sistema sofre alteração, passando para um comportamento oscilatório em torno dos dois pontos de equilíbrio. Esse tipo de comportamento é observado até $R R S=150 \%$. Para $R R S=200 \%$, a trajetória no espaço de fase apresenta-se como uma curva que preenche o espaço de fase, esse comportamento se estende até $R R S=500 \%$.

a)

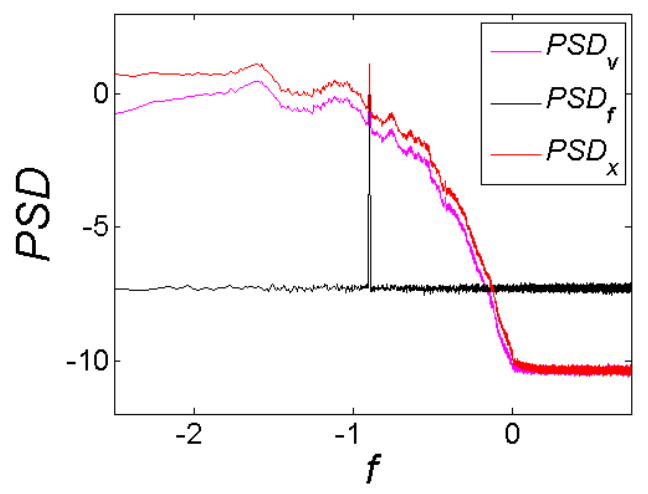

c)

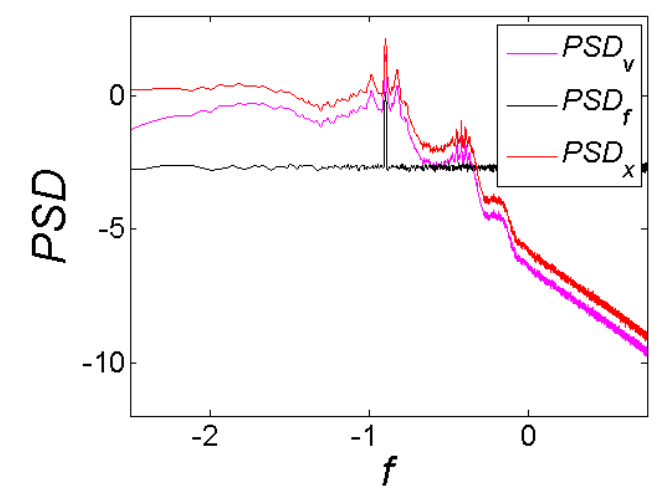

b)

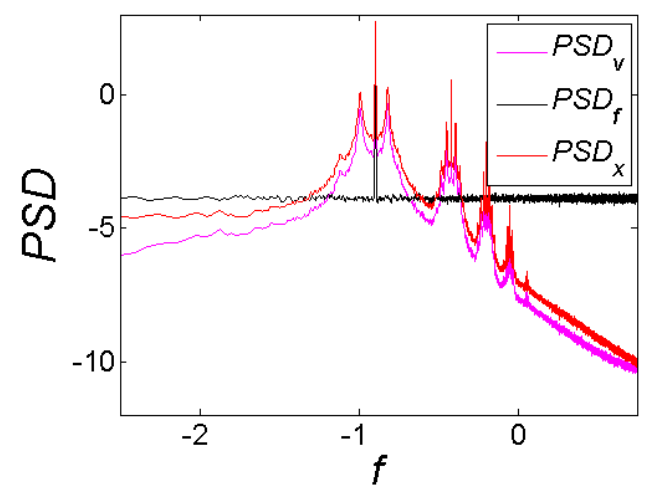

d)

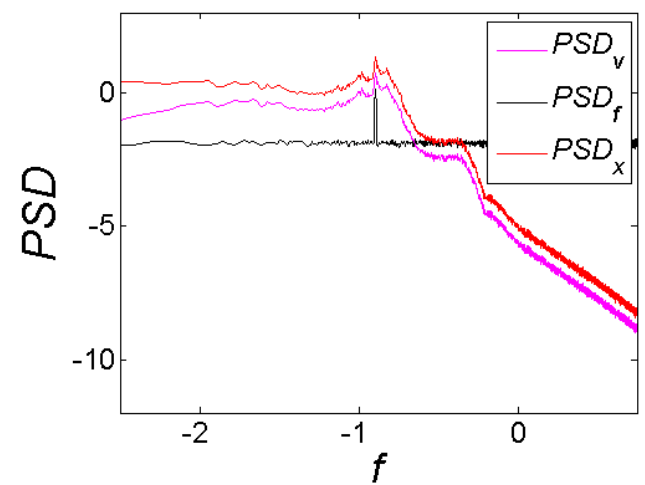

Figura 4.14 Curvas de PSD em função da frequência para forçamento harmônico contaminado com ruído com os níveis (a) $R R S=1 \%$, (b) $R R S=50 \%$, (c) $R R S=200 \%$ e (d) $R R S=500 \%$.

As curvas de PSD da Figura 4.14 confirmam a análise do espaço de fase. Para o valor de $R R S=1 \%$, a curva de PSD apresenta uma distribuição da energia para baixas frequências, o que leva a entender que essa resposta do sistema não é periódica, resultado obtido no espaço de fase e seção de Poincaré na Figura 4.13. Para $R R S=50 \%$, o sistema apresenta picos 
indicando uma certa periodicidade no sistema, o que é evidente pelo tipo de comportamento no espaço de fase. Para os casos de $R R S=200 \%$ e $R R S=500 \%$, as respostas do sistema apresentam uma distribuição para baixas frequências.

A Tabela 4.7 apresenta os resultados para os valores de PS e $r$ obtidos no caso em análise. Os valores de $P S_{f}$, referentes à excitação do sistema, apresentam um crescimento de acordo com o aumento do nível de ruído.

Como visto na análise dinâmica desse caso, no intervalo de $R R S=1 \%$ até $R R S=$ $30 \%$, o sistema responde com características semelhantes a uma resposta caótica, tal que os valores de $P S_{v}$ são muito próximos, com o maior valor de $P S_{v}$ para $R R S=10 \%$. Nesse sentindo, os valores de $r$, que verificam o desempenho, decrescem com o aumento do ruído.

Para o intervalo de valores de $R R S=50 \%$ até $R S S=150 \%$, os valores de $P S_{v}$ diminuem, porém estão em uma faixa de valor próxima pois apresentam o mesmo tipo de comportamento dinâmico. Por outro lado, os valores de $r$ são reduzidos devido ao grande aumento do $P S_{f}$, que é a energia do sinal de entrada, ocasionado pela elevação do ruído e nenhuma grande alteração do valor de $P S_{v}$.

$\mathrm{Na}$ transição de $R R S=150 \%$ para $R R S=200 \%, \quad$ o sistema altera seu comportamento, levando a uma diminuição nos valores de colheita de energia, $P S_{v}$. Após $R R S=200 \%$, os valores de $P S_{v}$ diminuem, assim como os valores de $r$.

Tabela 4.7 Valores da área sob a curva de PSD do forçamento e tensão elétrica para forçamento harmônico contaminado com ruído para o $3^{\circ}$ caso de excitação combinada.

\begin{tabular}{|c|c|c|c|}
\hline$R R S$ & $P S_{f}$ & $P S_{v}$ & $r$ \\
\hline $1 \%$ & $1,00 \cdot 10^{-4}$ & $3,21 \cdot 10^{-3}$ & 32,14 \\
\hline $5 \%$ & $1,00 \cdot 10^{-4}$ & $3,22 \cdot 10^{-3}$ & 32,04 \\
\hline $10 \%$ & $1,02 \cdot 10^{-4}$ & $3,24 \cdot 10^{-3}$ & 31,79 \\
\hline $30 \%$ & $1,18 \cdot 10^{-4}$ & $3,21 \cdot 10^{-3}$ & 27,20 \\
\hline $50 \%$ & $1,50 \cdot 10^{-4}$ & $7,09 \cdot 10^{-3}$ & 47,30 \\
\hline $70 \%$ & $1,98 \cdot 10^{-4}$ & $7,09 \cdot 10^{-3}$ & 35,83 \\
\hline $90 \%$ & $2,62 \cdot 10^{-4}$ & $7,09 \cdot 10^{-3}$ & 27,07 \\
\hline $100 \%$ & $3,00 \cdot 10^{-4}$ & $7,09 \cdot 10^{-3}$ & 23,64 \\
\hline $150 \%$ & $5,50 \cdot 10^{-4}$ & $7,07 \cdot 10^{-3}$ & 12,85 \\
\hline $200 \%$ & $9,00 \cdot 10^{-4}$ & $5,78 \cdot 10^{-3}$ & 6,42 \\
\hline $300 \%$ & $19,02 \cdot 10^{-4}$ & $5,20 \cdot 10^{-3}$ & 2,73 \\
\hline $500 \%$ & $51,06 \cdot 10^{-4}$ & $5,45 \cdot 10^{-3}$ & 1,06 \\
\hline
\end{tabular}


$4^{\circ}$ CASO

Nesse caso parte-se incialmente de uma órbita de período 5 , com as condições de forçamento de $f_{0}=0,093 \omega=0,8$. Repete-se os procedimentos de inserção de ruído para, primeiramente, analisar a dinâmica do sistema, e logo em seguida a análise de desempenho.

a)

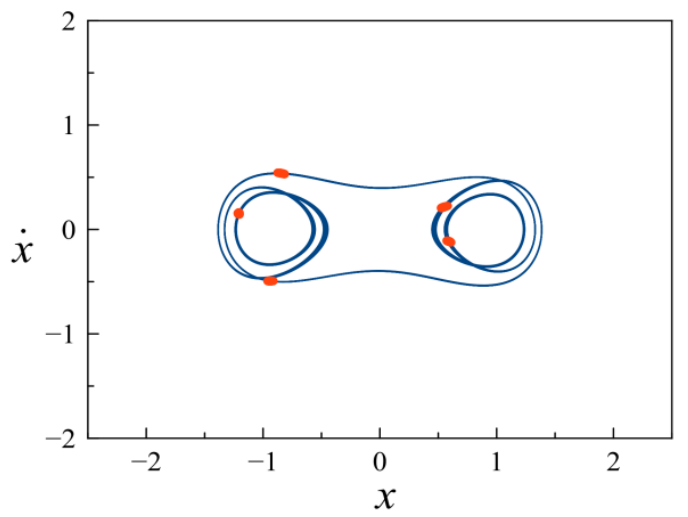

c)

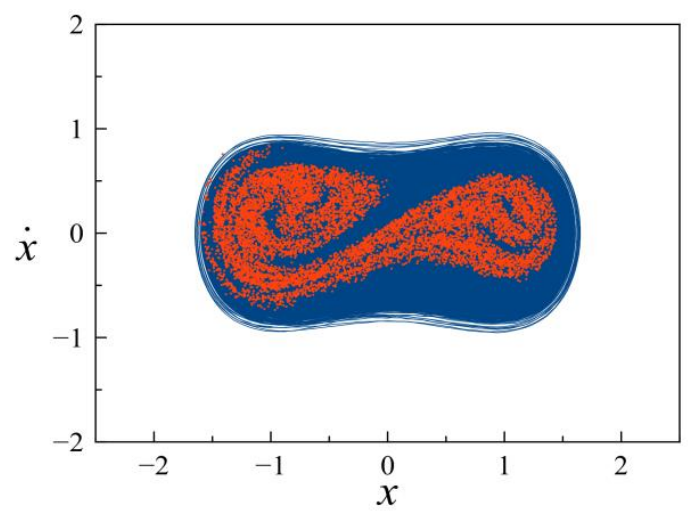

e)

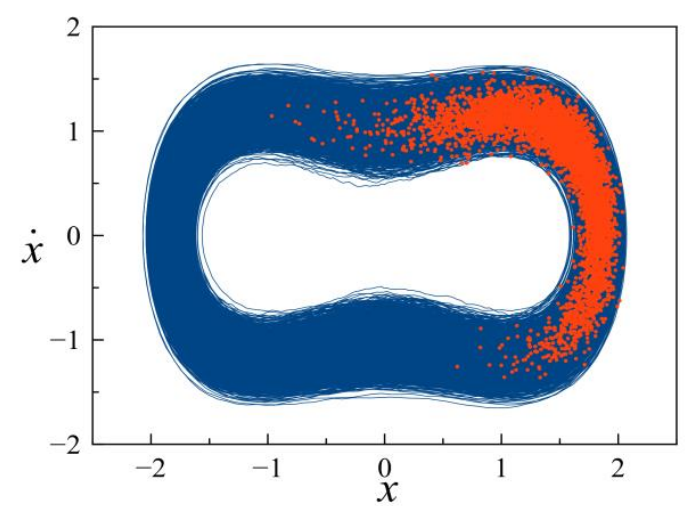

b)

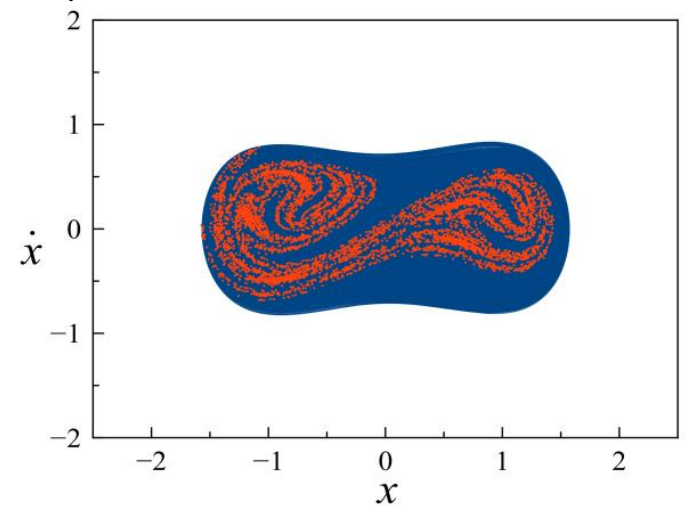

d)

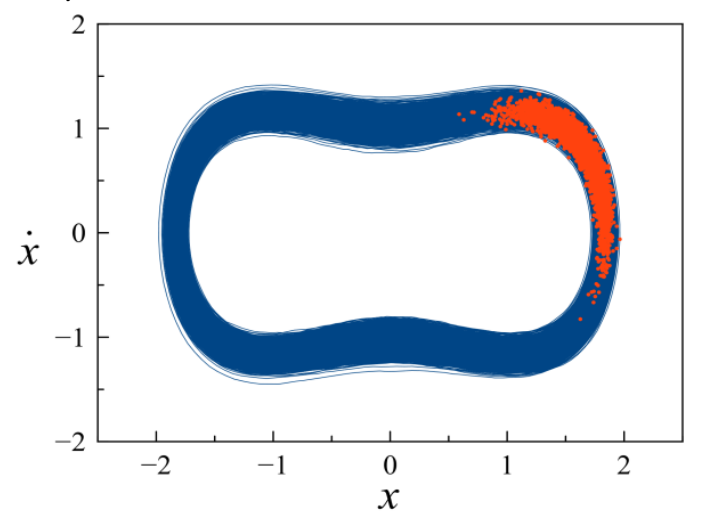

f)

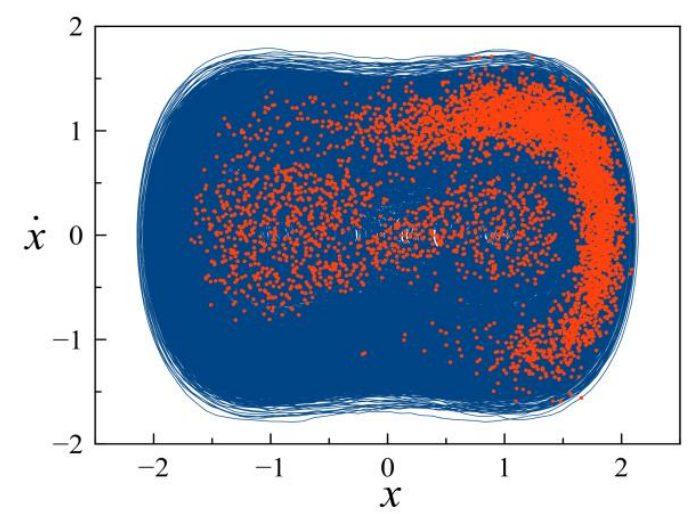

Figura 4.15 Espaço de fase (azul) e seção de Poincaré (vermelho) para forçamento harmônico com ruído de (a) $R R S=1 \%$, (b) $R R S=5 \%$, (c) $R R S=50 \%$, (d) $R R S=70 \%$, (e) $R R S=150 \%$ e (f) $R R S=500 \%$. 
A Figura 4.15 apresenta o espaço de fase e a seção de Poincaré para alguns níveis de ruído. Nota-se que com $R R S=1 \%$, o comportamento de periodicidade 5 ainda é recorrente. Entretanto, com $R R S=5 \%$ não se observa essa periodicidade e a seção de Poincaré possui características de uma resposta caótica. Esse comportamento se repete até $R R S=50 \%$. Para $R R S=70 \%$ até $R R S=150 \%$, nota-se um comportamento oscilatório em torno de ambos os pontos de equilíbrio. Após os valores de $R R S=150 \%$, o comportamento apresenta um espaço de fase denso. A Figura 4.16 mostra as curvas de PSD para alguns valores de RRS. No caso de RRS $=1 \%$, a curva apresenta diversos picos, mostrando que existe um número de frequências harmônicas no sinal, o que está de acordo com o resultado obtido anteriormente pela seção de Poincaré, indicando periodicidade 5. Para valores de $R R S=5 \%$ até $R R S=$ $50 \%$, a resposta do sistema apresenta uma banda larga nas baixas frequências. Para os valores de $R R S=70 \%$ até $150 \%$, as curvas de PSD para a resposta apresentam picos que indicam uma periodicidade do sinal. A partir de $R R S=200 \%$, as curvas de PSD da resposta do sistema apresentam novamente uma distribuição de potência numa banda de baixas frequências.

A Tabela 4.8 apresenta os valores de PS e de $r$ que auxiliam na análise do desempenho do sistema. Com o aumento de $R R S$, os valores de $P S_{f}$ apresentam um crescimento. $\mathrm{O}$ mesmo, no entando, não acontece para os valores de $P S_{v}$ devido à sua sensibilidade aos tipos de resposta do sistema. Para $R R S=1 \%$, verifica-se a tensão elétrica para um caso que apresenta periodicidade igual a 5 é de $P S_{v}=3,69 \cdot 10^{-3}$. Uma mudança no comportamento é apresentada na transição do caso de $R R S=1 \%$ para $R R S=5 \%$. Os valores de $P S_{v}$ para o intervalo de $R R S=5 \%$ até $50 \%$ colhem menos energia do que para o caso $R R S=1 \%$, levando-se a entender que o comportamento aparentemente periódico apresenta maior colheita de energia. Para os valores de $r$ o caso de $R R S=1 \%$ é mais eficiente que os casos de $R R S=5 \%$ até $50 \%$. Contudo, no intervalo de $R R S=70 \%$ até $150 \%$ o comportamento apresenta sempre uma oscilação em torno dos dois pontos de equilíbrio, levando o sistema a uma melhor colheita de energia que pode ser observada pelo valor de $P S_{v}$, porém os valores de $r$ decrescem com o aumento do nível de ruído. Outra transição de comportamento é apresentada entre os valores de $R R S=150 \%$ para $R R S=200 \%$. 
a)

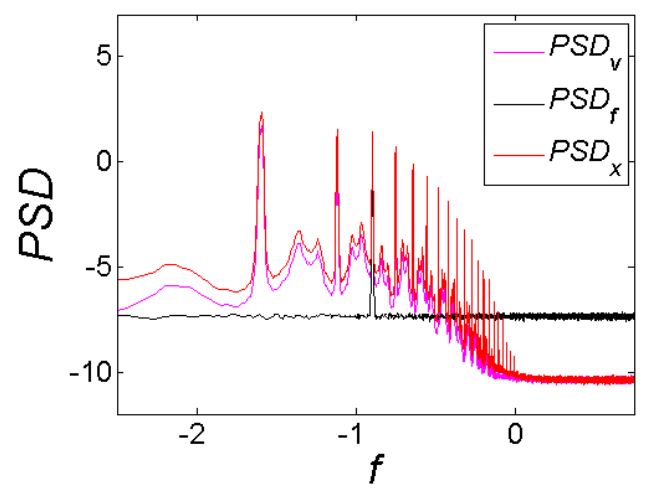

c)

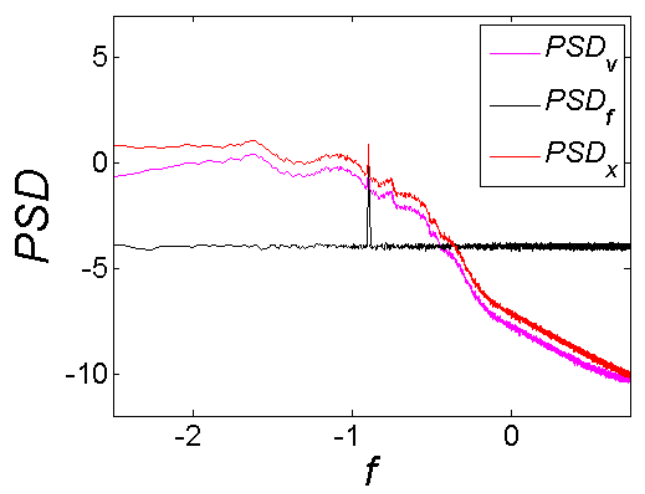

e)

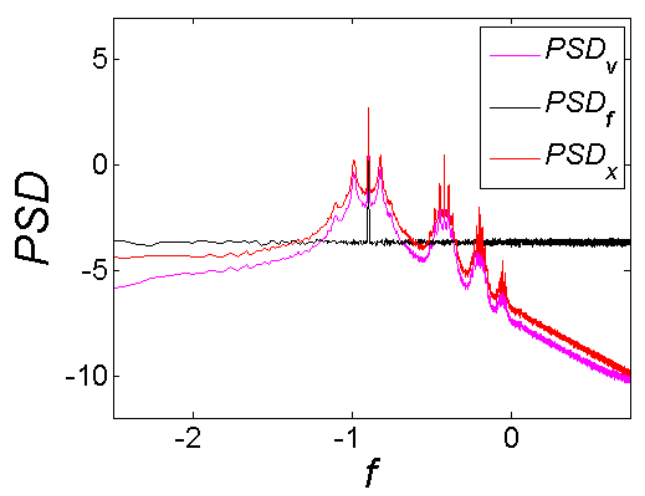

b)

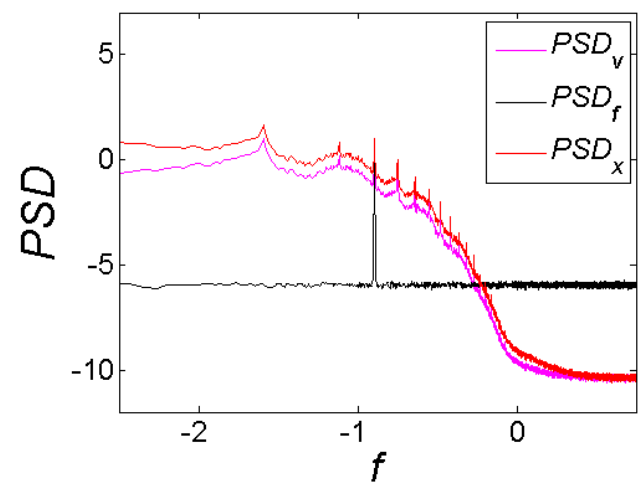

d)

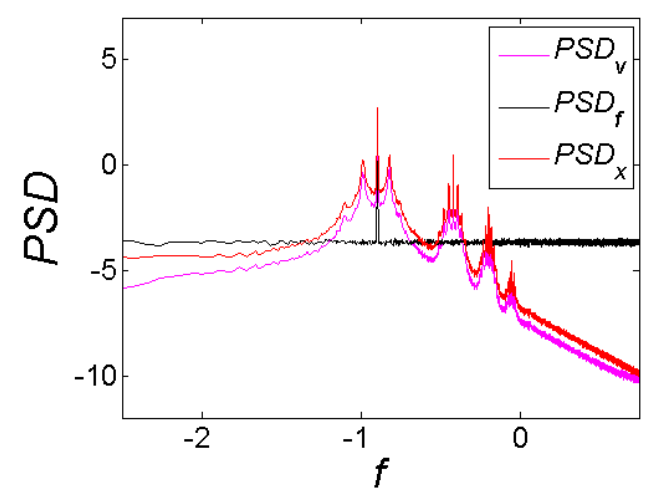

f)

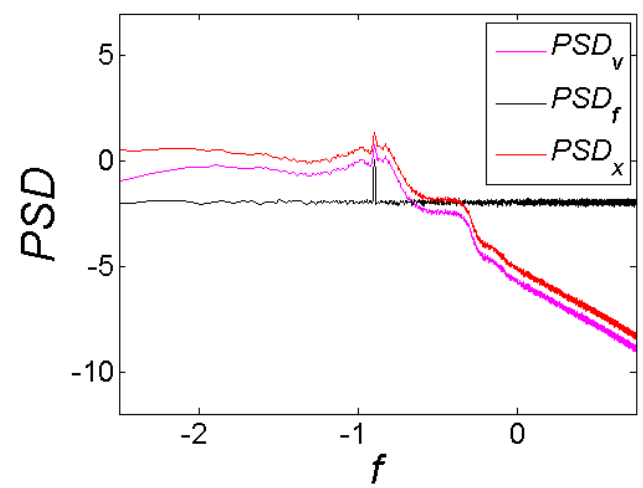

Figura 4.16 Curvas de Ppara os valores de ruído de a) $R R S=1 \%$, b) $R R S=5 \%$, c) $R R S=50 \%$, d) $R R S=70 \%$, e) $R R S=150 \%$ e f) $R R S=500 \%$ 
Tabela 4.8 Valores da área sob a curva de PSD do forçamento e tensão elétrica para forçamento harmônico contaminado com ruído para o $4^{\circ}$ caso de excitação combinada.

\begin{tabular}{|c|c|c|c|}
\hline$R R S$ & $P S_{f}$ & $P S_{v}$ & $r$ \\
\hline $1 \%$ & $0,86 \cdot 10^{-3}$ & $3,69 \cdot 10^{-3}$ & 42,73 \\
\hline $5 \%$ & $0,86 \cdot 10^{-3}$ & $3,18 \cdot 10^{-3}$ & 36,63 \\
\hline $10 \%$ & $0,88 \cdot 10^{-3}$ & $3,10 \cdot 10^{-3}$ & 35,26 \\
\hline $30 \%$ & $1,02 \cdot 10^{-3}$ & $3,10 \cdot 10^{-3}$ & 30,41 \\
\hline $50 \%$ & $1,29 \cdot 10^{-3}$ & $3,10 \cdot 10^{-3}$ & 23,92 \\
\hline $70 \%$ & $1,71 \cdot 10^{-3}$ & $7,06 \cdot 10^{-3}$ & 41,23 \\
\hline $90 \%$ & $2,26 \cdot 10^{-3}$ & $7,07 \cdot 10^{-3}$ & 31,21 \\
\hline $100 \%$ & $2,59 \cdot 10^{-3}$ & $7,06 \cdot 10^{-3}$ & 27,20 \\
\hline $150 \%$ & $4,76 \cdot 10^{-3}$ & $7,05 \cdot 10^{-3}$ & 14,82 \\
\hline $200 \%$ & $7,79 \cdot 10^{-3}$ & $6,10 \cdot 10^{-3}$ & 7,83 \\
\hline $300 \%$ & $16,45 \cdot 10^{-3}$ & $5,17 \cdot 10^{-3}$ & 3,14 \\
\hline $500 \%$ & $44,16 \cdot 10^{-3}$ & $5,10 \cdot 10^{-4}$ & 1,15 \\
\hline
\end{tabular}

\section{$5^{\circ}$ CASO}

O caso apresentado na Figura 4.17 parte inicialmente de paramentos de forçamento de $f_{0}=0,067$ e $\omega=0,8$ apresentando uma resposta periódica de oscilação em torno de apenas um ponto de equilíbrio. Com o acréscimo do ruído sob tais condições de forçamento harmônico percebe-se que a partir de um valor de $R R S=50 \%$, o sistema começa a oscilar em torno de ambos os pontos de equilíbrio. Para valores de $R R S=70 \%$ até $100 \%$, a seção de Poincaré fica mais cheia evidenciando que a trajetória do sistema visita mais vezes os pontos de equilíbrio estáveis.

Os valores de PS apresentados na Tabela 4.9 mostram que para os valores de $P S_{f}$ são crescentes para todos os níveis de ruído. Para o comportamento apresentado com valores de $R R S=1 \%$ até $R R S=30 \%$, os valores de $P S_{v}$ estão próximos e apresentam um decrescimento no desempenho do sistema, mensurado pelo valor $r$. A partir de $R R S=50 \%$ os valore de $P S_{v}$ são crescentes, porém isso não acontece para os valores de $r$, sendo $R R S=100 \%$ o caso com melhor desempenho. 
a)

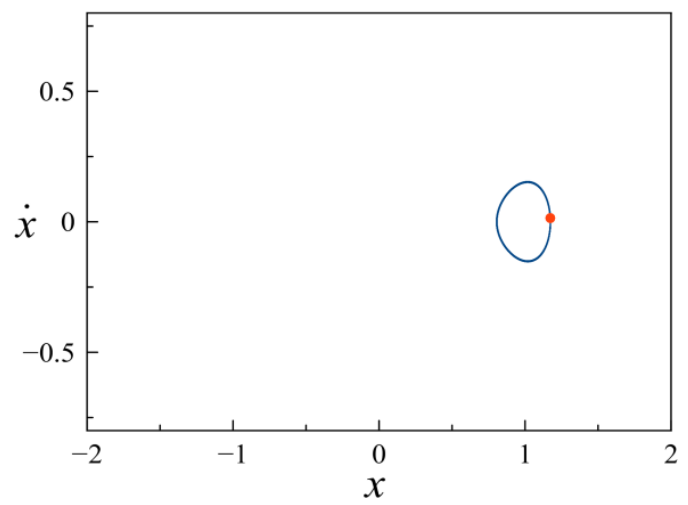

c)

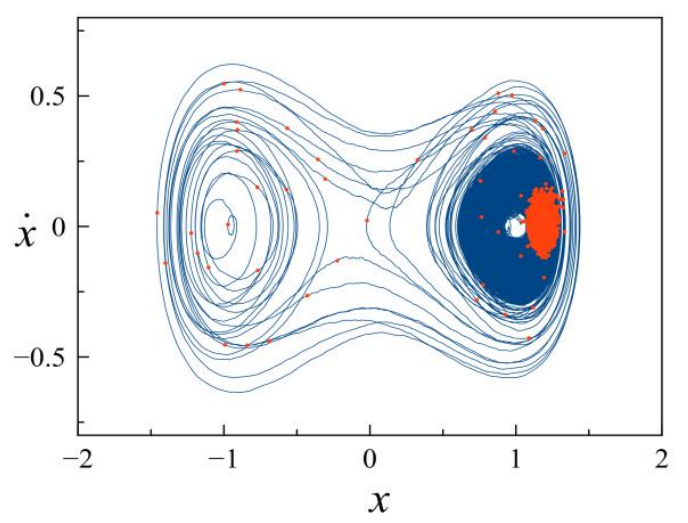

b)

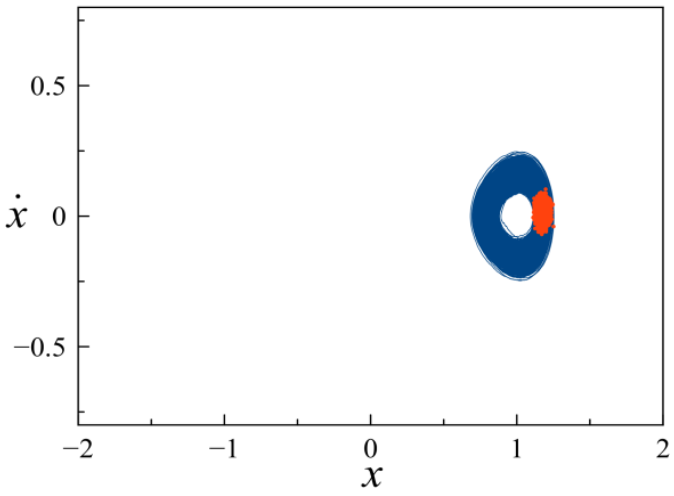

d)

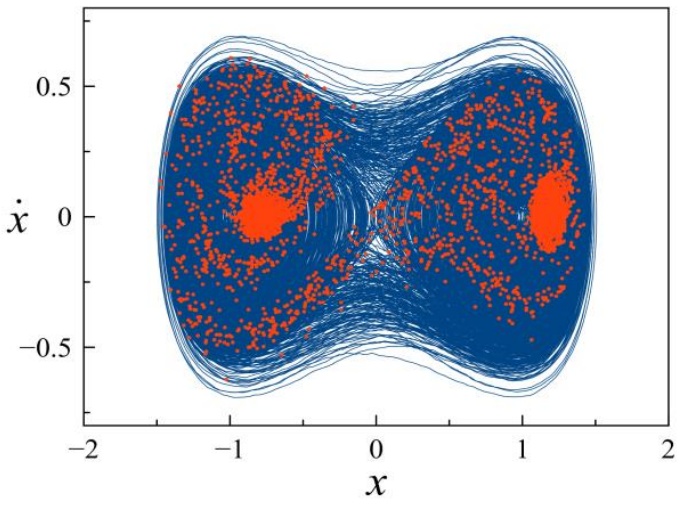

g)

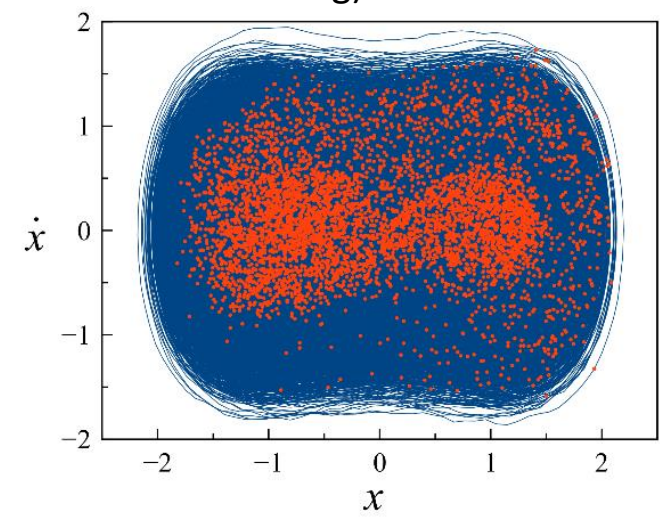

Figura 4.17 Espaço de fase (azul) e seção de Poincaré (vermelho) para forçamento harmônico com ruído de (a) $R R S=1 \%$, (b) $R R S=30 \%$, (c) $R R S=50 \%$, (d) $R R S=100 \%$ e (e) $R R S=500 \%$. 
a)

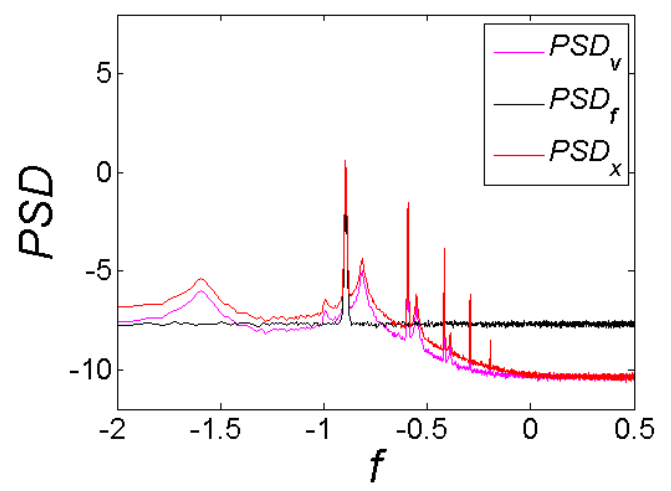

c)

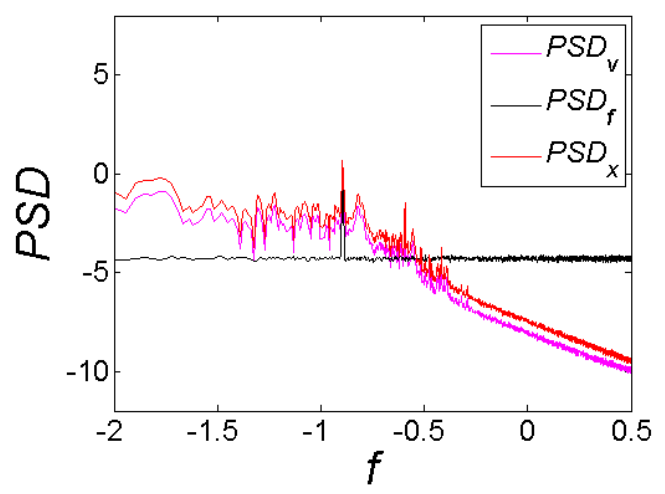

b)

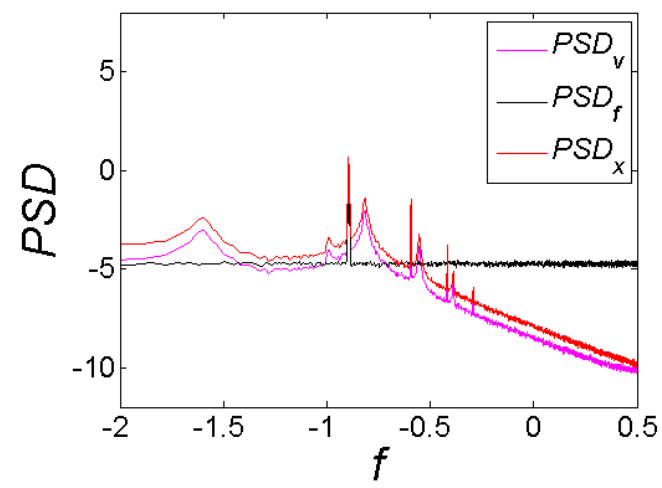

d)

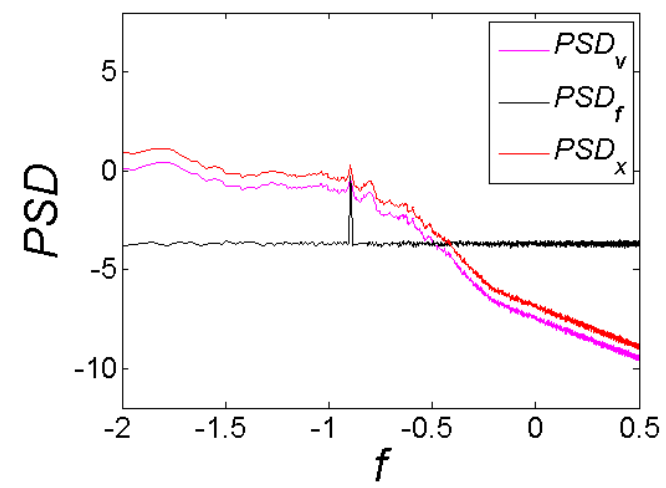

e)

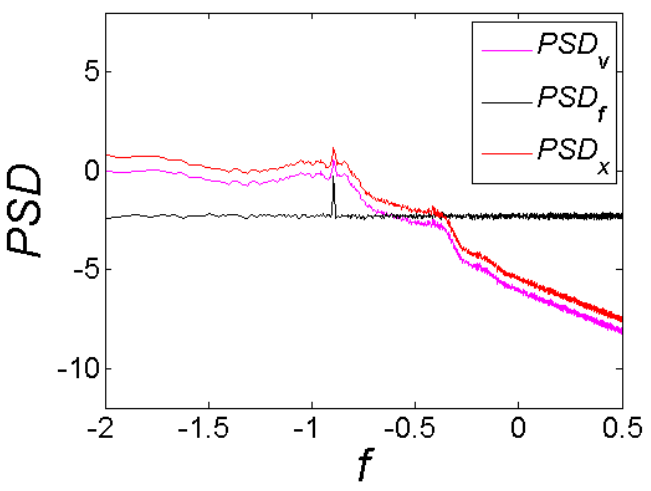

Figura 4.18 Curvas de $P S D$ para os valores de ruído de a) $R R S=1 \%$, b) $R R S=30 \%$, c) $R R S=50 \%, \mathrm{~d}) R R S=100 \%$, e) $R R S=500 \%$ 
Tabela 4.9 Valores da área sob a curva de PSD do forçamento e tensão elétrica para forçamento harmônico contaminado com ruído para o $1^{\circ}$ caso de excitação combinada.

\begin{tabular}{|c|c|c|c|}
\hline$R R S$ & $P S_{f}$ & $P S_{v}$ & $r$ \\
\hline $1 \%$ & $0,39 \cdot 10^{-4}$ & $0,08 \cdot 10^{-3}$ & 2,10 \\
\hline $5 \%$ & $0,39 \cdot 10^{-4}$ & $0,08 \cdot 10^{-3}$ & 2,10 \\
\hline $10 \%$ & $0,40 \cdot 10^{-4}$ & $0,08 \cdot 10^{-3}$ & 2,07 \\
\hline $30 \%$ & $0,46 \cdot 10^{-4}$ & $0,08 \cdot 10^{-3}$ & 1,89 \\
\hline $50 \%$ & $0,59 \cdot 10^{-4}$ & $0,14 \cdot 10^{-3}$ & 2,51 \\
\hline $70 \%$ & $0,78 \cdot 10^{-4}$ & $0,93 \cdot 10^{-3}$ & 11,92 \\
\hline $90 \%$ & $1,04 \cdot 10^{-4}$ & $1,52 \cdot 10^{-3}$ & 14,62 \\
\hline $100 \%$ & $1,19 \cdot 10^{-4}$ & $1,97 \cdot 10^{-3}$ & 16,57 \\
\hline $150 \%$ & $2,18 \cdot 10^{-4}$ & $2,31 \cdot 10^{-3}$ & 10,57 \\
\hline $200 \%$ & $3,57 \cdot 10^{-4}$ & $2,40 \cdot 10^{-3}$ & 6,73 \\
\hline $300 \%$ & $7,54 \cdot 10^{-4}$ & $2,68 \cdot 10^{-3}$ & 3,55 \\
\hline $500 \%$ & $20,26 \cdot 10^{-4}$ & $3,76 \cdot 10^{-3}$ & 1,85 \\
\hline
\end{tabular}




\section{CONCLUSÃO}

Este trabalho apresenta um estudo de um sistema biestável não-linear que tem por objetivo a colheita de energia presente em vibrações mecânicas. Três tipos de excitações diferentes são abordados. O primeiro caso de forçamento é relativo a um forçamento puramente harmônico. No segundo caso o sistema está submetido a condições de forçamento puramente aleatório. Enquanto no terceiro caso considera-se uma combinação dos forçamentos harmônico e aleatório.

Inicialmente apresenta-se uma análise dinâmica do sistema quando submetido a condições de forçamento harmônico. Uma análise qualitativa da resposta do sistema é realizada para diferentes condições de forçamento, através da seção de Poincaré, sendo possível indicar comportamentos periódicos, com diferentes amplitudes de resposta e diferentes periodicidades, e caótico. Além disso, através da construção da bacia de atração e de diagramas de bifurcação é possível concluir que existem regiões de coexistências de comportamentos periódico e caótico. A análise dinâmica do sistema mostra uma riqueza do sistema quanto às possibilidades de resposta.

Para avaliar o desempenho do gerador piezelétrico propõe-se um método de análise apropriado tanto para avaliar o sistema sujeito a excitação harmônica como sujeito a excitação aleatória. Essa abordagem é baseada na avaliação da PSD do sinal de entrada e saída. O sinal de entrada é o forçamento e a saída é a tensão elétrica.

Inicialmente um forçamento puramente harmônico é apresentado. A partir da análise dinâmica realizada inicialmente, diferentes casos são escolhidos para avaliação do desempenho. Esses casos são classificados quanto a natureza do seu comportamento: periodicidade 1 com oscilações em torno de dois pontos de equilíbrio estável; periodicidade 1 com oscilações em torno de apenas um ponto de equilíbrio estável; periodicidade igual a 5; e caótico.

Os comportamentos periódicos com oscilação em torno de ambos os pontos de equilíbrio estável apresentam os melhores desempenhos. As órbitas de periodicidade igual a 5 apresentam uma colheita de energia maior do que as órbitas caóticas, pois os valores de $r$ para todos os casos de periodicidade igual a 5 foram maiores do que para os casos caóticos. A órbita de periodicidade 1 com oscilações em torno de apenas um ponto de equilíbrio apresentou os piores valores de resposta elétrica e de desempenho. De uma forma geral, 
observa-se que as maiores amplitudes de resposta estão relacionadas com os melhores desempenhos.

Podemos, então, classificar em ordem decrescente de desempenho e em termos de colheita de energia os seguintes comportamentos: periodicidade igual a $1 \mathrm{em}$ torno de ambos os pontos de equilíbrio estável, periodicidade igual a 5, caótico e periodicidade igual a 1 em torno de apenas um ponto de equilíbrio estável.

Em um segundo momento o forçamento aleatório sozinho é considerado e valores de $\sigma$ entre 0,2 e 2 são analisados. Para valores de $\sigma$ entre 0,2 e 0,4 o sistema oscila em torno de apenas de um ponto de equilíbrio. Para valores maiores de $\sigma$, o sistema passa a oscilar em torno dos dois pontos de equilíbrio estável e o desempenho apresenta uma melhora notável. Para todos os casos analisados, observa-se que os valores de $P S_{v}$ são crescentes de acordo com o aumento de $\sigma$, mostrando que de acordo com que se aumenta a probabilidade de gerar forças maiores na entrada aumenta-se também a saída elétrica do sistema. Os valores de $r$, no entanto, não apresentam uma taxa de crescimento crescente. O melhor valor de $r$ é encontrado para o caso de $\sigma=1,2$.

Em um terceiro momento apresenta-se um forçamento combinado harmônico com ruído branco Gaussiano. Os níveis de ruído são mensurados através do parâmetro $R R S$, que é definido como sendo a razão entre o desvio padrão dos valores gerados no ruído branco Gaussino pelo valor da amplitude de forçamento.

Para uma investigação do comportamento global do sistema, quando uma parcela de aleatório é adicionado ao forçamento harmônico, diversos diagramas de bifurcação são construídos. Através da análise dos diagramas verifica-se que cinco casos apresentam mudanças significativas com o aumento da RRS, sendo escolhidos para análise.

A partir da análise de todos os casos é possível verificar que o melhor comportamento para a colheita de energia é apresentado para as oscilações periódicas que acontecem em torno dos dois pontos de equilíbrio estáveis. Esse comportamento é verificado em todos os casos, exceto no $5^{\circ}$. O surgimento desse comportamento ocorre com a adição do ruído, no entanto, com diferentes níveis de ruído para cada caso. Desta forma, tem-se que a adição de ruído a um forçamento harmônico pode melhorar o desempenho do gerador piezelétrico não-linear.

Outro fato interessante é que no $5^{\circ}$ caso de estudo escolheu-se uma órbita de periodicidade igual a 1 em torno de apenas um ponto de equilíbrio, e com a evolução do ruído essa órbita foi substituída por um comportamento em torno de ambos os pontos de equilíbrio com características não periódicas. Esse segundo comportamento apresentou valores de 
resposta elétrica e desempenho muito melhores do que o comportamento inicial para esse caso.

Para os três tipos de forçamento o sistema piezomagnetoelástico apresenta uma distribuição da potência em baixas frequências. Quando sujeito a um forçamento puramente harmônico, essa distribuição depende do tipo de resposta do sistema. Se a resposta é periódica o sistema apresenta uma distribuição apresentando picos bem definidos. Se a resposta é caótica tem-se uma distribuição uniforme. Quando sujeito a um forçamento puramente aleatório, o sistema também apresenta uma distribuição uniforme para baixas frequências, porém para valores baixos de $\sigma$ o sistema apresenta um pequeno pico. Para um forçamento combinado essas características dependem dos valores de ruído inseridos, que determinam a característica de resposta do sistema, contudo uma concentração de potência para baixas frequências é verificada em todos os casos.

Os melhores casos de estudo nesse trabalho estão relacionados a órbitas que apresentam as maiores amplitudes de resposta, com isso verifica-se que o sistema apresenta os maiores valores de $P S_{v}$ e $r$.

Também foi possível verificar que o ruído foi capaz de alterar a dinâmica do sistema, mostrando que em casos em que o ruído alterou a dinâmica do sistema, para respostas com maior amplitude, o ruído foi capaz de aumentar a colheita e desempenho do sistema. Em casos em que o ruído alterou a dinâmica do sistema, para um comportamento com menor amplitude, o ruído diminuiu a colheita e desempenho do sistema.

Como conclusão deste trabalho, apresenta-se um roteiro de sugestões para aplicações práticas do sistema piezomagnetoelástico sujeito a diferentes condições de forçamento:

- Verificar o tipo de vibração do ambiente em que o sistema será inserido, se as oscilações são puramente harmônica, puramente aleatória, ou combinada. Quando combinada mensurar os níveis médios de contaminação do ruído estabelecendo-se assim um valor de $R R S$;

- Se os parâmetros físicos do sistema não forem os mesmos dos utilizados neste trabalho, sugere-se então que uma avaliação qualitativa das órbitas do sistema através do diagrama de bifurcação seja realizada. Inicialmente, para um forçamento puramente harmônico, de forma a identificar as órbitas com maiores amplitudes, e em seguida para um forçamento combinado.

- Para as condições de vibração do ambiente previamente identificado deve-se verificar os valores de $P S_{v}$ e $P S_{f}$ assim como os valores de $r$ para verificar a 
colheita de energia e desempenho para diferentes casos. Se o forçamento do ambiente for sensível a condições iniciais, é interessante fornecer condições iniciais que levem a casos que oscilem em torno dos dois pontos de equilíbrio de maneira periódica.

Para trabalhos futuros sugere-se utilizar um modelo mais completo para a viga e não apenas um modelo de 1 grau de liberdade, baseado no seu primeiro modo de vibração. Quando um ruído Gaussiano é admitido, entende-se que ele excita de forma equivalente todas as frequências, assim, se o modelo apresentado assume apenas o primeiro modo a energia colhida pelos outros modos de vibração que tem frequências maiores não é levada em consideração

Sugere-se também a introdução de um ruído que excite apenas as frequências mais baixas, ou seja que apresentam energias maiores para valores menores de frequências já que os espectros de resposta apresentados ao longo do texto mostram que todas as respostas estão envolvidas em baixas frequências. 


\section{REFERÊNCIAS}

ADHIKARI, S.; FRISWELL, M. I.; INMAN, D. J. Piezoelectric energy harvesting from broadband random vibrations. Smart Materials and Structures, v. 18, n. 11, p. 115005, 2009.

BARBOSA, W. O. V.; PAULA, A. S. D.; SAVI, M. A.; INMAN, D. J. Chaos control applied to piezoelectric vibration-based energy harvesting systems. The European Physical Journal Special Topics, v. 224, n. 14-15, p. 2787-2801, 2015.

BEEBY, S. P.; TORAH, R. N.; TUDOR, M. J.; et al. A micro electromagnetic generator for vibration energy harvesting. Journal of Micromechanics and Microengineering, v. 17, n. 7, p. 1257-1265, 2007.

DE PAULA, A. S.; INMAN, D. J.; SAVI, M. A. Energy harvesting in a nonlinear piezomagnetoelastic beam subjected to random excitation. Mechanical Systems and Signal Processing, v. 54, p. 405-416, 2015.

ERTURK, A.; BILGEN, O.; INMAN, D. J. Power generation and shunt damping performance of a single crystal lead magnesium niobate-lead zirconate titanate unimorph: Analysis and experiment. Applied Physics Letters, v. 93, n. 22, p. 224102, 2008 .

ERTURK, A.; HOFFMANN, J.; INMAN, D. J. A piezomagnetoelastic structure for broadband vibration energy harvesting. Applied Physics Letters, v. 94, n. 25, p. $254102,2009$.

ERTURK, A.; INMAN, D. J. A Distributed Parameter Electromechanical Model for Cantilevered Piezoelectric Energy Harvesters. Journal of Vibration and Acoustics, v. 130, n. 4, p. 041002-041002, 2008.

ERTURK, A.; INMAN, D. J. Broadband piezoelectric power generation on high-energy orbits of the bistable Duffing oscillator with electromechanical coupling. Journal of Sound and Vibration, Dynamics of Vibro-Impact Systems., v. 330, n. 10, p. 2339$2353,2011$.

FEENSTRA, J.; GRANSTROM, J.; SODANO, H. Energy harvesting through a backpack employing a mechanically amplified piezoelectric stack. Mechanical Systems and Signal Processing, v. 22, n. 3, p. 721-734, 2008.

FERRARI, M.; BAÙ, M.; GUIZZETTI, M.; FERRARI, V. A single-magnet nonlinear piezoelectric converter for enhanced energy harvesting from random vibrations. 
Sensors and Actuators A: Physical, Eurosensors XXIV, Linz, Austria, 5-8 September 2010., v. 172, n. 1, p. 287-292, 2011.

GHANDCHI TEHRANI, M.; ELLIOTT, S. J. Extending the dynamic range of an energy harvester using nonlinear damping. Journal of Sound and Vibration, v. 333, n. 3, p. 623-629, 2014.

GRZEGORZ LITAK, M. I. F. Regular and chaotic vibration in a piezoelectric energy harvester. Meccanica, 2015.

LEO, D. J. Engineering Analysis of Smart Material Systems. 1 edition ed. Hoboken, N.J: Wiley, 2007.

LITAK, G.; FRISWELL, M. I.; ADHIKARI, S. Magnetopiezoelastic energy harvesting driven by random excitations. Applied Physics Letters, v. 96, n. 21, p. 214103, 2010.

LORENZ, E. N. Deterministic Nonperiodic Flow. Journal of the Atmospheric Sciences, v. 20, n. 2, p. 130-141, 1963.

MANN, B. P.; OWENS, B. A. Investigations of a nonlinear energy harvester with a bistable potential well. Journal of Sound and Vibration, v. 329, n. 9, p. 1215-1226, 2010.

MOON, F. C. Chaotic Vibrations: An Introduction for Applied Scientists and Engineers. 1 edition ed. New York: Wiley-VCH, 2004.

MOON, F. C.; HOLMES, P. J. A magnetoelastic strange attractor. Journal of Sound and Vibration, v. 65, n. 2, p. 275-296, 1979.

NEWLAND, D. E. An introduction to random vibrations, spectral and wavelet analysis. Longman Scientific \& Technical, 1993.

PAPOULIS, A.; PILLAI, S. U. Probability, random variables, and stochastic processes. McGraw-Hill, 2002.

ROME, L. C.; FLYNN, L.; GOLDMAN, E. M.; YOO, T. D. Generating electricity while walking with loads. Science (New York, N.Y.), v. 309, n. 5741, p. 1725-1728, 2005.

ROUNDY, S.; ZHANG, Y. Toward self-tuning adaptive vibration-based microgenerators. . v. 5649, p.373-384, 2005. Disponível em: <http://adsabs.harvard.edu/abs/2005SPIE.5649..373R>. Acesso em: 13/8/2016.

S. TOL, F. L. D. Piezoelectric power extraction from bending waves: Electroelastic modeling, experimental validation, and performance enhancement. Wave Motion, v. 60, 2015.

SAVI, M. A. Dinâmica Não-linear e Caos. $1^{0}$ edição ed. Rio de Janeiro: Editora E-papers, 2006. 
STANTON, S. C.; MCGEHEE, C. C.; MANN, B. P. Nonlinear dynamics for broadband energy harvesting: Investigation of a bistable piezoelectric inertial generator. Physica D: Nonlinear Phenomena, v. 239, n. 10, p. 640-653, 2010.

TANG, L.; YANG, Y.; SOH, C. K. Toward Broadband Vibration-based Energy Harvesting. Journal of Intelligent Material Systems and Structures, v. 21, n. 18, p. 1867-1897, 2010.

TRIPLETT, A.; QUINN, D. D. The Effect of Non-linear Piezoelectric Coupling on Vibrationbased Energy Harvesting. Journal of Intelligent Material Systems and Structures, v. 20, n. 16, p. 1959-1967, 2009.

YANG, Y.; WU, H.; SOH, C. K. Experiment and modeling of a two-dimensional piezoelectric energy harvester. Smart Materials and Structures, v. 24, n. 12, p. 125011, 2015.

ZHAO, S.; ERTURK, A. On the stochastic excitation of monostable and bistable electroelastic power generators: Relative advantages and tradeoffs in a physical system. Applied Physics Letters, v. 102, n. 10, p. 103902, 2013. 


\section{ANEXO A: DINÂMICA NÃO LINEAR}

\section{Sistemas Dinâmicos}

Sistemas dinâmicos são definidos como sistemas que tem variações de acordo com a evolução do tempo, relacionados sempre a uma transformação nos estados do sistema. A modelagem de sistemas dinâmicos está ligada diretamente com equações diferencias ou mapas. Para descrever um sistema que evolui de forma contínua no tempo usam-se equações diferenciais, o uso de equações diferenciais parciais é incluído na modelagem dinâmica quando as características espaciais são contínuas, para sistemas discretos no domínio físico usam-se equações diferenciais ordinárias. Os sistemas dinâmicos também podem ser modelados como mapas, que são utilizados para descrever sistemas que não são contínuos no domínio do tempo.

As equações a seguir representam um sistema dinâmico que pode ser descrito através de equações diferenciais:

$$
\left\{\begin{array}{c}
\dot{x}_{1}=f_{1}\left(x_{1}, \ldots x_{n}\right) \\
\vdots \\
\dot{x}_{n}=f_{n}\left(x_{1}, \ldots x_{n}\right)
\end{array}\right.
$$

onde $x_{n}$ são as variáveis de estado e $n>0 \in \mathbb{N}$. O símbolo ' representa a derivada em relação ao tempo. O conjunto de equações diferencias representado anteriormente formam um campo vetorial que sofre transformações realizadas pelas funções $f_{i}$, com $n=1 \ldots n$, cujo domínio é $\left(x_{1}, \ldots x_{n}\right)$ contido no $R^{n}$ e imagem $f_{1}, \ldots, f_{n}$ também contida no $R^{n}$.

De modo análogo apresentam-se os mapas logísticos, representado pela equação a seguir onde $X \in R^{n}$, e $F\left(X_{n}\right)$ é a função que transforma os estados do sistema anteriores nos atuais.

$$
X_{n+1}=F\left(X_{n}\right)
$$

\section{Espaço de fase}

Os sistemas apresentados anteriormente apresentam $n$ soluções. Entende-se então que a solução do sistema dinâmico é representado por $\left(x_{1}(t), \ldots, x_{n}(t)\right)$. Essas soluções podem ser representadas como curvas parametrizadas no $R^{n}$. A Figura 0.1 (a) ilustra a curva 
parametrizada. Quando incluímos a evolução do tempo na visualização da solução do sistema podemos dizer que as curvas estão reparametrizadas ou simplesmente que é uma curva integral, Figura 0.1 (b).

Com isso podemos dizer que o espaço de fase é um conjunto aberto no $R^{n}$ que contêm todas as curvas soluções em sua forma parametrizada. Disso decorre imediatamente que o espaço de fase é o domínio que contém as variáveis de estado

Para a resolução do sistema dinâmico é necessário saber informações sobre as condições iniciais, $\left(x_{0,1}, \ldots, x_{0, n}\right)$. As órbitas podem ser entendidas como curvas parametrizadas no espaço de estado.

(a)

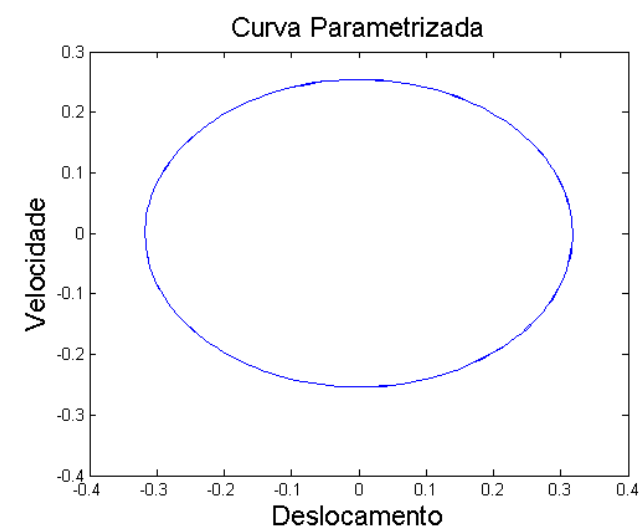

(b)

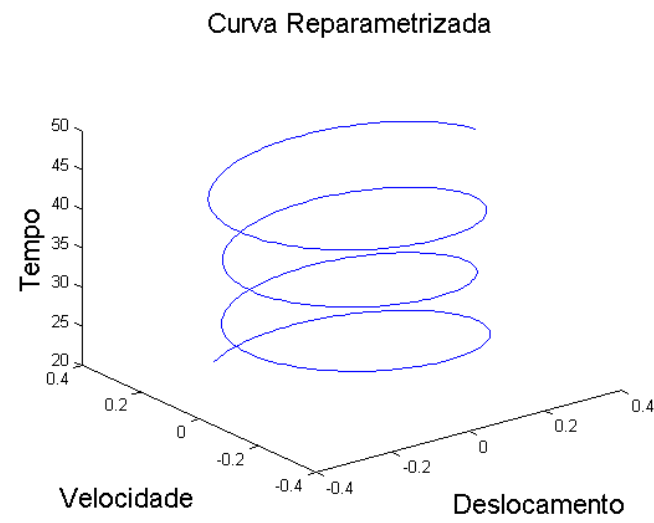

Figura 0.1 Órbita periódica (a) parametrizada e (b) reparametrizada

\section{Seção de Poincaré}

A análise da periodicidade da resposta de sistemas dinâmicos não-lineares é um ponto bastante relevante. Entende-se que a periodicidade da solução do sistema dinâmico está relacionada com órbitas fechadas, pois:

$$
\left(x_{1}(t), \ldots, x_{n}(t)\right)=\left(x_{1}(t+\check{t}), \ldots, x_{1}(t+\check{t})\right)
$$

onde $\check{t}$ é o período de oscilação da resposta. Por apresentar um comportamento periódico, o sistema visita os mesmos pontos na curva parametrizada, formando uma curva fechada. De modo a se avaliar a periodicidade das órbitas analisa-se a quantidade de períodos de forçamento necessária para o retorno do sistema às variáveis de estado retornar aos valores inicialmente estabelecidos, a quantidade de períodos necessária para esse retorno é dito 
periodicidade do sistema. Na Figura 0.1 a resposta apresenta periodicidade igual a 1 e a Figura 0.2 apresenta uma órbita com periodicidade igual a 5. Uma ferramenta para identificação dessa periodicidade é a Seção de Poincaré

(a)

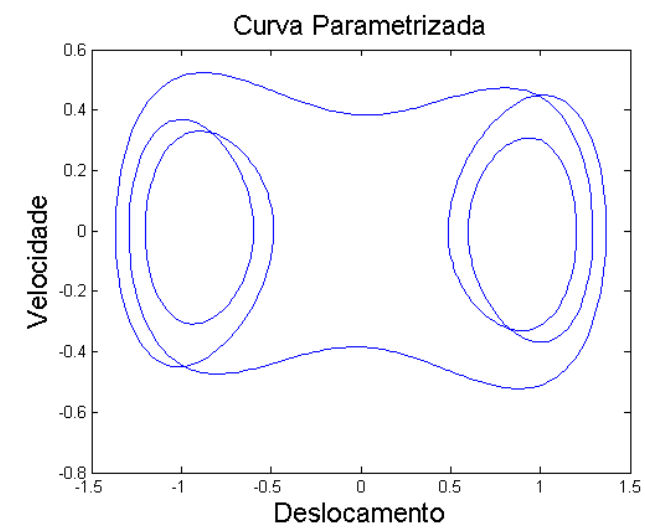

(b)

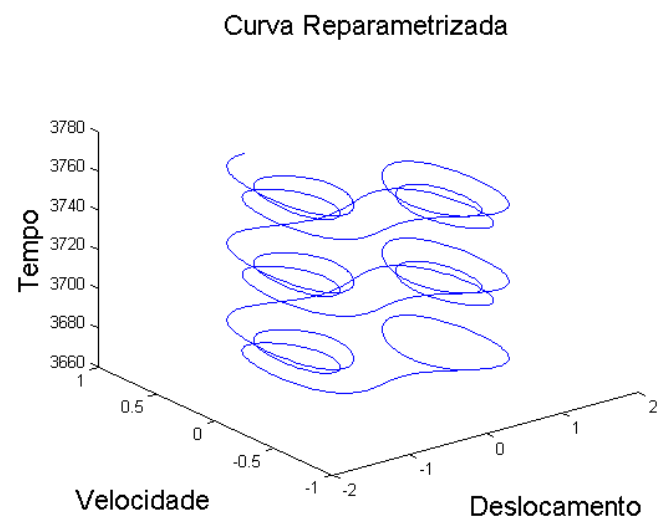

Figura 0.2 Órbita periódica (a) parametrizada e (b) reparametrizada

Uma seção de Poincaré pode ser definida como uma sequência de pontos no espaço de fase gerado pela observação da evolução contínua da trajetória através de uma superfície generalizada ou um plano no espaço de fase. Moon (2004)

Através dessa observação em uma superfície generalizada o sistema dinâmico contínuo no tempo (fluxo) é reduzido a um domínio discreto (mapa), eliminando ao menos uma variável do sistema. Para um sistema dinâmico governado por uma equação diferencial ordinária de segunda ordem e com forçamento harmônico, a seção de Poincaré pode ser obtida pela observação estroboscópica das variáveis de estado em uma fase específica do forçamento. A ideia da seção de Poincaré pode ser observada na Figura 0.3 (a).

Pela Figura 0.3 percebe-se que para qualquer seção de forçamento escolhida para analisar a periodicidade do sistema a mesma quantidade de pontos serão encontrados, no caso, são apresentados cinco pontos. Lembrando que um ponto só pode ser escolhido para a seção de Poincaré quando cruza a seção no mesmo sentido de todos os outros. 
(a)

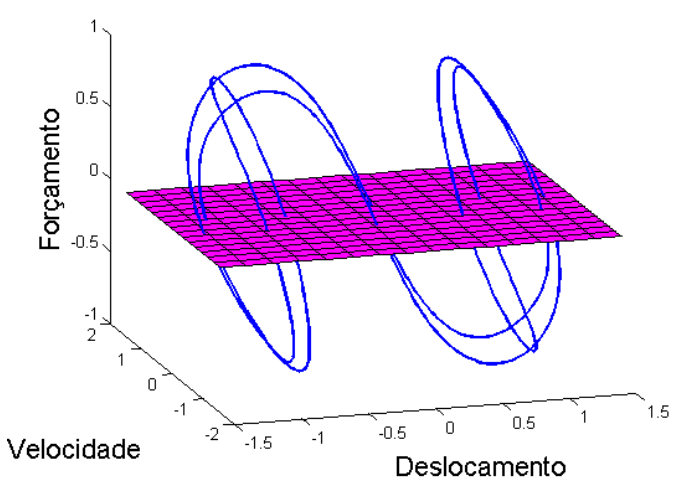

(b)

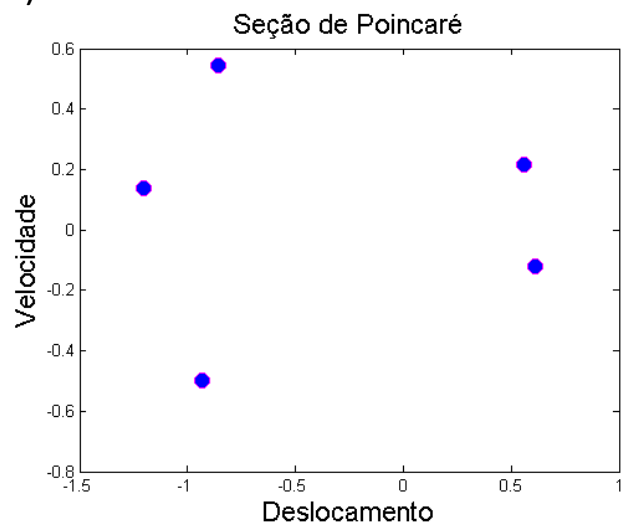

Figura 0.3 Ilustração da Seção de Poincaré

\section{Bifurcação}

As bifurcações estão associadas com a ideia de avaliar mudanças qualitativas na estrutura do espaço de fase de acordo com a variação dos parâmetros do sistema. Dessa forma é possível verificar e classificar os tipos de comportamento de um sistema, assim como essas alterações acontecem se variado algum parâmetro do sistema. As bifurcações estão diretamente relacionadas com a existência do caos, porém a reciproca não é verdadeira Savi (2006)

Os diagramas de bifurcação apresentados nesse trabalho foram construídos pelo método da força bruta.

\section{Sensibilidade às condições iniciais}

A ideia de caos está relacionada com a sensibilidade a condições inicias também conhecido como efeito borboleta. Lorenz (1963) ao analisar um modelo de previsão do tempo percebeu grandes diferenças nas respostas no domínio do tempo quando pequenas perturbações ou erros numéricos eram inseridos, tais erros cresciam de acordo com o número de iterações para obtenção da resposta. A Figura 0.4 apresenta uma simulação para condições iniciais muito próximas. Pode-se perceber a divergência das respostas com a evolução do tempo. 


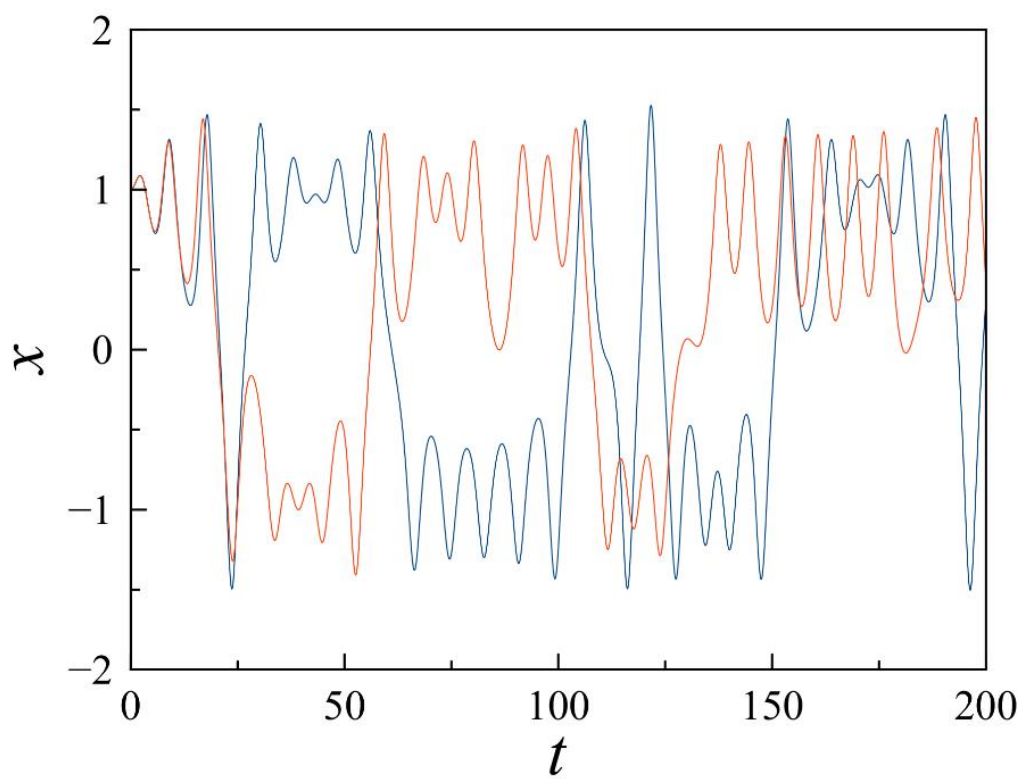

Figura 0.4 Resposta no domínio do tempo para condições inicias próximas. 


\section{ANEXO B: VARIÁVEIS ALEATÓRIAS, PROCESSOS ESTOCÁSTICOS, FUNÇÃO DE DENSIDADE.}

A realização experimental que depende de fatores geométricos e de propriedades dos materiais pode acontecer de modo que as variações em seus parâmetros não sejam desprezíveis. Dois exemplos dessas variações são bem recorrentes na engenharia, por exemplo, uma viga que é produzida de forma a se obter um comprimento $l$, e na verdade tem um comprimento próximo de $l$; outro exemplo é o valor do módulo de elasticidade de um material que deve ser determinado apenas após a realização de diversos ensaios sobre um conjunto de amostras, onde cada amostra produz um valor específico de módulo de elasticidade, porém estão todas próximas.

As variáveis sobre as quais acontecem variações são chamadas de variáveis aleatórias. Usualmente diz-se que:

$$
X: \Omega \rightarrow \mathbb{R}
$$

onde $X$ é a variável aleatória que mapeia um espaço de amostras $\Omega$ nos números reais.

As variáveis aleatórias podem ser discretas ou contínuas. Quando discretas, as variáveis aleatórias podem assumir valores em um conjunto enumerável. Quando contínuas elas não assumem valores em um conjunto enumerável.

A cada elemento contido em $\Omega$ se relaciona uma probabilidade, diz-se então que a distribuição de probabilidade $P(x)$ de uma variável aleatória está contida no intervalo de $[0,1]$. A distribuição de probabilidade de $X$ é o conjunto de pares ordenados $\left(x_{i}, P\left(x_{i}\right)\right)$, onde $x_{i}$ é o valor que a variável aleatória pode assumir, e $P\left(x_{i}\right)$ é probabilidade de $x_{i}$. A relação a seguir deve ser satisfeita:

$$
\begin{aligned}
& \sum_{i=1}^{i=\infty} P\left(x_{i}\right)=1 \rightarrow \text { discreta }, \\
& \int_{x \in \Omega} P(x) d x=1 \rightarrow \text { contínua. }
\end{aligned}
$$

Um processo estocástico pode ser definido como um processo que coleciona infinitas realizações de variáveis aleatórias independente e identicamente distribuída. As realizações acontecem em instantes de tempo distintos, assim temos que $X(x, t)$.

Dizemos que a média de uma variável aleatória pode ser dada por 


$$
m_{x}=E[X]=\left\{\begin{array}{l}
\sum_{i=1}^{n} X_{i} P\left(x_{i}\right) \rightarrow \text { discreta }, \\
\int_{-\infty}^{\infty} X P(x) d x \rightarrow \text { contínua } .
\end{array}\right.
$$

